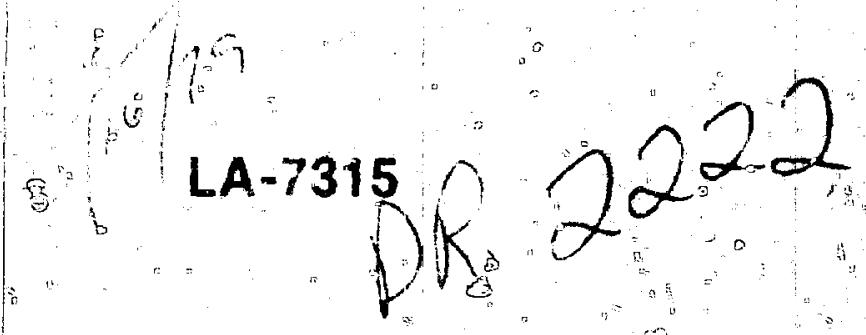

Concepts for Inventory Verflication in.

\}.

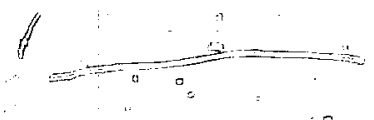

Critica Facilities

$\frac{9}{5}$

6
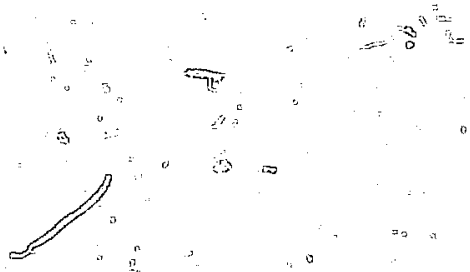
UC-15

Issued: December 1978

\title{
Concepts for Inventory Verification in Critical Facilities
}

\author{
D. D. Cobb \\ J. L. Sapir \\ E. A. Kern \\ R. J. Dietz
}

This report was prepared as an aceount of vest sponsored by the Unired States Govemment. Netther the

United States nor the United States Depariment of

contraciors, subcontractors, or thesr employees, makes

any wass iny, express of implied, or scsumes any lesal

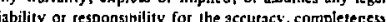

lisbily or

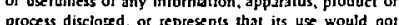

procests disciosed. Of represents that its use would not
infringe privately owned rights. 


\section{EXECUTIVE SUMMARY}

This report is the second in a series intended to develop advanced safeguards concepts for special nuclear materials (SNM) measurement and inventory verification in large, fast-critical-assembly facilities. It supersedes the report LA-7028-MS, "Preliminary Concepts for Materials Measurement and Accounting in Critical Facilities," which was also produced by the Los Alamos Scientific Laboratory (LASL) for the Department of Energy's Office of Safeguards and Security (DOE/SS). The study of advanced safeguards for critical facilities is part of a continuing effort to develop improved integrated safeguards systems for a broad spectrum of nuclear facilities. In these studies LASL provides conceptual designs for materials management (including fissile materials measurement and accounting) and Sandia Laboratories, Albuquerque (SLA) provides designs concepts for physical security, materials containment, and surveillance.

The conceptual designs of advanced materials management systems presented in this report are intencled to provide an effective inventory verificaiion capability for critical facilities without disrupting the experimental programs. Because the proposed concepts have not been implemented in an actual facility, it is important to evaluate them on a trial hasis to deiermine their safeguards effectiveness and operational acceptability. Only after the concepts have been evaluated thoroughly will it be practical to consider their formal implementation.

Large, fast-critical-assembly research facilities, used to simulate plutonium-fueled breeder reactors, are currently operating in several countries. The largest of these facilities can simulate fast-breeder reactors of $1000 \mathrm{MWe}$ with cores containing hundreds of kilograms of fuel. Such facilities typically are located in national nuclear research centers that maintain strict domestic safeguards including personnel controls and other physical protection measures.
Large critical facilities present a difficult problem for the application of international safeguards systems, which are based primarily on materials accounting complemented by containment and surveillance. Several of these facilities may soon be placed under International Atomic Energy Agency (IAEA) safeguards, thus emphasizing the international aspects and the urgency of the problem of safeguarding critical facilities. LASL and SLA have agreed to develop advanced safeguards concepts for use by safeguards authorities and systems developers. The results of the SLA conceptual study of containment and surveillance are reported separately in SAND 78-0168, "International Safeguards for Fast Critical Facilities." The concepts include frequent inspector surveillance and unattended containment and surveillance instruments placed at the boundary of the Materials Access Area (MAA).

The model facility developed as a reference for this study is intended to represent a large, experimentally active plutonium critical facility. The critical assembly is of the horizontal split-table type, consisting of a large matrix of steel tubes divided into halves. Thin plates containing fuel and nonfuel mockup materials are placed in open metal "drawers" about 2 in.* square, which are inserted into the matrix tubes. Automated fuel handling is available to insert and retrieve the reactor drawers. The final configuration is formed by bringing the reactor halves together and withdrawing poisonbearing control rods to reach criticality. The reference reactor contains $1200-1600 \mathrm{~kg}$ of plutonium distributed among 1600-2200 fuel drawers.

In facilities of this size, physical inventories are tedious and time-consuming, and they result in

\footnotetext{
*The British unit of length, unches (in.), is used frequently in this report for the dimensions of fabricated items: note that 1 in. = $2.74 \mathrm{~cm}$.
} 
significant radiation exposure of the operating personnel. For these reasons physical inventories are performed relatively infrequently, perhaps annually. Conventional international inspections can be expected to be even less thorough because of negotiated and economic restrictions on inspector access and manpower. The major problem in safeguarding these facilities then becomes one of timely and independent verification of facility inventories, using limited resources and without serious disruption of reactor operations. The inventory verification methods that are proposed for the model facility are sensitive to the diversion of a significant quantity ( $8 \mathrm{~kg}$ of plutonium) within a period of 6 months with alarm limits set at the 3- $\sigma$ level of significance (false alarm rate of $\sim 1$ in 1000) and with $95 \%$ probability of detection.

The maximum inspection effort for the model facility is more than 1000 man-days per year under the safeguards conditions of the Non-Proliferation Treaty (NPT safeguards). This number is a function of total SNM inventory and, while considerably smaller for some fast-critical facilities of interest, it still permits up to daily inspection. To satisfy these requirements we have chosen to discard the traditional onerous and time-consuming item inventory, based on counting thousands of individual fuel pieces, in favor of more frequent, rapid, collectiveinventory techniques.

The inspection strategy developed in this study is consistent with these constraints and comprises a spectrum of inspection and verification activities that increase in intensity during important operational or inventory verification activities or when diversion is suspected. The first level of activity is routine, frequent inspection by one inspector of the integrity of the containment area and the containment and surveillance systems. The inspector also regularly monitors the experimental program and the facility records and calibrates the safeguards instruments. He seals vault canisters that are not currently part of the dynamic inventory and verifies their contents by nondestructive assay (NDA). These activities occur during normal facility operations and do not significantly affect the routine flow of materials. The inspector is available, on call, for special or abnormal operational situations during this period and uses a portion of his time to prepare for the next level of activity: the routine inventory verification.
Routine inventory verification involves two or three inspectors and occurs at a negotiated interval, taken as 1.3 months for the model facility. The unsealed portion of the vault inventory is sealed and verified using NDA measurements, and the integrity of the sealed portion is checked. One means for reactor inventory verification is the statistical sampling and NDA measurement of $\sim 10 \%$ of the reference reactor inventory. It is estimated that each routine sampling verification of the reference reactor could be completed within two consecutive 8-h shifts, using automated handling and NDA measurement of reactor drawers. It could be scheduled when the reactor is not operating, that is, on nights, holidays, or weekends. The statistical sampling techniques, if repeatedly implemented at the recommended frequency, provide adequate verification at the $8-\mathrm{kg}$ detection level for diversion of whole-drawer quantities or individual fuel plates.

If diversion is limited to a very large number of very small removals, each one less than the smallest increment of fuel in the facility inventory $(1 \mathrm{in.}$ of plutonium fuel plate in the model facility), the detection sensitivity is $\sim 20 \mathrm{~kg}$ at the $3-\sigma$ alarm limit, which is $\leqslant 2 \%$ of the reference reactor inventory. Such diversion strategies would require either covert machining of a large number of fuel plates or falsification of the fuel manufacturer's assay data. Those strategies would be very difficult for even a facility operator to implement; hence, they are judged to be very unlikely.

This possibility and virtually all others are addressed by periodically substituting an integral reactivity experiment for the statistical verification plan. Reactivity measurements could be used to verify the gross fissile content of the entire reactor, in place. For this purpose it is necessary to return the reactor to one of several reference configurations having a precisely known reactivity and in-core inventory. The in-core inventory of a particular reference configuration can be determined by sampling and measurement when the refererce is first established.

While more sensitive (probably to $<1 \mathrm{~kg}$ of plutonium) and possibly less time-consuming than the statistical sampling verification, the reactivity measurement is vulnerable to a specious reactor configuration. However. the statistical sampling techniques and the inspector's presence along with supplementary measurements of additional reactor 
parameters should provide adequate protection from a deliberately misstated configuration. Establishment of a suitable reference configuration is facilitated by selecting from several candidate configurations the one that most closely resembles the working configuration at some convenient time. It is estimated that the reference reactor could be returned to a reference configuration about four times per year without undue disruption of the experimental program.

A mix of sampling and reactivity verifications of the reference reactor inventory totaling eight per year on the average is judged to be a reasonable compromise for the model facility. For example, this could consist of six sampling and two reactivity or four sampling and four reactivity verifications. The mixed verification strategy, especially if the type of verification is not announced well in advance, has important advantages, both as a psychological deterrent and because the two strategies, statistical sampling and integral reactivity, complement each other in the manner described above.

The most intense level of activity is associated with the special inventory verification, which occurs only under extraordinary circumstances such as when the inspectorate is convinced that an attempted diversion has occurred and an intensive inventory effort is warranted to determine the form and amount of missing material. Frequent inspections and routine inventory verifications obviate the need for complete inventories under normal circumstances.

If a diversion is suspected, the inspectorate must make an assessment to determine the appropriate response. If a special inventory verification is necessary, this would involve shutting down the model facility and fielding a team of six or more inspectors for a period estimated to be 7-14 days. The facility records are oudited. All vault inventory seals are inspected for integrity and the unsealed portion of the vault contents is verified by NDA. A $50 \%$ statistical sample of the reactor inventory may be verified by whatever techniques seem most appropriate to the inspection team for the particular alarm situation. Sampling at the $50 \%$ level provides a very high probability of detecting $8 \mathrm{~kg}$ or more missing from the reactor. If no significant diversion is discovered, the reactor may be returned to a reference configuration for the integral reactivity check. If significant diversion is confirmed, the inspection team may decide to complete the physical inventory.

The effectiveness of these inspection strategies against a variety of diversion strategies has been assessed for the model facility by modeling and simulating the operational procedures, the materials transfers, and the sampling procedures and measurements for a full year of operation using actual operating data. For example, the probability of detecting $8 \mathrm{~kg}$ of plutonium missing from the reference reactor through routine inventory verification with a $10 \%$ bimonthly statistical sampling plan is shown in the table below. The probability of detecting $8 \mathrm{~kg}$ missing either in individual plates or in whole-drawer amounts is near 95\% after 6 months, that is, after three samples totaling $30 \%$ of the inventory have been taken. Sampling about $30 \%$ of the reactor inventory every 6 months also provides a $95 \%$ probability of detecting $8 \mathrm{~kg}$. However, smaller samples taken more frequently provide timely detection, and they do not require shutting down the reactor for extended periods. Note that each $10 \%$ sample gives a $95 \%$ probability of detecting $\sim 30 \mathrm{~kg}$ missing from the reactor inventory, whereas six bimonthly $10 \%$ samples give a $95 \%$ probability of detecting the protracted diversion of $\sim 8 \mathrm{~kg}$ during $1 \mathrm{yr}$.

\begin{tabular}{|c|c|c|}
\hline $\begin{array}{c}\text { Detection } \\
\text { Time } \\
\text { (months) }\end{array}$ & $\begin{array}{c}\text { Cumulative } \\
\text { Sampling } \\
\text { Fraction } \\
(\%) \\
\end{array}$ & $\begin{array}{c}\text { Detection } \\
\text { Probability } \\
(\%) \\
\end{array}$ \\
\hline 2 & 10 & 61 \\
\hline 4 & 20 & 82 \\
\hline 6 & 30 & 93 \\
\hline 8 & 40 & 97 \\
\hline 10 & 50 & $>99$ \\
\hline 12 & 60 & $>99$ \\
\hline
\end{tabular}

The following table shows detection sensitivities calculated for a proposed integral reactivity check of several reference configurations. In all cases the detection limits are considerably $<1 \mathrm{~kg}$ of plutonium out of an inventory of $>1000 \mathrm{~kg}$. The reactivity technique, including supplementary 
measurements such as foil activation and materials worth, is being evaluated in operating critical facilities.

\begin{tabular}{|c|c|c|}
\hline $\begin{array}{c}\text { Config- } \\
\text { uration } \\
\text { No. }\end{array}$ & $\begin{array}{c}\text { Detection Limit } \\
\text { for 1-in. } \\
\text { Removals } \\
\text { (kg Pu) }\end{array}$ & $\begin{array}{c}\text { Detection Limit } \\
\text { for 4-in. } \\
\text { Removals } \\
\text { (kg Pu) }\end{array}$ \\
\hline $3-1 B$ & $0.3 \pi$ & 0.31 \\
\hline $4-1$ & 0.37 & 0.31 \\
\hline $4-3$ & 0.35 & 0.29 \\
\hline $5 \operatorname{Ref} B^{b}$ & 0.53 & 0.42 \\
\hline $5 \operatorname{Ref} B^{c}$ & 0.46 & 0.38 \\
\hline ;) $\mathbf{F S}^{\mathrm{b}}$ & 0.34 & 0.27 \\
\hline $\bar{j} \mathbf{F S}^{\mathrm{c}}$ & 0.28 & 0.23 \\
\hline $6 \mathrm{EOC}$ & 0.44 & 0.35 \\
\hline
\end{tabular}

${ }^{\text {A }}$ Corresponding to a 3 -Ih change in reactivity produced by removing fuel from regions of minimum worth.

${ }^{\mathrm{b}}$ Axial half 1.

"Axial half 2.

The inspection and inventory verification concepts developed in this study and the containment and surveillance concepts developed in the SLA study are design concepts for a model critical facility. Facility-specific design and operating features are of fundamental importance in making safeguards design choices for a real facility. Field testing of prototype hardware systems and proposed safeguards procedures to determine their effectiveness, reliability, and operational acceptability is recommended. Such test and evaluation exercises would provide essential data to both safeguards authorities and safeguards designers.

Section I of this repori contains a list of the world's largest critical assemblies. The facility model taken as a reference for this study is described in detail in Sec. II, along with its operational procedures and materials flow paths and a description of the fuel configurations and inventory.

Section III describes several options for the inspection and inventory verification system, the measurement techniques and the methodology for each level of inventory verification activity, and the sampling plans employed. The effectiveness of the sampling verification procedures proposed for the model facility is evaluated in Sec. IV, using modeling and simulation techniques.

Section V summarizes the results, conclusions, and recommendations of the main body of this report and identifies areas of investigation and techniques that require further development and experimental confirmation. Foremost among these areas are the integral reactivity technique and the NDA instrumentation required for inventory verification.

Detailed technical treatment of the concepts and techniques invoked in this study are contained in a series of technical appendixes. Appendix A describes the current status of applicable gammaray and neutron NDA techniques, whereas App. C describes autoradiographic NDA techniques for in situ measurement of individual fuel pieces.

Appendix B treats in some detail the integral reaciivity technique proposed for reactor inventory verification and suggests how it could be made more effective and be verified experimentally.

Statistical sampling procedures and data evaluation methods are reviewed in App. D, which also treats the problem of optimizing the combined attributes (small numbers of large removals) and variables (large numbers of small removals) samp!ing plans that are necessary for addressing these diversion strategies.

Appendix $\mathrm{E}$ describes sealing teciniques and the types of modern seals, including self-monitoring fiber optics seals, that are suggested by SLA for use in critical facilities. 


\section{CONTENTS}

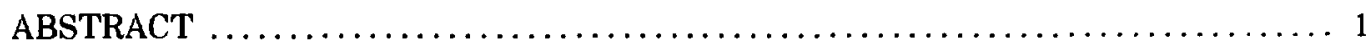

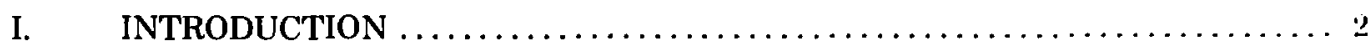

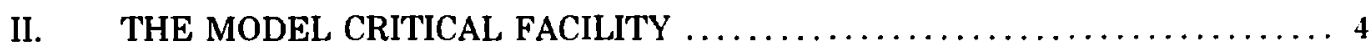

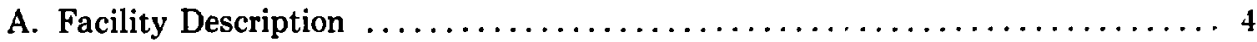

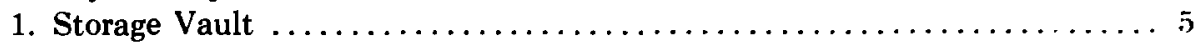

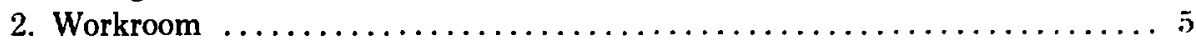

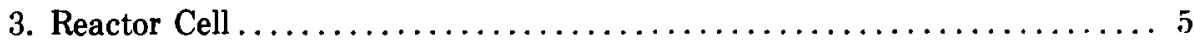

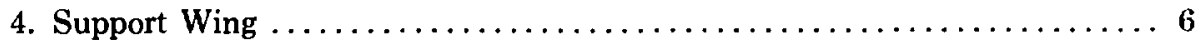

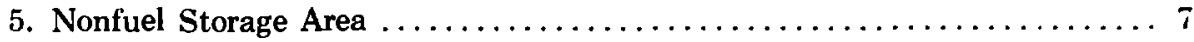

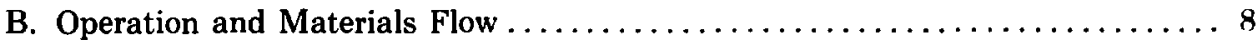

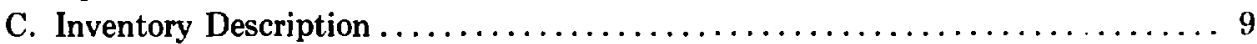

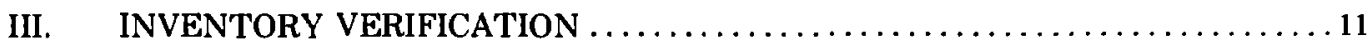

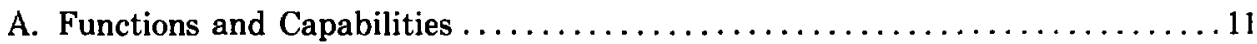

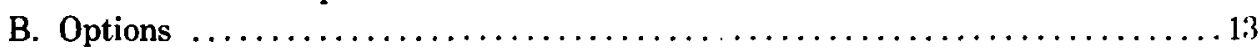

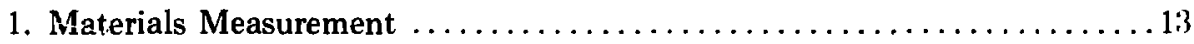

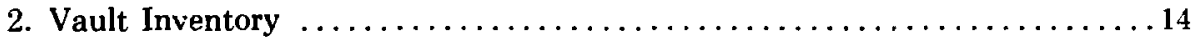

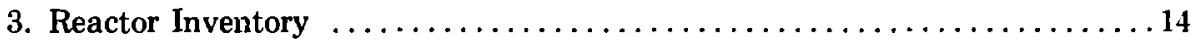

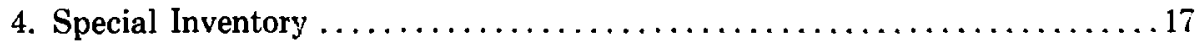

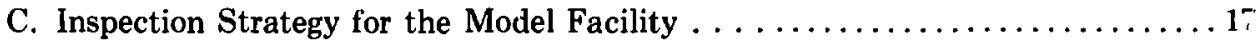

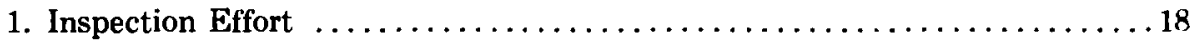

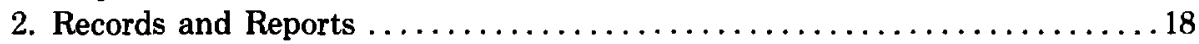

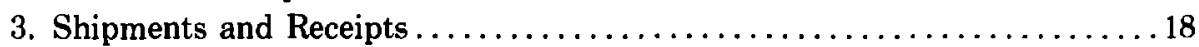

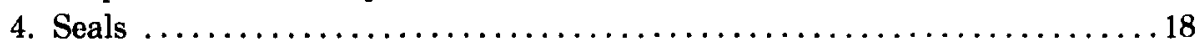

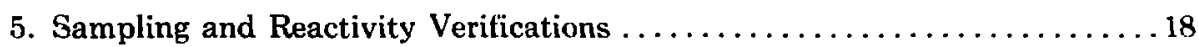

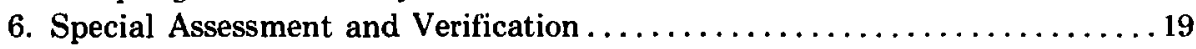

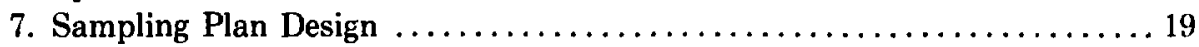

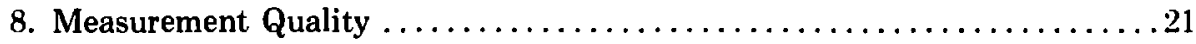

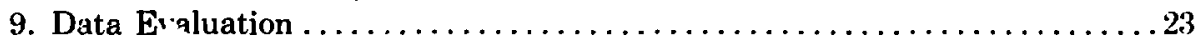

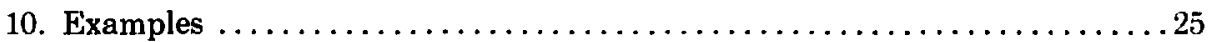

IV. EFFECTIVENESS OF SAMPLING VERIFICATION $\ldots \ldots \ldots \ldots \ldots \ldots \ldots \ldots \ldots$

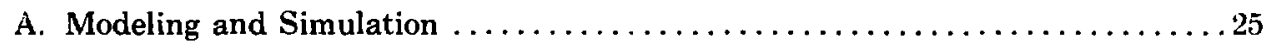

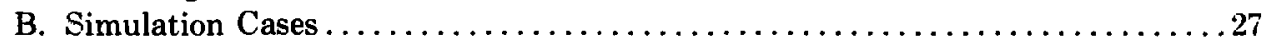

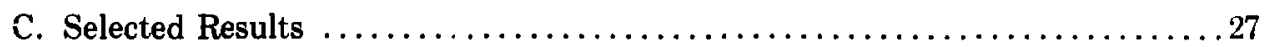

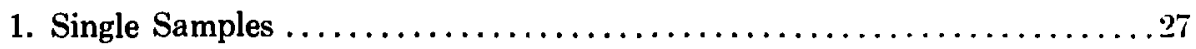

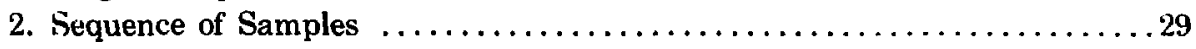

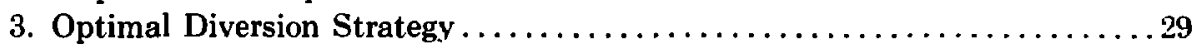

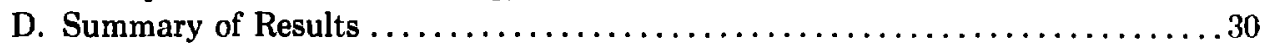


v. RESUITS, CONCLUSIONS, AND RECOMMENDATIONS

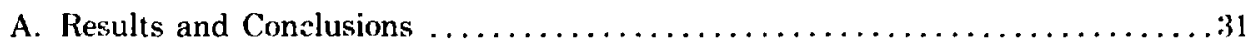

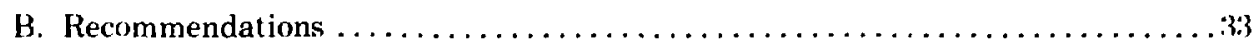

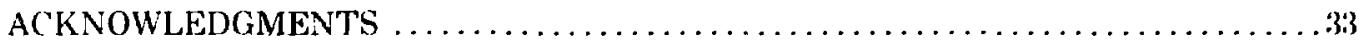

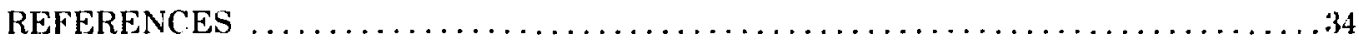

APPENDIX A. NONDESTRUCTIVE ASSAY METHODS

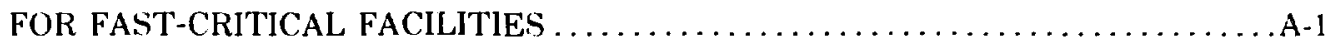

PART I. SURVEY OF METHODS FOR PLUTONIUM

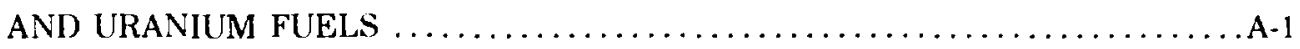

PAR'T II. NEW APPROACHES TO RAPID NONDESTRUCTIVE

VERIFICATION OF PLUTONIUM FUELS $\ldots \ldots \ldots \ldots \ldots \ldots \ldots \ldots \ldots \ldots \ldots$ A-13

APPENDIX B. INTEGRAL REACTIVITY MEASUREMENTS $\ldots \ldots \ldots \ldots \ldots \ldots \ldots$. B-1

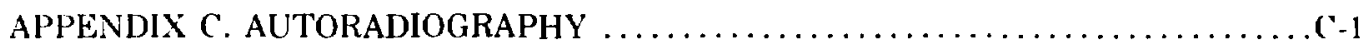

APPENDIX D. SAMPLING PLANS AND DATA ANALYSIS METHODS

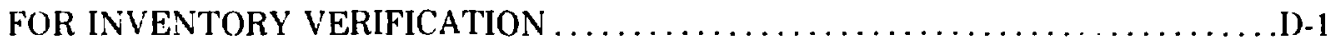

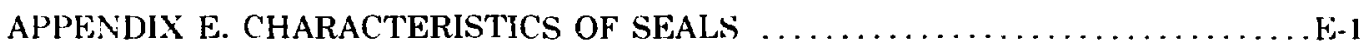

\section{TABLES}

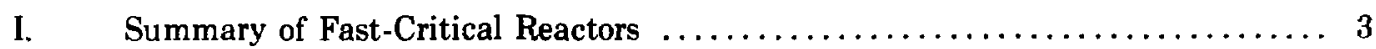

II. Fuel Plates in the Model Facility Inventory $\ldots \ldots \ldots \ldots \ldots \ldots \ldots \ldots \ldots, 9$

III. Vault Inventory with the Reactor Unloaded $\ldots \ldots \ldots \ldots \ldots \ldots \ldots \ldots \ldots \ldots$

IV. Fuel Drawers in a Reference Configuration $\ldots \ldots \ldots \ldots \ldots \ldots \ldots \ldots \ldots \ldots \ldots \ldots \ldots$

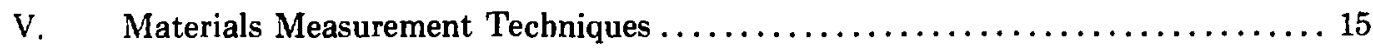

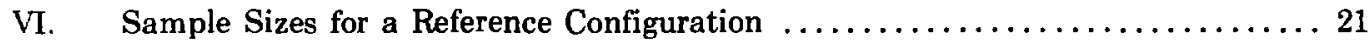

VII. Probability of Detecting $8 \mathrm{~kg}$ of Plutonium

Missing from the Reference Reactor with a Single Sample $\ldots \ldots \ldots \ldots \ldots \ldots 28$

VIII. Probability of Detecting $8 \mathrm{~kg}$ of Plutonium

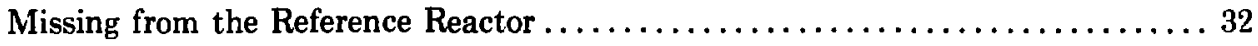

IX. Detection Limits for Integral Reactivity

Checks of Eight Reference Configurations $\ldots \ldots \ldots \ldots \ldots \ldots \ldots \ldots \ldots \ldots \ldots \ldots$ 
A-I. Matrix Material Effects on the Assay of Fuel Drawers with the HLNCC

A-II. $\quad{ }^{252} \mathrm{Cf}$ Shuffler Performance Data for $0.5-\mathrm{mg}{ }^{252} \mathrm{Cf}$ Source

A-III. Typical Isotopic Values for Five Classes of Plutonium Fuels in a Critical Facility

A-IV. Measured (or Calculated) Neutron and Gamma Responses for Five Classes of Plutonium Fuels

B-I. $\quad{ }^{299} \mathrm{Pu}$ Worth Data and Detection Sensitivities for 15 Plutonium Assemblies

D-I. Probability that a Sample of Size $\mathrm{n}$ Will Include at Least One Out of D Defects in a Population of 1000

D-II. Attributes Sample Sizes Required for Four Values of Detection Probability $\mathrm{DP}_{\mathbf{0}}$ When Sampling with Replacement

D-III. Attributes Sample Sizes Required for Four Values of Detection Probability DP 1 When Sampling with Replacement

D-IV. Attributes Sample Sizes Required for Four Values of Detection Probability $\mathrm{DP}_{1}$ When Sampling without Replacement

D-V. Probability that a Sample of Size $n$ Will Contain One or More Defects after Diversion of $8 \mathrm{~kg}$ in $\gamma$-Size Removals . . . . . . . D 8

D.VI. Standard Deviation of the Sample Fraction Defective f (Sampling with Replacement)

D-VII. Alarm Limits of a One-Sided $\dot{\chi}^{2}$ Test for $\sigma_{\mathrm{M}}>\sigma_{0}$

\section{FIGURES}

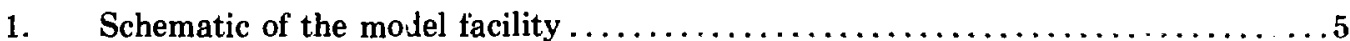

2. Fuel storage canister containing $\mathrm{Pu} / \mathrm{Mo} / \mathrm{L}$ iuel plates

3. Fuel drawer containing two rows of plutonium plates interspersed with plates of depleted uranium, sodium, and aluminum 
4. Assembly matrix with a few drawers projecting from the matrix tubes

5. Matrix loader for automated fuel drawer handling $\ldots \ldots \ldots \ldots \ldots \ldots \ldots \ldots$

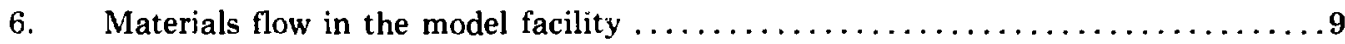

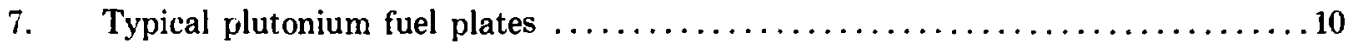

8. Schematic cross section of the reference configuration $\ldots \ldots \ldots \ldots \ldots \ldots \ldots \ldots \ldots \ldots \ldots$

9. Schematic of the covert diversion sequence and the integrated detection capability of the safeguards system $\ldots \ldots \ldots \ldots \ldots \ldots \ldots 12$

10. Regions of sampling-plan sensitivity that correspond to removing various amounts of plutonium from a fuel drawer compared with the uniform sensitivity of integral reactivity measurements

11. Cross sections of the reference reactor 26

12. The increase in detection probability provided by a series of monthly $10 \%$ samples of the reference reactor inventory

13. Protracted diversion of $4 \mathrm{~kg}$ of plutonium in whole-drawer amounts plus $4 \mathrm{~kg}$ in 1-in.-plate amounts by random removals during 6 months of operation of the reference reactor

14. Probability of detecting $8 \mathrm{~kg}$ of plutonium missing from the reference reactor with sequences of 5,10 , and $30 \%$ samples

A-1. Measurement setup for a fuel drawer

A-2. Experimental configuration for gamma-ray measurements on a fast-critical-assembly fuel drawer

A-3. Relative counting rate for the 414-keV gamma line as a function of plutonium loading in the drawer

A-4. Coincidence response versus plutonium loading

for plates in a storage canister.

A-5. Neutron coincidence counts per gram as a function of plutonium loading for stacked plates

A-6. Total neutron counts per gram as a function of plutonium loading for stacked plates 
A-7. Schematic of the ${ }^{262} \mathrm{Cf}$ Shuffier system showing the neutron well detector, the decoupling shield, and the dwell tank

A-8. Passive neutron coincidence results for the Shuffler system applied to uranium-plutonium mixed-oxide fuel peilets

A-9. Schematic of proposed neutron/gamma rapid scanning instrument for reactor drawers containing plutonium fuel

A-10. Relative thermal- (fast-) neutron backgrounds measured in a typical plutonium storage vault

B-1. Reference core reactivity loss in a large plutonium assembly

B-2. Radial reactivity worth of ${ }^{239} \mathrm{Pu}$ in various plutonium assemblies

B-3. Axial reactivity worth of ${ }^{230} \mathrm{Pu}$ in various plutonium assemblies

C-1. Composite print of autoradiographs from

fuel drawers in the reactor

C-2. Autoradiograph of a storage canister containing twenty-four 4 -in. plutonium fuel plates

C-3. Autoradiograph of a partially filled storage canister with a missing plate

C-4. Autoradiograph of a partially filled storage canister with a dummy solid stainless steel plate in the center of the right side

D-1. Probability of detecting attributes defects for four sample sizes

D-2. Attributes sample sizes for four values of detection probability

D-3. Probability of detecting attributes defects for various sample sizes D-6

D-4. Attributes sample sizes for four values of detection probability D-6

D-5. Probability of occurrence of measured values for hypotheses $H_{0}$ and $H_{1}$ 
D-6. Dependence of the false alarm probability

on the choice of alarm limit

D- $\bar{\imath}$. The power of a normal test for several

choices of alarm limit

D-8. Power of the normal test applied to single

measurements for several values of $\sigma_{\epsilon}$

D-11

D-9. Power of the ncrmal test applied to single measurements or several values of $\sigma_{n}$

D-10. Power of the normal test applied to the sample mean for several values of $\sigma$,

D-11. Power of the normal test applied to the sample mean for several values of $\sigma_{n}$

D-12. Power of the normal test applied to the sample mean for several sample sizes

E.1. LAEA metallic seal E-1

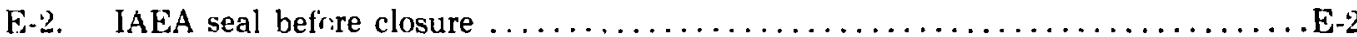

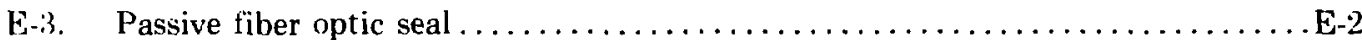

E-4. Internal components of fiber-locking assembly block $\ldots \ldots \ldots \ldots \ldots \ldots \ldots \ldots$

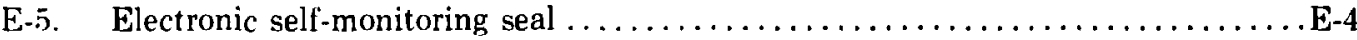

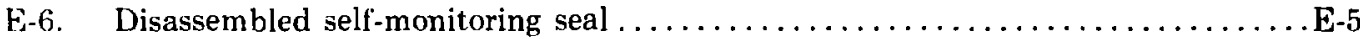

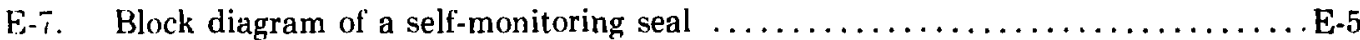


CONCEPTS FOR INVENTORY VERIFICATION IN CRITICAL FACILITIES

by

D. D. Cobb, J. L. Sapir, E. A. Kern, and R. J. Dietz

\begin{abstract}
Materials measurement and inventory verification concepts for safeguarding large critical facilities are presented. Inspection strategies and methods for applying international safeguards to such facilities are proposed. The conceptual approach to routine inventory verification includes frequent visits to the facility by one inspector, and the use of seals and nondestructive assay (NDA) measurements to verify the portion of the inventory maintained in vault storage. Periodic verification of the reactor inventory is accomplished by sampling and NDA measurement of in-core fuel elements combined with measurements of integral reactivity and related reactor parameters that are sensitive to the total fissile inventory. A combination of statistical sampling and NDA verification with measurements of reactor parameters is more effective than either technique used by itself. Special procedures for assessment and verification for abnormal safeguards conditions are also considered. When the inspection strategies and inventory verification methods are combined with strict containment and surveillance methods, they provide a high degree of assurance that any slandestine attempt to divert a significant quantity of fissile material from a critical facility inventory will be detected. Field testing of specific hardware systems and procedures to determine their sensitivity, reliability, and operational acceptability is recommended. The results obtained from conceptual studies and operational testing and evaluation exercises will provide much needed information to safeguards authorities and to designers of future safeguards systems for large critical facilities. This work was performed as part of the Department of Energy, Office of Safeguards and Security Research and Development Program.
\end{abstract}




\section{INTRODUCTION*}

Fast-critical-assembly research facilities provide a wide range of experimental data used for the design and development of breeder power reactors. Because of the inadequacy of basic nuclear data and the complexity of detailed computational models, fast reactor design relies heavily on mockup critical experiments. These experiments are used to confirm the general analytical methods and to provide sperific information about critical mass, reactor kinetics and control, power distribution, sodium void and Doppler coefficients, effects of design changes, and other areas pertinent to the design of safe, economical breeder reactors. ${ }^{1}$

Large fast-critical researcin facilities are operating in several countries (Table I).$^{2-11}$ The two basic types of large critical-assembly machines are the horizontal split table and the integral vertical. The horizontal split-table assembly consists of two approximately equal portions that move apart when the reactor is shut down. Fuel elements in the form of open "drawers" are loaded, usually manually, from between the halves into a horizontal matrix structure.

In the int egral vertical assembly, full-length, selfcontained fuel elements are suspended from a grid plate. There is no provision to separate large portions of the assembly during shutdown; the necessary shutdown margin is obtained by withdrawing control elements. Automated machines typically are used to assemble fuel elements and to load them into the reactor. During an experimental program, individual fuel pieces are usually more accessible in a split-table assembly than in an integral one.

Critical facilities typically are located in nuclear research centers that maintain strict national safeguards including personnel controls and other physical protection measures. However, several critical facilities are coming under international safeguards, which depend on materials accounting as the basic safeguards measure complemented by containment and surveillance activities. The application of international safeguards to such facilities is difficuli because of the many small items

*The British unit of length, inches (in.), is used frequently in this report for the dimensions of fabricated items; note that 1 in. = $2.54 \mathrm{~cm}$. distributed in reactor fuel elements and in storage containers.

For this reason, the Department of Energy's Office of Safeguards and Security (DOE/SS) has tasked the Los Alamos Scientific Laboratory (LASL) and Sandia Laboratories, Albuquerque, (SLA) to develor advanced concepts for safeguarding critical facilities, with special emphasis to be placed on the international aspects of the safeguards problem. DOE/SS also administers a related program, the US Program for Technical Assistance to the International Atomic Energy Agency (IAEA), through its International Safeguards Project Office (ISPO) at the Brookhaven National Laboratory. ${ }^{12}$

The initial LASL report ${ }^{13}$ presents preliminary concepts for improved materials measurement and accounting and identifies several promising inventory verification techniques. A companion SLA report ${ }^{2}$ compares several approaches to safeguarding critical facilities and selects a system concept that incorporates daily surveillance and inspection by IAEA inspectors, containment and surveillance by unattended equipment placed at the boundary of the Material Access Area (MAA), routine inventory verifications during normal operation, and special inventory procedures when an abnormal safeguards condition is encountered.

Of the 10 critical facilities listed in Table I, 3 (FCA, SNEAK, and PROTEUS) are located in nonweapons states, and all 10 are located in states that either are signatories of the Non-Proliferation Treaty (NPT) or have agreed in principle to the safeguards provisions of the NPT. Therefore, guidance for this study is taken from the NPT safeguards provisions, outlined in INFCIRC/153 ${ }^{14}$ and amplified in other IAEA technical documents ${ }^{15-}$ ${ }^{17}$ and in consultations with IAEA personnel.

NPT safeguards include on-site inspections at nuclear facilities and independent verification of special nuclear material (SNM) inventories. The recommended level of assurance ${ }^{15.16}$ is at least a $95 \%$ probability of detecting the misappropriation of a significant quantity $\left(8 \mathrm{~kg} \mathrm{Pu}\right.$ or $25 \mathrm{~kg}{ }^{235} \mathrm{U}$ in uranium enriched to $>20 \%$ ). The minimum time required to convert relatively pure, unirradiated nuclear materials to weapons-useable material is estimated to be days to weeks, ${ }^{15}$ and a safeguards advisory group ${ }^{18}$ has recommended that adequate 
TABLE I

\section{SUMMARY OF FAST-CRITICAL REACTORS}

\begin{tabular}{|c|c|c|c|c|c|c|c|c|c|}
\hline Location & Name & Reactor Type & Fuel & Element Size & Fuel Assembly & $\begin{array}{c}\text { Fuel } \\
\text { Inventory }\end{array}$ & $\begin{array}{c}\text { Structure } \\
\text { Containment }\end{array}$ & Fuel Handling & Ref \\
\hline $\begin{array}{l}\text { Idaho Falls, } \\
\text { ID, USA }\end{array}$ & ZPPR & $\begin{array}{l}\text { Split table with } \\
\text { horizontal matrix } \\
\text { tubes }\end{array}$ & $\begin{array}{l}\text { Pualloy } \\
\mathrm{PuO}_{2} \text { UO }_{z} \\
\mathrm{HEU}^{\mathrm{W}} \text { metal }\end{array}$ & $\begin{array}{l}\text { Plates: } 51 \mathrm{~mm} \text { high } \\
\text { up to } 65 \mathrm{lnm} \text { thick } \\
\text { up to } 203 \mathrm{~mm} \text { long } \\
\text { Pins: } 95 \mathrm{~mm} \text { diam } \\
152 \mathrm{~mm} \text { long }\end{array}$ & $\begin{array}{l}\text { 53. by } 53-\text { by } \\
\text { 915-mm unsealed } \\
\text { drawers }\end{array}$ & $\begin{array}{l}1000 \mathrm{~s} \\
\text { of } \mathrm{kg}\end{array}$ & $\begin{array}{l}\text { Reinforced con- } \\
\text { crete with } \\
\text { earth over- } \\
\text { burden }\end{array}$ & $\begin{array}{l}\text { Manual fuel element } \\
\text { loading; manual } \\
\text { transport; manual } \\
\text { core loading }\end{array}$ & 3 \\
\hline $\begin{array}{l}\text { Argonne, } \\
\text { II, USA }\end{array}$ & ZPR-6 & $\begin{array}{l}\text { Split table with } \\
\text { horizontal matrix } \\
\text { tubes }\end{array}$ & $\begin{array}{l}\text { Pualloy } \\
\mathrm{PuO}_{2} \\
\mathrm{HEU} \text { met ai }\end{array}$ & Same as above & Same as above & $\begin{array}{l}100^{\prime} \mathrm{s} \\
\text { of } \mathrm{kg}\end{array}$ & $\begin{array}{l}\text { Reactor cell: } \\
\text { Reinforced con- } \\
\text { crete shell } \\
\text { Vault: Rein- } \\
\text { forced concrete }\end{array}$ & Same as above & 4 \\
\hline $\begin{array}{l}\text { Argonne, } \\
\text { II, USA }\end{array}$ & ZPR-9 & $\begin{array}{l}\text { Split table with } \\
\text { horizontal matrix } \\
\text { tubes }\end{array}$ & $\begin{array}{l}\text { Pu alloy } \\
\text { PuO } \\
\text { HEU metal }\end{array}$ & Same as above & Same as above & $\begin{array}{l}100 ' \mathrm{~s} \\
\text { of kg }\end{array}$ & $\begin{array}{l}\text { Reactor cell: } \\
\text { Reinforced con- } \\
\text { crete shell } \\
\text { Vault: Rein- } \\
\text { forced concrete }\end{array}$ & Same as above & 5 \\
\hline $\begin{array}{l}\text { Tokaj-Mura, } \\
\text { Japan }\end{array}$ & FCA & $\begin{array}{l}\text { Split table with } \\
\text { horizontal matrix } \\
\text { tubes }\end{array}$ & $\begin{array}{l}\text { Pu alloy } \\
\mathrm{PuO}_{2}-\mathrm{UO}_{2} \\
\mathrm{HEU} \text { metal }\end{array}$ & $\begin{array}{l}\text { Plates: } 51 \mathrm{~mm} \text { high } \\
\text { up to } 65 \mathrm{~mm} \text { thick } \\
\text { up to } 51 \mathrm{~mm} \text { long }\end{array}$ & $\begin{array}{l}\text { 53- by 53-by } \\
665-\mathrm{mm} \text { unsealed } \\
\text { drawers }\end{array}$ & $\begin{array}{l}100^{\prime} \mathrm{s} \\
\text { of } \mathrm{kg}\end{array}$ & $\begin{array}{l}\text { Reactor cell: } \\
\text { Double shell of } \\
\text { reinforced con- } \\
\text { crete }\end{array}$ & $\begin{array}{l}\text { Manual fuel element } \\
\text { loading; two fuel } \\
\text { assembly transport } \\
\text { luhes; manual core } \\
\text { loading }\end{array}$ & 6 \\
\hline $\begin{array}{l}\text { Karlsnuhe, } \\
\text { FRG }\end{array}$ & SNEAK & $\begin{array}{l}\text { Integral vertical } \\
\text { assembly }\end{array}$ & $\begin{array}{c}\mathrm{HEU} \text { metal } \\
\mathrm{PuO}_{2}-\mathrm{UO}_{2}\end{array}$ & $\begin{array}{l}\text { Plates: } 51 \mathrm{~mm} \text { square } \\
\text { up to } 625 \mathrm{~mm} \text { thick }\end{array}$ & $\begin{array}{l}\text { 54-mm-square by } \\
3118 \cdot \mathrm{mm}-\mathrm{long} \\
\text { fuel rods }\end{array}$ & $\begin{array}{l}100 \text { 's } \\
\text { of } \mathrm{kg}\end{array}$ & $\begin{array}{l}\text { React or cell: } \\
\text { Double-shell } \\
\text { steel with con- } \\
\text { crete shielding }\end{array}$ & $\begin{array}{l}\text { Automated fuel ele. } \\
\text { ment loading: tran- } \\
\text { sit tube: fuel } \\
\text { assembly loading } \\
\text { machine }\end{array}$ & 7 \\
\hline $\begin{array}{l}\text { Cadarache, } \\
\text { France }\end{array}$ & MASURCA & Vertical lattice & $\begin{array}{l}\text { Pu alloy } \\
\text { HEU metal }\end{array}$ & $\begin{array}{l}\text { Rods: } 127 \mathrm{~mm} \text { square } \\
10 \mathrm{~mm} \text { long }\end{array}$ & $\begin{array}{l}\text { 105-mm-square } \\
\text { by } 3200 \text {-mm-long } \\
\text { fuel rods }\end{array}$ & $\begin{array}{c}100 \mathrm{~s} \\
\text { of } \mathrm{kg}\end{array}$ & $\begin{array}{l}\text { Reactor cell: } \\
\text { Steel shell }\end{array}$ & $\begin{array}{l}\text { Automated fuel ele. } \\
\text { ment loading: fuel } \\
\text { nasembly transport } \\
\text { tube; fuel assembly } \\
\text { londing mathine }\end{array}$ & 8 \\
\hline $\begin{array}{l}\text { Winfritr } \\
\text { UK }\end{array}$ & ZEBRA & $\begin{array}{l}\text { Integral vertical } \\
\text { assembly }\end{array}$ & $\begin{array}{l}\text { HEU metal } \\
\text { Pualloy } \\
\mathrm{PuO}_{2}-\mathrm{UO}_{2}\end{array}$ & $\begin{array}{l}\text { Plates: } 51 \mathrm{~mm} \text { square } \\
\text { up to } 625 \mathrm{~mm} \text { thick }\end{array}$ & $\begin{array}{l}54-\mathrm{mm} \text {-square hy } \\
2997 \cdot \mathrm{mm} \cdot \mathrm{lohg} \\
\text { fuel rods }\end{array}$ & $\begin{array}{l}1001 \mathrm{~s} \\
\text { of } \mathrm{kg}\end{array}$ & $\begin{array}{l}\text { Reactor cell: } \\
\text { Steel cylinder } \\
\text { containment with } \\
\text { concrete shield }\end{array}$ & $\begin{array}{l}\text { Autonssted fuel ele- } \\
\text { ment londing: tran- } \\
\text { sit tube: fuel assem- } \\
\text { hly loading machine }\end{array}$ & 9 \\
\hline $\begin{array}{l}\text { Aldermaston, } \\
\text { UK }\end{array}$ & VERA & $\begin{array}{l}\text { Split table } \\
\text { vertical matrix }\end{array}$ & $\underset{\text { Pu alloy }}{\text { HEU metal }}$ & $\begin{array}{l}\text { Plates: } 432 \mathrm{~mm} \\
\text { square, thickness } \\
\text { variable }\end{array}$ & $\begin{array}{l}\text { 46.mm-square by } \\
1170-m n-l o n g \\
\text { fuel boxes }\end{array}$ & $\begin{array}{l}100 / \mathrm{s} \\
\text { of } \mathrm{kg}\end{array}$ & $\begin{array}{l}\text { Reactor cell: } \\
\text { Concrete shell }\end{array}$ & $n$ & 10 \\
\hline $\begin{array}{l}\text { Obninsk, } \\
\text { USSR }\end{array}$ & BF'S & $\begin{array}{l}\text { Integral verticul } \\
\text { assembly }\end{array}$ & $\underset{\text { Pu (?) }}{\mathrm{HEU}}$ & $?$ & ? & $?$ & ? & $?$ & 11 \\
\hline Switzerland & PROTEUS & $\begin{array}{l}\text { Integral vertical } \\
\text { assembly }\end{array}$ & $\begin{array}{c}\mathrm{PuO}_{2}^{-} \mathrm{UO}_{2} \\
\mathrm{HEU}\end{array}$ & $\begin{array}{l}\text { Pins: } 67 \mathrm{~m} m \text { diam } \\
56 \mathrm{~mm} \text { long }\end{array}$ & $\begin{array}{l}\text { 84-mm-diam by } \\
\text { !400-mm-long } \\
\text { fiut. rodi: }\end{array}$ & $\begin{array}{c}-100 \\
\mathrm{~kg}\end{array}$ & $?$ & $\begin{array}{l}\text { Manual fuel element } \\
\text { londing: manual } \\
\text { core londing }\end{array}$ & . \\
\hline
\end{tabular}


safeguards for critical facilities should be able to detect a significant-quantity diversion within 10 days. At fast-critical facilities where the inventory consists of many thousands of small fuel pieces, the prompt detection of diversion must rely on stringent containment/surveillance measures backed up by less timely but quantitative verifications of the inventory to ensure that the containment/surveillance systems are not being subverted or bypassed.

In this study we have assumed as a guideline that the inventory verification procedures (alone) for international safeguarding of critical facilities should be capable of detecting a significant diversion within a period of 6 months with $95 \%$ probability. It is assumed to be conceivable that a nonweapons state might attempt to acquire the fissile material for one or more nuclear explosive devices by covert diversion of fuel from a critical facility inventory, employing various concealment strategies to escape detection. Overt diversion is an abrogation of the NPT with immediate detection and international response.

Our approach is to develop inventory verification concepts with reference to a model plutonium critical facility having a split-table assembly. This model facility is described in Sec. II and is similar to the one assumed by SLA in Ref. 2. Although it does not represent a specific operating facility, the model facility incorporates features of operating facilities in sufficient detail to permit both development and evaluation of inventory verification concepts.

In Sec. III, several options for inventory verification are considered in terms of the overall safeguards system concept and with regard to the requirements for effective IAEA safeguards and safe and efficient facility operation. We develop an approach to inventory verification for the model facility. This approach incorporates sealing of fuel storage containers, periodic sampling of the reactor inventory, and a combination of state-of-the-art safeguards measurements including nondestructive assay (NDA) techniques and measurements of integral reactivity and related reactor parameters.

The effectiveness of sampling verifications of the reference reactor inventory is evaluated in Sec. IV. Modeling and simulation are used to obtain quantitative estimates for the probability of detecting the diversion of a significant quantity by various strategies. These diversion strategies are imposed on the normal operation of the model critical facility by simulating typical operations for a 1-yr period using actual operating data including thousands of reactor loading changes.

Results and conclusions are presented in Sec. V. The conceptual approach to verifying the model critical facility inventory is summarized, and specific areas requiring further development and demonstration are identified.

Five technical appendixes are included. Each appendix is a stand-alone, topical survey containing important technical data relevant to safeguarding fast-critical facilities. The topics surveyed are: gamma-ray and neutron NDA instruments and methods (App. A), integral reactivity and related measurements (App. B), autoradiographic NDA techniques (App. C), sampling plans and data evaluation methods (App. D), and tamperindicating seals (App. E).

\section{THE MODEL CRITICAL FACILITY}

The morlel critical facility developed as a reference for this study is not intended to represent any specific operating facility in detail. It has been selected to be descriptive of the large plutonium critical facilities operated in the United States and abroad to simulate fast-breeder reactor cores. The model facility incorporates features of an operating facility in sufficient detail to permit us to develop inventory-verification concepts. The information upon which this model facility is based has been supplied by Argonne National Laboratory (ANL) personnel.

Figure 1 is a schematic of the model facility. Major functional areas are (1) the material access area (MAA), which includes the fuel storage vault, the workroom, and the reactor cell; (2) the support wing, which includes the reactor control room; and (3) the nonfuel storage area.

\section{A. Facility Description}

The MAA is enclosed within a containment barrier having controlled access. Normally, all of the facility's SNM is contained within the MAA. 


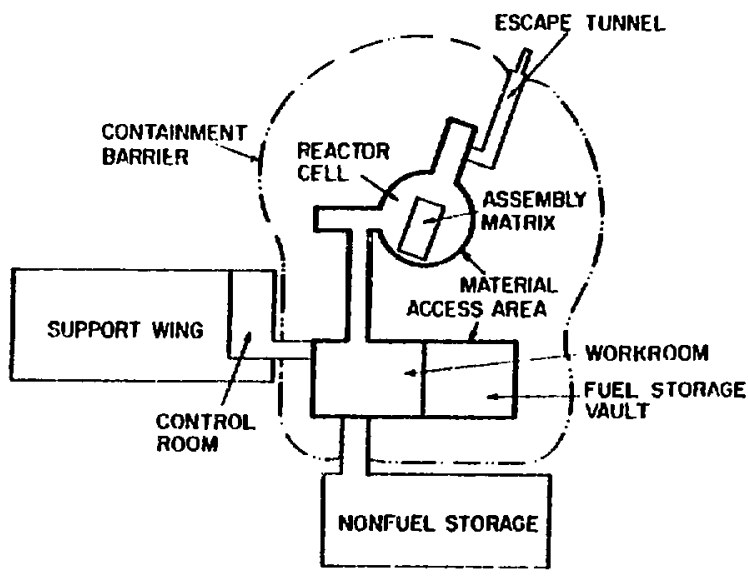

Fig. 1.

Schematic of the model facility.

1. Storage Vault. Except for the reactor assembly, the vault is the only authorized area for storage of fissile materials. Plutonium fuel plates are placed in aluminum canisters (Fig. 2), nominally 11.25 in. long by 7.5 in. wide by 2.75 in. high, which are stored in slots in borated-concrete bins. These bins provide radiation shielding and minimize the possibility of accidental criticality. Canisters are numbered with the storage-bin location into which they are loaded. Administrative controls require that, except for rejects, one canister will contain only plates of one length stored in a specified geometry. An attempt is made to fill canisters to their capacity, although, depending on loading and unloading operations, this cannot always be accomplished. The maxinum amount of plutonium permitted in a canister is $3 \mathrm{~kg}$.

The vault has storage capacity for several hundred canisters. In addition, specially designed bins are set aside for temporary storage of $\sim 100$ loaded reactor drawers. Neutron sources and miscellaneous special experimental devices containing fissile materials (that is, fission chambers, activation foils, and reactivity-worth samples) are also stored in the vault. Access to the vault is through a single doorway from the workroom.

2. Workroom. The workroom is the only area in the facility where manual handling of fuel pieces is permitted. Here, fuel pieces are loaded into and unloaded from reactor drawers and transferred to and from storage canisters. All handling is done inside ventilated hoods. Loaded fuel drawers are transferred to the reactor cell either on metal carts through the main access corridor and connecting air lock or on an automated conveyor passing through a small tunnel between the workroom and reactor cell. Metal carts are used to transfer storage canisters to and from the vault. Fissile material is not permitted to remain inside the workroom after working hours.

The reactor drawers are made of stainless steel and are nominally 2 in. square by 23 or 36 in. long. Each fuel-bearing drawer is numbered with the reactor matrix position into which it is loaded. The loaded drawers contain either one or two 18-in.-long rows of fuel plates interspersed among nonfissile materials that simulate the structural, coolant. blanket, and reflector materials in a fast reactor. A loaded fuel drawer containing two rows of plutonium plates is shown in Fig. 3.

Three routes allow access to the workroom. These are (1) from the reactor cell through a double set of blast and seal doors, (2) from the reactor control room through a seal door, and (3) from the nonfuel storage area through a seal door.

3. Reactor Cell. The heart of the facility is the reactor cell, which contains the critical assembly. In the model facility the assembly is a horizontal, split table consisting of a large ( $\sim 50$ by 50 ) array of stainless steel matrix tubes divided into separable halves (Fig. 4). Drawers are loaded into the matrix tubes from between the halves. An adjustable loading platform is driven between the halves to facilitate manual loading. The model facility also contains a matrix loader (Fig. 5), which can be programmed to insert or remove reactor drawers automatically at any designated matrix position. Use of the loader eliminates the need for personnel to work between the matrix halves, thereby reducing the radiation dose accumulated during loading and unloading.

During loading operations and whenever the reactor is shut down, the faces of the matrix halves are covered with large Benelex and steel biological shields. When the shields are in place, they preclude access to the reactor drawers. However, they can be moved in sections so that a few matrix columns are exposed to allow drawer insertions or removals.

To perform a reactor experiment the shields and loading platforms are driven from between the halves, and the movable half is then driven by 


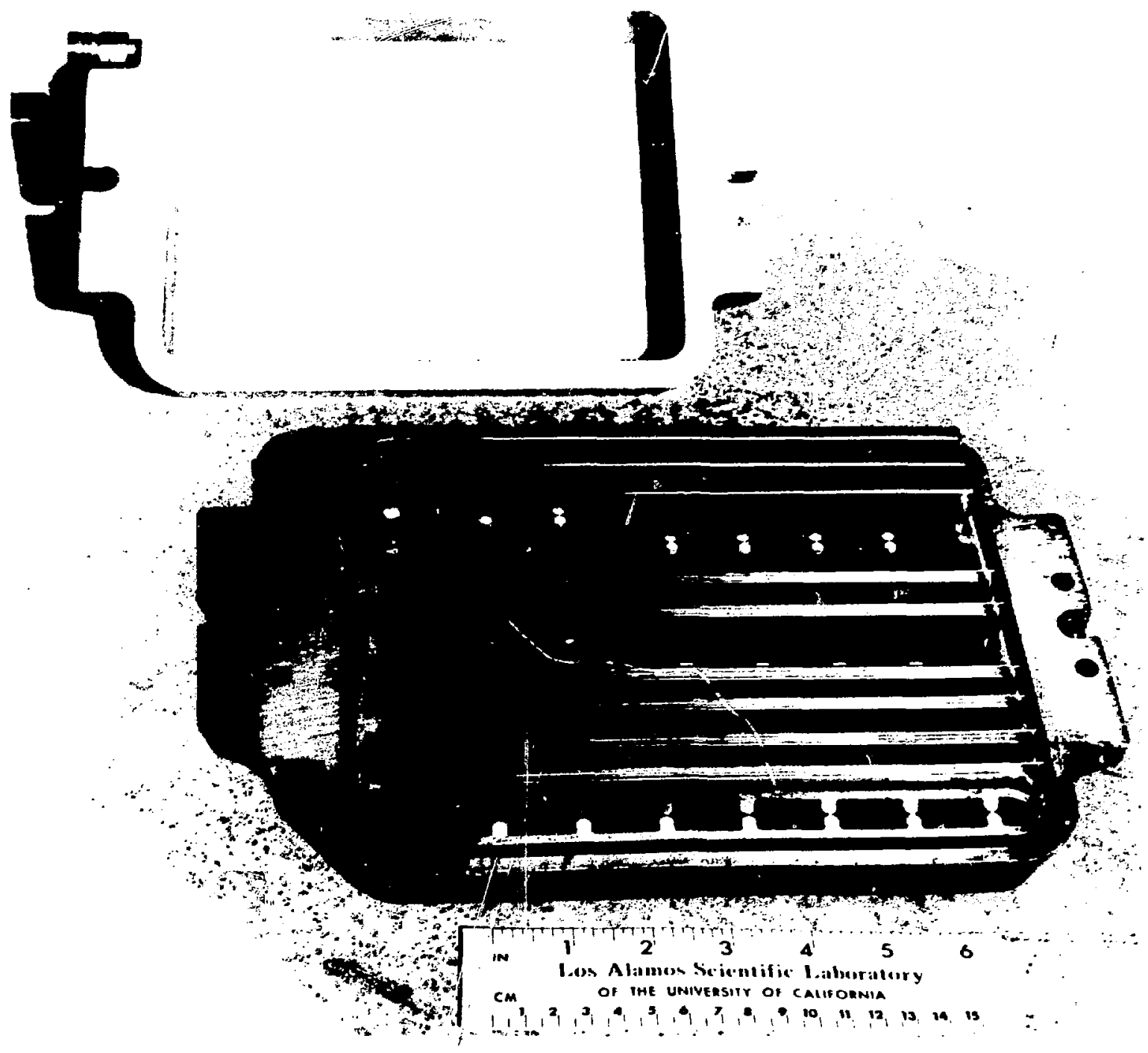

Fig. 2.

Fuel storage canister containing Pu/Mo/U fuel plates.

remote control against the stationary half. Final criticality is reached by slowly removing poisonbearing control rods. The cell is vacated of all personnel during reactor operation.

Access to the reactor cell is through a corridor from the workroom to the cell or through an emergency escape tunnel. Both routes contain double sets of blast and seal doors.
4. Support Wing. The support wing houses the reactor control room, a computer room, staff offices, and an area for measuring irradiated foils. The support wing is outside the containment structure to facilitate access. Except for small irradiation foils and fission chambers, SNM is not normally permitted inside the support wing. 


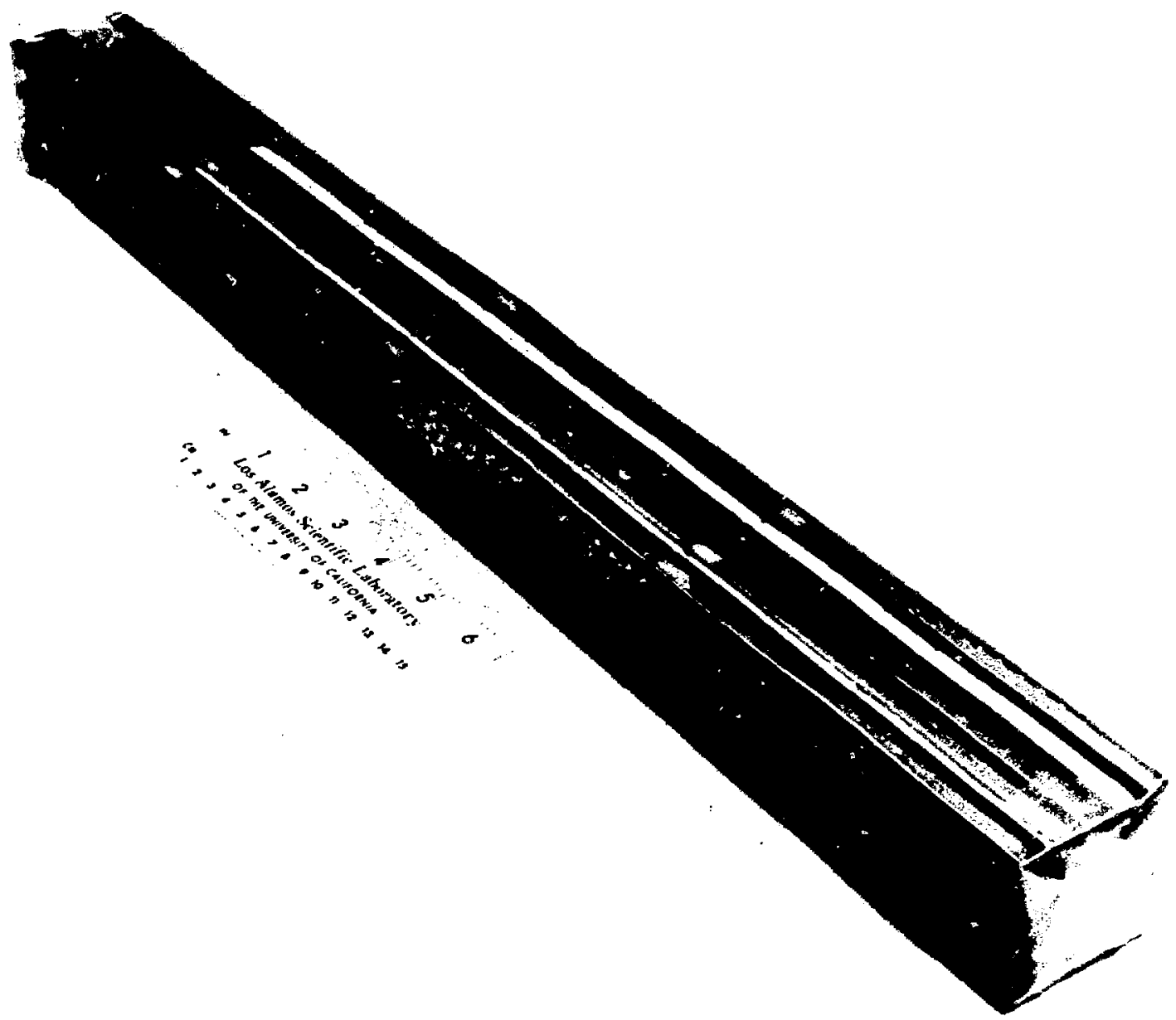

Fig. 3.

Fuel drawer containing two rows of pluionium plates interspersed with plates of depleted uranium, sodium, and aluminum.

Reactor operations are monitored and controlled from the reactor control room. During loading operations and reactor experiments, a closed-circuit television display of the reactor matrix is available in the control room. Fuel handling operations in the workroom can be monitored by voice-phone communications.

A small computer is available for routine reactor calculations and for storing SNM inventory data. The inventory data are updated from terminals in the control room.
5. Nonfuel Storage Area. As is the support wing, the nonfuel storage area is outside the containment barrier. A fire and seal door controls access between the nonfuel storage area and the workroom inside the MAA. Although fissile material is not normally handled in this area, shipments and receipts of SNM may pass through.

All nonfuel mockup materials are stored in the nonfuel storage area, including several tonnes of depleted uranium. Reactor drawers are loaded with the nonfuel mockup materials and transferred either 


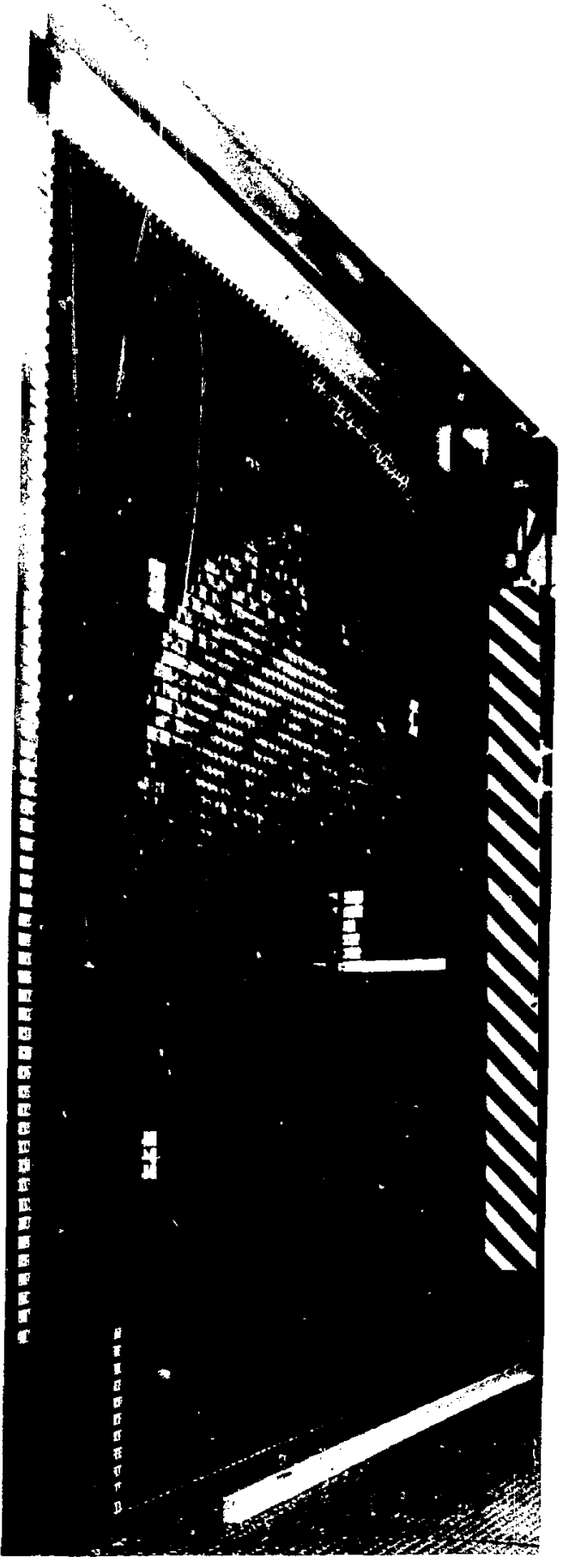

Fig. 4.

Assem bly matrix with a few drawers projecting from the matrix tubes.

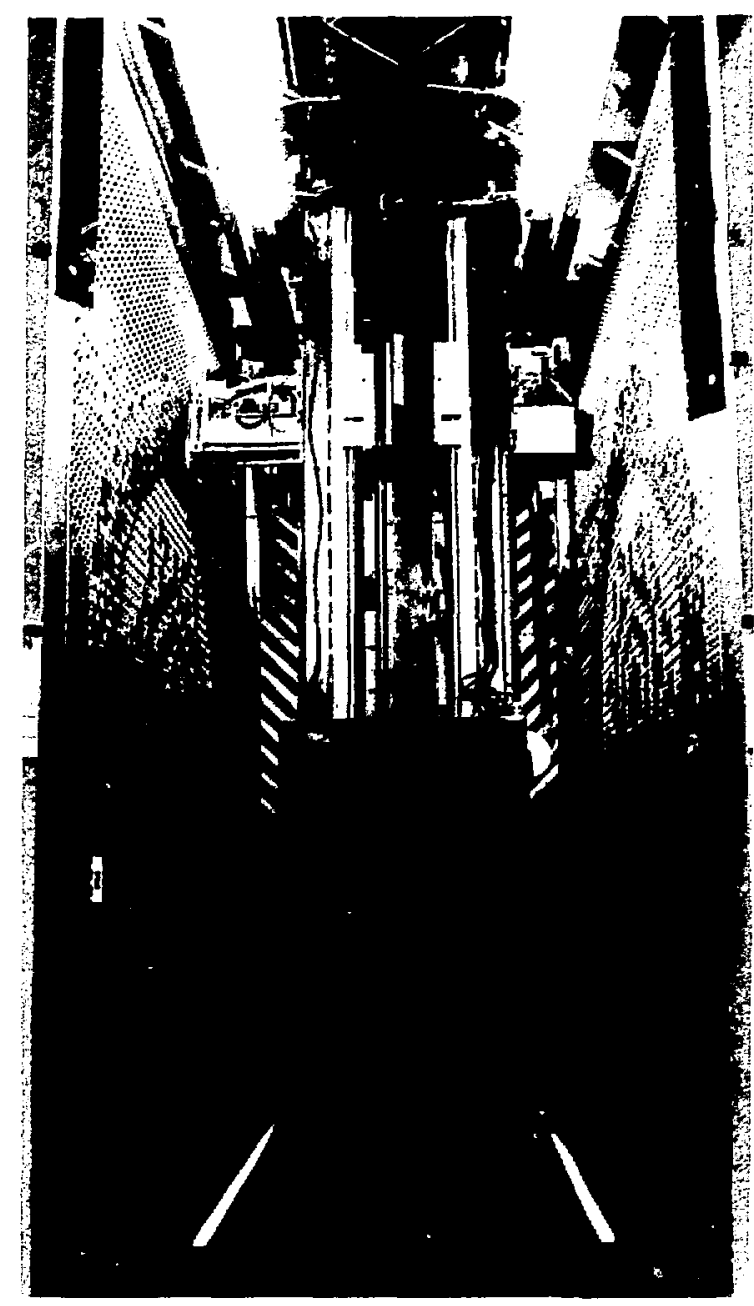

Fig. 5.

Matrix loader for automated fuel drawer handling.

to the fuel-handling area in the workroom or directly through the workroom into the reactor cell. A possible alternative physical arrangement would have nonfuel material stored inside the MAA, thereby reducing the amount of material flowing across the MAA boundary.

\section{B. Operation and Materials Flow}

The experimental program at the model facility requires frequent changes in the reactor configuration, which result in an extensive flow of materials 


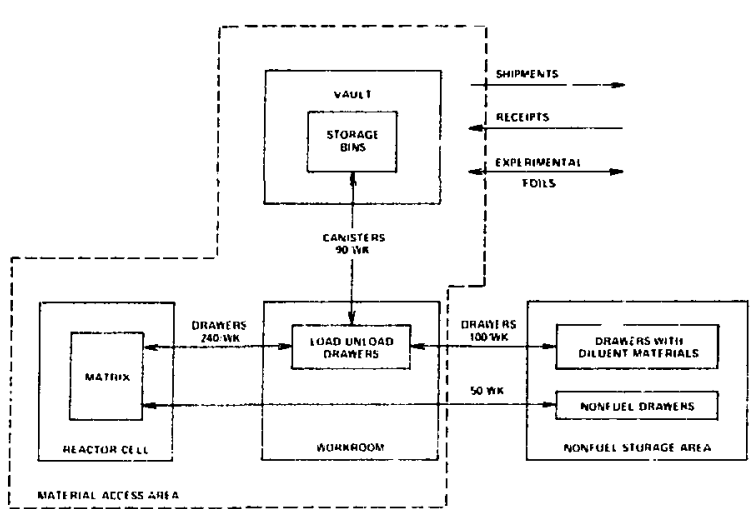

Fig. 6.

Materials flow in the model facility.

within and across the MAA boundary. Figure 6 schematically illustrates the paths and amounts of these flows. The flow amounts are the average numbers of drawers and canisters transferred in both directions each week during normal operation. The average flow of SNM between the vault and the reactor is $\sim 100$ fuel plates, or $\sim 17 \mathrm{~kg}$ of plutonium, per week each way. Flow of SNM across the MAA boundary normally is limited to shipments, receipts, and experimental activation foils. During normal operation, quantities in these categories are relatively small.

Significant quantities of SNM are moved between the workroom and either the reactor cell (drawers) or the storage vault (canisters). At the end of a working shift no SNM remains inside the workroom. Significant quantities of nonfissile materials cross the MAA boundary between the nonfuel storage area and the workroom.

In a typical loading operation, the reactor drawers are loaded with their nonfissile components in the nonfuel storage z:ea. These drawers are then moved into the workroom. The reflector or blanket drawers, which will not contain SNM, are transferred directly into the reactor cell for insertion into the matrix. Fuel drawers are transferred into ventilation hoods and are loaded with fuel plates obtained either from canisters brought from the vault or from other fuel drawers brought from the reactor cell for unloading.

During an unloading operation, the fuel drawers are transferred from the reactor cell to the workroom, the fuel plates are removed, placed in canisters, and returned to the vault, and the drawers with the remaining diluent materials are returned to the nonfuel storage area. Reflector and blanket drawers are moved directly from the reactor cell to the nonfuel storage area.

The model facility maintains a fuel inventory program that records all fuel transfers and keeps track of the location of every fuel piece. Thus, the location of all fuel pieces can be determined, and the fuel contents of any location (reactor matrix or storage bin) can be identified.

\section{Inventory Description}

The fuel inventory in the model facility consists of thin metal plates, 0.25 in. thick, 2 in. wide, and 4 to 8 in. long. Each plate contains a ternary alloy of plutonium, depleted uranium, and molybdenum $(\mathrm{Pu} / \mathrm{U} / \mathrm{Mo})$ enclosed by a stainless steel jacket. The nominal alloy enrichment is $28 \mathrm{wt} \%$ plutonium. The nominal plutonium isotopic composition is $87 \%$ ${ }^{239} \mathrm{Pu}, 11.5 \%{ }^{240} \mathrm{Pu}, \sim 1 \%{ }^{241} \mathrm{Pu}$, and $<0.5 \%{ }^{239} \mathrm{Pu}+$ ${ }^{242} \mathrm{Pu}$. The total inventory is $>1000 \mathrm{~kg}$ of plutonium, distributed among the fuel plates as shown in Table II. The average amount of plutonium per inch of

\section{TABLE II}

\section{FUEL PLATES IN THE MODEL FACILITY INVENTORY"}

\begin{tabular}{|c|c|c|c|}
\hline $\begin{array}{c}\text { Plate } \\
\text { Length } \\
\text { (in.) }\end{array}$ & $\begin{array}{c}\text { Pu per } \\
\text { Plate } \\
(\mathrm{g}) \\
\end{array}$ & $\begin{array}{c}{ }^{240} \text { Pu per } \\
\text { Plate } \\
\text { (g) }\end{array}$ & $\begin{array}{l}\text { Fraction of } \\
\text { Inventory }\end{array}$ \\
\hline 4 & 123.2 & 14.2 & 0.12 \\
\hline 5 & 155.8 & 17.9 & 0.23 \\
\hline 6 & 188.2 & 21.6 & 0.19 \\
\hline 7 & 220.4 & 25.3 & 0.22 \\
\hline 8 & 253.6 & 29.2 & 0.24 \\
\hline
\end{tabular}

${ }^{\text {"}}$ This is not the actual inventory in any facility, but it represents a possible inventory in a large plutonium critical facility. 
plate is $31.3 \mathrm{~g}$. The relative standard deviation (RSD) of the plutonium-plate content is $\sim 1.3 \%$ for all plates, based on typical assay data from fuel manufacturers.

In general, a greater variety of fuel materials exists at the operating critical facilities (Table I). The fuel geometry is usually a thin plate $(1 / 16$ to $1 / 4$ in. thick, $\sim 2$ in. wide, and 1 to 8 in. long) or small rods $(\sim 3 / 8$ in. in diameter by 3 to 8 in. long). The uranium fuel is usually in the form of metal or oxide with ${ }^{235} \mathrm{U}$ enrichments of $20-93 \%$. The plutoniumi is present in the form of mixed oxides and alloys of uranium, aluminum, iron, or molybdenum. The ${ }^{240} \mathrm{Pu}$ isotopic fraction may vary from 5 to $25 \%$. Figure 7 shows three types of plutonium plates.

The variety of fuels in an operating facility makes stratification of the inventory for verification difficuit. The greatest impact is likely to be on the NDA instrumentation required to measure the different types of fuel and on the required calibration and measurement control program. Appendixes A and $C$ survey possible NDA instruments and methods that apply to a wider variety of fuels than is contained in the model facility.

One possible configuration of the model facility's inventory, which occurs when the reactor is completely unloaded and all the fuel is stored in the vault, is given in Table III. The RSD of the plutonium content of each full canister is $\sim 0.27 \%$ for 4 -in.-plate canisters, $\sim 0.33 \%$ for 5 - and 6 -in.plate canisters, and $\sim 0.38 \%$ for 7 - and 8 -in.-plate canisters.
At the start of a series of experiments, the reactor is loaded in a particular reference (standard) configuration. The distribution of fuel plates in reactor drawers for a postulated reference configuration is given in Table IV. The total inventory of plutonium in this reference loading is $1220 \mathrm{~kg}$ in 1584 fuel drawers. The fueled length is $18 \mathrm{in}$. and drawers contain either one or two rows of fuel plates.

Graphic displays have been developed to help us monitor the many changes in reactor loading that occur during simulated operation of the model facility. Figure 8 shows a computer-generated, schematic cross section of fuel drawers in the reference reactor configuration (the loading is symmetric). The numbers in the figure refer to fuel drawers containing one or two rows of fuel plates. The nominal plutonium contents of one- and tworow fuel drawers are 0.565 and $1.130 \mathrm{~kg}$, and the RSDs of the drawer contents are $\sim 0.78$ and $0.55 \%$, respectively.

The facility inventory is divided into classes of similar items for sampling and measurement during inventory verification. A vault inventory class would consist of all canisters loaded with the same fuel, for example, all fuel canisters containing 4-in. plutonium plates with the same enrichment and isotopic composition. The classificition of fuel drawers is complicated somewhat by mixing of fuel plates and by different arrangements of nonfuel mockup materials in the drawers. The classification of fuel drawers for sampling verification is discussed in Sec. III.
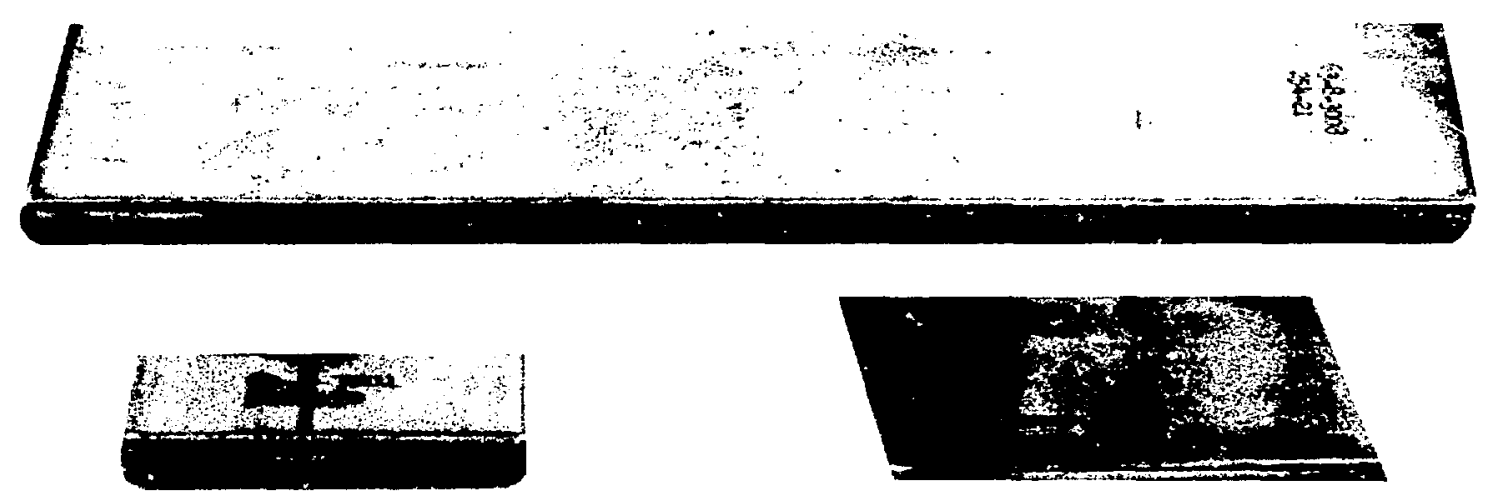

Fig. 7.

Typical plutonium fuel plates: upper, 0.25- by 2- by 8-in. Pu/Mo/U; lower left, 0.25- by 2- by 1-in. Pu/Mo/U; lower right, $0.125-$ by 2- by 2-in. Pu/Al. (The images are not to scale.) 
TABLE III

VAULT INVENTORY WITH THE REACTOR UNLOADED

\begin{tabular}{|c|c|c|c|c|}
\hline $\begin{array}{l}\text { Plate } \\
\text { Length } \\
\text { (in.) }\end{array}$ & $\begin{array}{c}\text { No. of } \\
\text { Plates per } \\
\text { Full Canister }\end{array}$ & $\begin{array}{c}\text { Pu per } \\
\text { Canister } \\
\text { (kg) }\end{array}$ & $\begin{array}{c}\text { No. of } \\
\text { Plates per } \\
\text { Partial } \\
\text { Canister }\end{array}$ & $\begin{array}{l}\text { Fraction of } \\
\text { Inventory }\end{array}$ \\
\hline 4 & 24 & 2.957 & 0 & 0.12 \\
\hline 5 & 16 & 2.493 & 8 & 0.23 \\
\hline 6 & 16 & 3.012 & 10 & 0.19 \\
\hline 7 & 12 & 2.645 & 0 & 0.22 \\
\hline 8 & 12 & 3.043 & 11 & 0.24 \\
\hline
\end{tabular}

TABLE IV

\section{FUEL DRAWERS IN A REFERENCE CONFIGURATION}

\begin{tabular}{|c|c|c|c|}
\hline $\begin{array}{l}\text { Plate Lengths } \\
\text { per Drawer } \\
\text { (in.) }\end{array}$ & $\begin{array}{c}\text { No. of } \\
\text { Drawers }\end{array}$ & $\begin{array}{c}\text { Pu per } \\
\text { Drawer } \\
\text { (kg) }\end{array}$ & $\begin{array}{c}\text { Total Pu } \\
\text { (kg) }\end{array}$ \\
\hline $5,6,7$ & 748 & 0.564 & 422.2 \\
\hline $5,5,8$ & 260 & 0.565 & 147.0 \\
\hline $\left.\begin{array}{l}4,6,8 \\
4,6,8\end{array}\right\}$ & 376 & 1.130 & 424.9 \\
\hline $\left.\begin{array}{l}5,6,7 \\
5,6,7\end{array}\right\}$ & 104 & 1.129 & 117.4 \\
\hline $\left.\begin{array}{l}5,5,8 \\
5,5,8\end{array}\right\}$ & 96 & 1.131 & 108.5 \\
\hline Total & 1584 & & 1220 \\
\hline
\end{tabular}

\section{INVENTORY VERIFICATION}

A balanced and effective international safeguards system for fast-critical facilities consists of integrated modules of containment, surveillance, and inventory verification. Figure 9 illustrates a system concept that protects against the basic covert diversion sequence: ${ }^{10}$ obtain the material, remove it from the containment area, and avoid detection. The stippled boxes in the right-hand portion of the figure indicate primary detection capability, whereas the open boxes denote back-up capability. For example, in this system concept the primary method of detecting removals of material through clandestine paths is by inspector surveillance, whereas the unattended containment/surveillance instruments provide the primary capability for detecting unauthorized removals through normal paths.

The IAEA postulates days to weeks for detecting diversion of a significant quantity of unirradiated nuclear material..$^{15}$ If the detection time for diversion of critical-facility materials should be short, containment/surveillance measures must provide the system's capability for prompt detection. Independent verification of large inventories consisting of many small items is relatively slow. This is the major argument for enhanced containment/surveillance measures with frequent inspection visits to such facilities as a necessary part of the surveillance capability.?

\section{A. Functions and Capabilities}

Inventory verification has two essential functions, routine inventory verification and special assessment and verification if the inspector suspects that diversion has occurred. Routine inventory verification and inspector surveillance provide the system's capability for detecting covert misappropriation of SNM within the containment area (Fig. 9). Routine inventory verification and inspector surveillance 

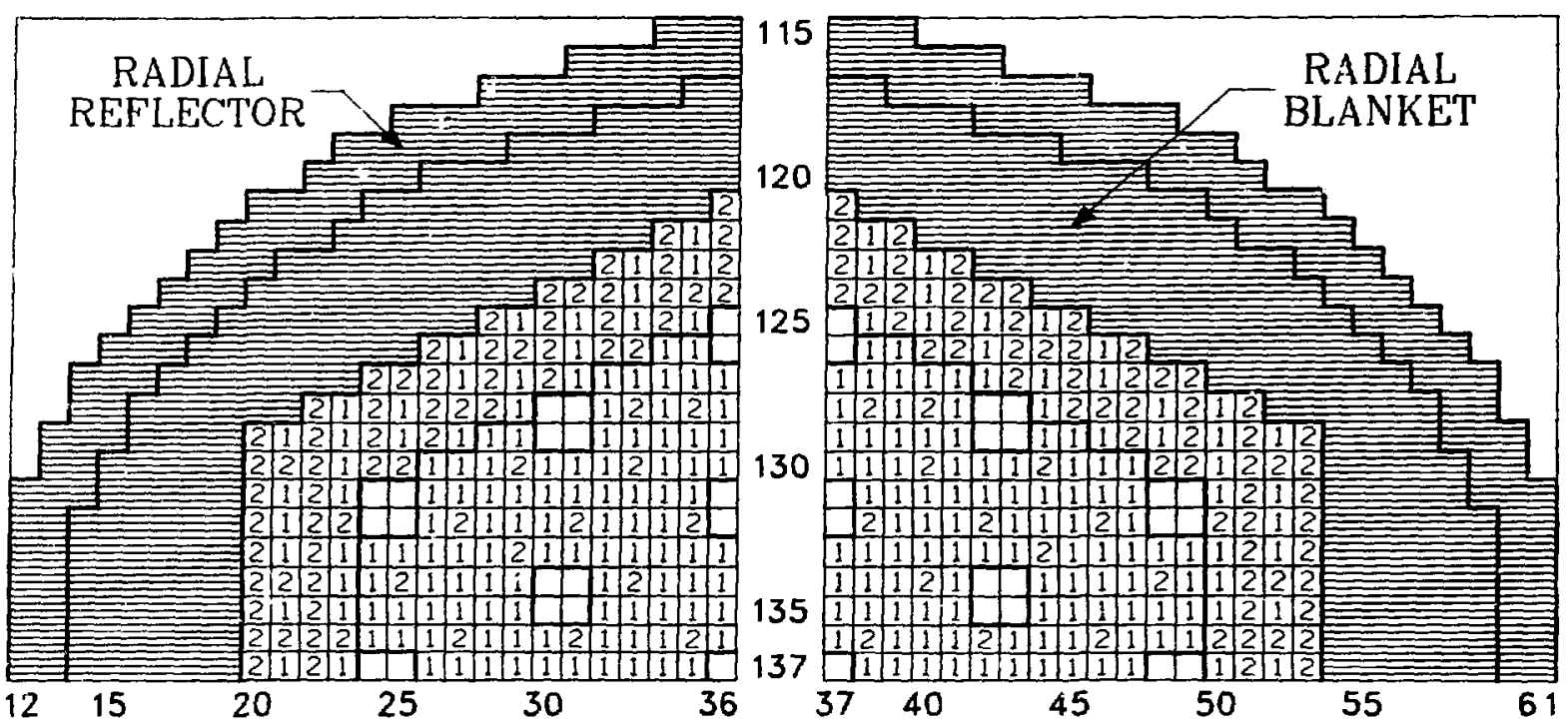

Fig. 8.

Schematic cross section of a reference configuration.
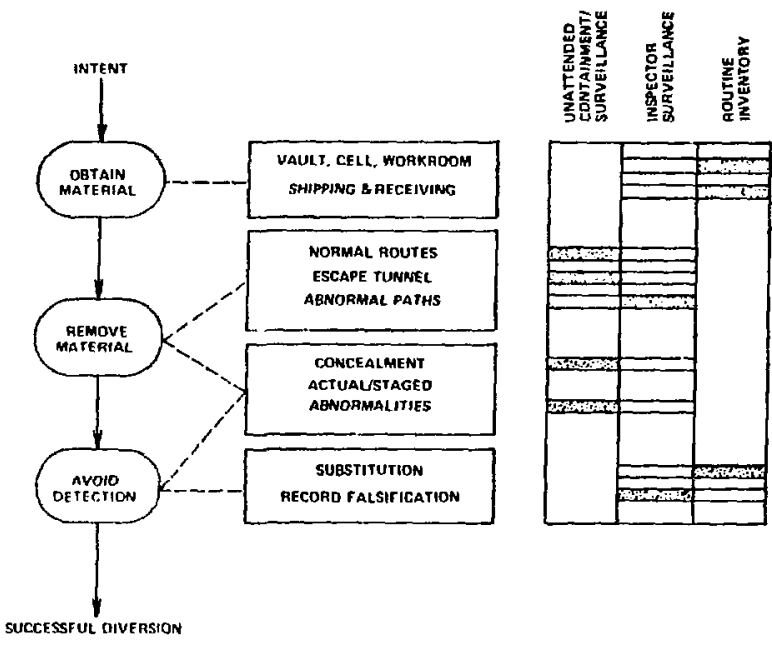

Fig. 9.

Schematic of the covert diversion sequence and the integrated detection capability of the safeguards system.

also must verify that the unattended containment/surveillance instruments are not being subverted or bypassed.

The tradeoff between inspector surveillance and the intensity of routine inventory verification must be considered carefully because, in general, independent verification procedures can seriously impede facility operations. Frequent inspections should reduce inventory-verification requirements.

In this study we have used the detection of a significant-quantity diversion within 6 months with at least $\mathbf{9 5 \%}$ probability as a guideline for comparing routine inventory-verification options. Wie propose distributing the onerous effort required for a conventional physical inventory, based on piece counting and item identification, into more frequent, partial inventories using collectivemeasurement techniques. Each partial inventory requires considerably less inspection effort and interference with the experimental program than does a physical inventory. The overall verification objectives are met by combining the results of the partial inventories. Each partial inventory provides relatively timely detection, albeit with lower assurance.

The special assessment and inventory functions are well defined. If the inspector suspects that SNM has been misappropriated from the facility inventory, he must make an assessment to determine the appropriate response. If the IAEA concludes that a special inventory is warranted, independent verification procedures must be available to provide 
the Agency with accurate information concerning the form and amount of missing material. Specifically, we assume that special verification methods and procedures must be available to determine, with at least $95 \%$ probability, whether a significant quantity of SNM has been diverted.

\section{B. Options}

The potential safeguards benefit of each option for inventory verification must be weighed against the required inspection effort, cost, and operator acceptability. Under NPT safeguards ${ }^{14}$ the IAEA must be allowed to implement verification strategies that can detect the illicit removal of a significant quantity from the inventory by any combination of the following diversion strategies: ${ }^{15}$ (1) a few removals of relatively large quantities, including the possibility of replacement with lower grade or inert materials; (2) many removals of relatively small quantities with or without replacement; and (3) records falsification, including deliberate misstatements of item locations and contents or of the operator's uncertainty of the contents. On the other hand, the operator must be assured that the impact of verification procedures on his facility is kept within acceptable limits with regard to additional radiation exposure of personnel, lost operating time, and additional operating cost.

1. Materials Measurement. Because of the many fuel pieces in the inventory and their disposition inside reactor fuel drawers and vault storage containers, inventory verification based on measuring individual fuel pieces is time consuming and adversely affects the productivity of the experimental program. A complete physical inventory based on manual piece counting takes many days to complete and causes significant radiation exposure of personnel because of the large amount of fuel handling involved.

It is desirable, therefore, to inventory the fuel "collectively" in relatively large units and to integrate these collective verification measures into the normal facility operation without requiring extended shutdown periods. For example, a physical inventory might best be scheduled to coincide with a complete reactor unloading so that all the fuel could be inventoried collectively in vault storage containers, in parallel with other routine facility activities scheduled during the shutdown. Furthermore, the integration of routine inventory procedures, based on collective measurements, into the experimental program would minimize disruptions and could obviate the need for physical inventories under normal conditions. Collectivemeasurement techniques identified for verification of critical-facility fuels include gamma-ray and neutron NDA, autoradiographic NDA, and integral reactivity and related reactor-parameter measurements.

NDA methods quantitatively determine the elemental and isotopic composition of uranium- and plutonium-bearing materials by detecting and recording unique gamma-ray or neutron signatures. Instruments that are sufficiently reliable and accurate to satisfy safeguards needs have been developed and demonstrated. Such instruments are coming into routine use by IAEA inspectors, because they provide portable, or at least transportable, capability for making independent verification measurements. Appendix A presents a survey of gamma-ray and neutron NDA instruments and methods for possible application to critical-facility fuels. Plutonium-bearing fuels can be assayed using "passive" methods that measure the naturally occurring gamma and neutron radiations. Enriched uranium fuels may require "active" methods in which induced-fission radiation is detected after interrogation by an external radiation source. In general, NDA instruments should be optimized for the specific application, such as fuel composition, geometry, and environment.

Autoradiography uses spontaneously emitted radiation (the $60-\mathrm{keV}$ gamma ray from ${ }^{241} \mathrm{Am}$ in the case of plutonium) to form images of individual fuel pieces on x-ray film (App. C). This technique is developed and has been used successfully to inventory plutonium fuel plates in situ in reactor drawers and vault storage canisters. Distinct images are formed of each fuel plate. Removal of a fuel plate or substitution of a dummy plate containing inert material is detected readily in the autoradiographs.

It is especially attractive to consider the adaptation of SNM-sensitive measurements commonly made in fast-critical assembly experiments to the 
routine verification of in-reactor inventory. One promising technique is the use of integral reactivity and related measurements (App. B), currently being developed and evaluated for safeguards application. As the method is now conceived, the assembly is returned periodically to a reference configuration, and the reactivity and other characteristic parameters of this reference are checked for changes indicating that a shift in the inventory has occurred. If the reactor inventory is unchanged, only the SNM inventory in vault storage remains to be verified to provide a complete verification of the facility inventory. The operator normally establishes a new reference configuration each time the experimental program requires a major loading change. Such changes might occur once or twice a year. To apply the reactivity technique, the inspector requircs independent verification of the SNM quantity and distribution in each new reference configuration. He also requires assurance that the operator has returned the reactor to the proper reference each time a reactivity check is made. This assurance can be obtained by making supplementary measurements such as foil activation and material worth.

Table $V$ is a summary of collective-measurement techniques including the capabilities and limitations of each. The measurements are sensitive to different properties and characteristics of the SNM fuels. Although it may be possible to subvert any one measurement technique, a combination of these techniques provides increased assurance and reduced vulnerability. The sensitivity, reliability, and operational acceptability of prototype hardware systems and proposed measurement procedures must be evaluated in operating critical facilities. The appropriate mix of measurement methods for any operating facility must be determined in the context of facility-specific design and operating features.

2. Vauit Inventory. When SNM fuels are not in use in the reactor. they are placed in specially designed containers and stored in a secure vault. Tamper-indicating seals (App. E) can be used on the vault storage containers. The contents of each container can be verified by direct NDA measurement after sealing. This procedure substantially reduces the effort required for inventory verification.
The inspection effort required to maintain the vault inventory under seal depends on specific design features of the critical facility. In the model facility, a considerable fraction of the inventory often resides in the vault, and $40-50$ vault canisters are opened each week during normal operation. In other facilities, most of the inventory is in the reactor, and fewer changes are made in the residual vault inventory. Generically, the inspector's goal is to have the entire vault inventory sealed during routine reactor inventory verification so that the inspection team can concentrate on verifying the reactor inventory, with only a check required of the sealed vault containers.

With this strategy, seals and verification measurements are applied frequently to the unsealed portion of the vault inventoiy. However, maintaining the vault inventory under continuous seal is not required; that is, each unsealed container of SNM does not have to be resealed and measured before it is placed in the vault. The only requirement is that the entire vault inventory be sealed when the reactor inventory is verified. Because the vault is accessible during reactor operation, the application of seals and verification measurements to storage containers during normal working hours need not interrupt the experimental program. The required effort would be smaller in less active facilities and could be reduced in all facilities by sealing only that portion of the vault inventory not scheduled for near-term use in reactor experiments.

For a major loading change, inspectors are present during reactor unloading and reloading to monitor the fuel handling and to verify the new reactor reference configuration. If the time between unloading and reloading is relatively short (a few days), there is little benefit in sealing the vault in. ventory during the interim; that is, seals are applied to the residual inventory in the vault only after the new loading is complete.

3. Reactor Inventory. Timely reactor inventory verification is the most difficult and challenging problem in safeguarding fast-critical facilities. Reactor inventory verification requires considerable inspection effort and can make great impact on facility operations. The inspector may be able to monitor facility activities, especially the movement of fuel and the operator's experimental data, which 
TABLE V

MATERIALS MEASUREMENT TECHNIQUES ${ }^{a}$

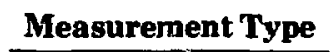

Gamma spectroscopy

Passive ne itron

Total counts

Passive neutron

Total and coincidence counts

Active neutron

Autoradiography

Reactivity

Material worth

Foil activation
Capabilities

Isotopic ratios;

fissile $\mathrm{Pu}$ enrichment.

Content of even Pu isotopes; relatively simple instrum 'n'

Content of even $\mathrm{Pu}$ isotopes; sensitive to changes in geometry; corrections for background and $(\alpha, n)$ reactions.

${ }^{235} \mathrm{U}$ content of HEU fuels; total fissile content of mixed (U,Pu) fuels; can be operated in passive mode for Pu fuels.

Image of edge area of each $\mathrm{Pu}$ fuel piece; very fast; minimum fuel handling; relatively simple and inexpansive.

Total in-reactor inventory; very sensitive

\section{Reactivity-compensating changes in fuel dersity, neutron spectrum, and power profile.}
Reactivity-compensating changes in fuel density, neutron spectrum, and power profile.
Limitations
Significant self-attenua- tion; affected by gamma background; marginal for HEU fuels; fuel handling required.
Fissile $\mathrm{Pu}$ isotopes not measured directly; affected by $(\alpha, n)$ reactions; affected by neutron background; fuel handling required; no $\mathrm{HEU}$ fuels.

Fissile $\mathrm{Pu}$ isotopes not measured directly; fuel handling required; no HEU fuels.

External radiation source required; relatively bulky and complex instrumentation; fuel handling required.

Surface effect; may not be SNM sperific; film processing and readisig required. HEU fuels?

Relatively easy for operator to subvert by itself; supplementary measurements required; some fuel handling required.

Supplementary to reactivity measurements.

Supplementary to reactivity measurements

asee Appendixes A, B, and C. 
contain much useful information concerning the inventory. However, even with continuous inspector surveillance, independent verification of the reactor inventory is necessary.

Options for reactor inventory verification fall into two categories, ${ }^{13}$ (1) those that require "in-line" verification of norma fuel transfers with containment measures placed inside the MAA and (2) those that require perionlic verification of the reactor invento containthent measures placed at the MA er. The selection of the best combinat : depends on the specific facility. pptions have several safeguards adexample, all the fuel entering and lea rector can be measured using NDA techniques. A unique measurement signature is assigned to each fuel element when it is loaded initially. Later, when the fuel element is unloaded from the reactor, it is remeasured and verified by a simple and very sensitive comparison of measurement signatures. If the critical-assembly machine or the access paths to the reactor cell are sealed between loading changes, direct verification of the reactor inventory would be necessary only infrequently, for example, when the reactor is unloaded.

Category 1 procedures were practicable in a facility such as one with a vertical assembly in which loading changes are relatively few and access to fuel elements within the assembly is difficult. However, in an active facility with frequent loading changes and relatively easy access to in-reactor fuel elements, such procedures impose a heavy burden on both the inspector and the operator. On the average, more than 200 fuel drawers enter or leave the model facility's reactor each week. If Category 1 procedures were applied to the model facility, at least one inspector would have to be present during all operating periods and the inspection effort would be extremely intensive during a major loading change. If a component of the safeguards system failed, either operations would have to cease or safeguards assurance would be seriously compromised.

Category 2 options include all procedures for periodic verification of the reactor inventory. They range from, say, weekly sampling of the reactor inventory or weekly checks of integral reactivity to annual physical inventory by unloading the reactor and counting fuel pieces. For active critical facilities such as the model facility, Category 2 options can provide adequate verification of reactor inventory without obstructing normal materials-flow paths with containment measures or unloading the reactor for physical inventory. This is the safeguardssystem concept illustrated by Fig. 9 .

One means of verifying the reactor inventory is by sampling and NDA measurement of in-core reactor drawers (App. D). A summary of results from modeling and simulation studies of sampling the reference reactor is given in Sec. IV. The effectiveness of many combinations of sample size and inventory frequency for various diversion strategies was evaluated. The results show that a combination of small samples provides essentially the same detection capability as does a single large sample. This is true despite frequent and sometimes rather large changes in the reactor inventory during the experimental program. For example, three $10 \%$ samples or one $30 \%$ sample provide $\sim 95 \%$ probability of detecting $8 \mathrm{~kg}$ of plutonium missing from the reference reactor. Thus, $10 \%$ bimonthly or $30 \%$ semiannual sampling verifications could satisfy the inventory verification guideline.

There is, in fact, a continuum of sample sizes and inventory frequencies that satisfy the guideline. However, a 6-month inventory period is judged to be too long to provide adequate assurance that the containment/surveillance measures are not being subverted. Furthermore, verifying $30 \%$ of the reactor inventory requires ather intense inspection effort and a relatively long operating delay. Weekly inventories provide timely assurance and require a relatively small sampling effort $(<5 \%$ of the reactor inventory). However, this sampling plan requires a time period each week, such as every weekend, during which the reactor is not operating, the inspection team is available, the instrumentation is calibrated and in place, and the vault inventory is sealed, and therefore may be difficult to implement.

An inventory period of 1-3 months is judged to be a reasonable compromise, assuming that instruments are calibrated and maintained at the facility under tamper-indicating seal and that inspectors are located nearby. Scheduling should be flexible to have minimum impact on the experimental program. For example, the inventory activity could be scheduled during weekends when the reactor normally is not operating. The instruments should be 
calibrated and installed before the time scheduled for verification and the total time allotted in the reactor cell for measurements should be fixed. If problems are encountered and the goals of the verification plan are not achieved during the allotted time, the time until the next routine verification is not excessive.

The integral reactivity technique is another method for routine reactor-inventory verification. A combination of integral reactivity checks and sampling verifications provides better assurance than either technique provides by itself. With this combination, the inspector must verify the inventory of each new reference configuration established by the operator. One approach is to measure a random sampling of fuel during reloading of the reactor into a new reference. Such measurcments would constitute one of the routine sampling verifications.

Periodically, a sampling verification would be replaced with a reactivity verification, in which the reactivity and other parameters of a reference configuration are checked. The choice of verification method, sampling or reactivity, could be made on a random basis. The schedule for reference reactivity checks should be flexible to minimize the number of loading changes required to return a reactor to a particular reference. The reactor loading is much closer to a particular reference at certain points in the experimental program than at other times, and reactivity checks could be scheduled at some of these points by random selection. During a long experimental program, the operator may establish a series of reference configurations.

4. Special Inventory. A special inventory is requested by the IAEA if it is probable that SNM has been misappropriated. The Agency's decision is based primarily on monitoring facility activities, records, and reports, and quantitative evidence from the containment, surveillance, and inventoryverification systems.

When an abnormal safeguards condition occurs, the inspector must make an assessment. If he suspects that material has been diverted, he can use any of the routine inspection methods to confirm or allay his suspicions. Clearly, effective special inspections must rely on effective techniques for routine inspections.
If the Agency concludes that diversion probably has occurred and that a special inventory is necessary, a special inspection team should be available on short notice for an intensive inspection to determine the form and quantity of material missing from the inventory. All sealed storage containers in the vault are checked for seal integrity. The contents of unsealed containers are verified by NDA measurement. Sampling and measurement of $50 \%$ of the reactor inventory provides $>95 \%$ probability of detection for a missing significant quantity.

The $50 \%$ sample size is deduced as follows. A $30 \%$ sample provides $\sim 95 \%$ probability of detecting a significant quantity for routine inventory. If evidence of diversion has been obtained already, a larger sample is required to provide the same assurance. The situation is analogous to accepting some defects in an item inventory as long as the number does not exceed a specified limit (App. D).

The mix of measurement techniques to be used during a special inventory depends on the type of diversion suspected by the inspector (for example, removal of the entire contents of fuel drawers or replacement of individual fuel plates by dummy plates). If diversion is discovered at any point in the sampling, the inspection team could proceed with a complete check of the reactor inventory. If no diversion is found, there is high confidence that a significant quantity of SNM is not missing from the reactor, but surveillance and verification measures could be increased, for example, by returning the reactor to a reference configuration for a reactivity check within a reasonably short period of time.

\section{Inspection Strategy for the Model Facility}

The following is a conceptual approach to international inspections for the model critical facility. Specific elements of this approach depend on assumed design and operating features of the model facility such as the automated fuel-handling capability and the accessability of reactor drawers for NDA measurement. The inspection strategy for the model facility is developed as an example. The actual strategy developed for any real facility will differ in many respects. 
1. Inspection Effort. Under NPT safeguards, the maximum routine inspection effort (Ref. 14, Article 80 ) is $30 \sqrt{E}$ man-days per year, where $E$ is the facility inventory in effective kilograms. ( $E$ is lefined in Article 104 as the weight of plutonium in kilograms plus the weight of HEU multiplied by the square of its enrichment.) For any large critical facility, the maximum annual inspection effort permitted under NPT is several hundred man-days. The model facility would have more than 1000 mandavs under NPT.

Frequent visits are made to the model facility by one inspector to check the integrity of the materials containment. ${ }^{2}$ to monitor iacility records and experiments, and to perform other routine inspection procedures such as sealing vault containers and calibrating instruments. Two or three inspectors are needed during short periods of more intense inspection activity, for example, during routine verification of the reactor inventory. Under extraordinary circumstances, a team of six or more inspectors is required for a special inventory to complete it in $1-2$ wk.

2. Records and Reports. Facilities under LAEA safeguards must maintain accounting and operating records that include source data and physical inventory procedures (Ref. 14, Articles 51-58). The state must submit reports ${ }^{20}$ to the IAEA (Ref. 14, Articles 59-69) that describe inventory changes (monthly), physical inventories, and materials balances. The reports should be relatively simple for a critical facility because of the discrete-item and essentially static nature of the inventory.

The facility records are audited, perhaps semiannually, for internal consistency, bookkeeping errors, and to see that they agree with the reports transmitted to the IAEA. The records may be rejected if inaccuracies are discovered totaling to significantquantity amounts. ${ }^{15}$

Checking of facility records is an integral part of routine inspection. The automated records system at the model critical facility facilitates frequent checking of records and monitoring of experimental activity. In addition, automated bookkeeping minimizes the number of unintentional errors in the data base. Graphic displays (Fig. 8) facilitate the monitoring of reactor loading changes.
3. Shipments and Receipts. The total inventory in the model critical facility is normally static, and slipments or receipts of SNM are infrequent. If possible, transfers between facilities under IAEA safeguards are verified by evaluating shipper and receiver measurement differences. ${ }^{15.21,22}$ Shipments from a critical facility normally consist of fuel removed from vault storage containers, whereas receipts normally consist of similar fuel that is placed in vault storage. Thus, verification of shipments and receipts should be relatively simple and should not affect the experimental program if adequate inventory verification measures are implemented in the vault area.

4. Seals. The use of tamper-indicating seals and NDA verification measurements on vault storage containers facilitates inventory verification at the model facility. The unsealed static portion of the vault inventory is sealed and verified weekly. The entire vault inventory is sealed when the reactor inventory is verified.

The use of seals in no way denies access to the material. When material is needed for normal use, the operator or the inspector removes the seal and the contents of that container become part of the bulk inventory that requires verification. Seals are also applied to unattended containment/surveillance instruments, verification instruments, and storage areas for calibration standards lorated at the facility.

5. Sampling and Reactivity Verifications. The inventory in the model facility reactor is verified by sampling or reactivity verifications randomly scheduled at 1 - to 3-month intervals. Reactor downtime during a routine verification is limited to two 8-h shifts that can be scheduled during normal shutdown, that is, on nights and weekends. Automated fuel handling is used to minimize radiation exposure of personnel.

During a sampling verification, $\sim 10 \%$ of the reactor inventory is verified using a combination of NDA techniques (Table $V$ ) to measure fuel in reactor drawers. Instruments are calibrated before installation in the reactor cell.

The reactor can be loaded in a reference configuration for a reactivity verification about four 
times per year without seriously disrupting the experimental program. One or two such verifications are performed every 6 months when the reactor loading is near a reference configuration.

A major loading change occurs and a new reference is established every 6 months on the average. A routine sampling verification is performed to verify the fuel content of the new reference configuration. One or two additional sampling verifications are performed every 6 months.

In the model facility, therefore, the reactor inventory is verified by a randomly selected combination of sampling and reactivity verifications totaling 6 to 10 (average of 8 ) annually. If eight routine verifications occur during $1 \mathrm{yr}$, for example, they could include six sampling and two reactivity or four sampling and four reactivity verifications.

The period between routine verifications is no less than 1 nor more than 3 months. The maximum permitted reactor downtime for routine verification is 2 shifts for each verification and a total of 20 shifts annually. This corresponds to a maximum of $8 \%$ of reacior operating time assuming 250 operating shifts annually. The actual downtime is reduced by scheduling some of the routine verification activities during normal shutdown.

6. Special Assessment and Verification. When an abnormal safeguards condition occurs, the inspector investigates the cause. Many abnormalities are caused by equipment malfunctions or by unintentional errors made by the operator or the inspector. A few abnormalities are more difficult to explain and require a more thorough investigation.

The available techniques and procedures for such investigations include those used during routine inspections. For example, if an abnormality is indicated by one of the unattended containment/surveillance instruments and the operator offers no satisfactory explanation, the inspector can sichedule a routine inventory verification. An abnormality discovered during routine inventory may be explained or discounted by repeating measurements or by taking additional samples. If a discrepancy is discovered when data from a routine inventory are analyzed, the inspector can request that the entire inventory or any portion thereof be repeated. If the inspector is convinced by his investigations that SNM has been diverted from the facility, the international agency can request a special inspection to determine the form and quantity of missing material. A special inspection includes auditing the facility records, checking the integrity of seals, and verifying the unsealed inventory in the vault and the reactor. The inspector develops a special inspection plan based on his evidence concerning the diversion strategy. This plan could ir 'ide a . ...pling verification of $50 \%$ of the rea. or in untory to provide $>95 \%$ probability of detecting a missing significant quantity.

We estimate that a team of about six inspectors could complete a special inspection of the model facility in 1-2 wk. The required time depends mainly on what procedures are used to verify the reactor inventory; that is, a reactivity verification requires much less time than unloading the reactor for a complete inventory.

7. Sampling Plan Design. Statistical sampling procedures and appropriate data evaluation methods are reviewed in App. D. An acceptable sampling plan must be capable of detecting a few relatively large removals (so-called attributes defects) or many relatively small removals (socalled variables defects), within a variety of concealment strategies.

A combined attributes and variables sampling plan for verifying the reactor inventory is described in App. D and the references therein. Such sampling plans have been developed previously for safeguards applications. ${ }^{22-25}$ The boundary between attributes and variables defects is referred $t n$ as the attributes limit. Attributes defects are detected by a single gono-go measurement, whereas variables defects are detected by a collective-analysis of many measurements.

Based on the sensitivity of similar NDA instrumentation (App. A), the attributes limit for neutron NDA drawer measurements is expected to be $\leqslant 10 \%$ of the contents of a fuel drawer. Detection of a few removals of quantities much larger than the attributes limit, such as the entire fuel contents of drawers, is difficult because very few such removal: are required to obtain a significant quantity. In the model facility, 14 one-row or 7 two-row drawers contain $8 \mathrm{~kg}$ of plutonium out of a total of $\sim 1600$ fuel drawers containing more than $1000 \mathrm{~kg}$. Detection of many removals of amounts much smaller than the 
attributes limit, such as individual fuel plates, is also difficult because of intrinsic measurement and sampling uncertainties; that is, the detection of many small removals is based on analyzing the sample verification measurements collectively, but the measurement methods may not be sufficiently sensitive and the sample may not be a sufficiently accurate representation of the inventory.

A combined attributes-variables sampling plan is most sensitive to many removals, each approximately equal in size to the attributes limit, because techniques for detecting both relatively large and relatively small removals are effective near this limit. An effective sampling plan must have adequate sensitivity to detect a significant-quantity diversion obtained in a few large removals, each much greater than the attributes limit, or in many small removals, each much less than the attributes limit; that is, removals of whole-drawer contents or removals of individual fuel plates. The desired probability of detecting a significant diversion in whole-drawer removals primarily determines the sample size. Data evaluation techniques (Sec. III.C.9 and App. D) partially overcome the combined effects of measurement and sampling uncertainties on the detection of small removals.

To implement the sampling plan, the inventory first must be stratified into classes based on the contents of the fuel containers and the characteristics of the measurement techniques. Fuel drawers are classified for verification by NDA according to the amount of plutonium, the plutonium isotopic composition, and the arrangement of fuel plates and nonfuel mockup materials within the drawer. Fuelplate arrangement affects reutron signatures by changing the neutron multiplication. The effect of nonfuel materials on neutron signatures is produced mainly by the quantity of depleted uranium in the drawer and its proximity to the fuel plates (App. A, Table A-I).

To estimate the number of fuel-drawer classes that might be encountered in practice, we examined actual reactor loadings in a plutonium critical facility during $1 \mathrm{yr}$ of operation. All fuel drawers contained one or two 18 -in. rows of plutonium plates, and fuel plates with three isotopic compositions were used. The drawers also contained various amounts and arrangements of depleted uranium and other nonfuel materials along the 18-in. fueled length. Based on these differences, we identified six classes of one-row drawers and five classes of tworow drawers for the entire year of operation. The fuel piates were sufficiently uniform that differences based on plate length alone were not significant. The 11 classes contained several small subclasses with some variation in the type and arrangement of nonfuel materials. These differences were judged to be minor in their effect on neutron signatures. Thus, the effort required to stratify the reactor inventory for measuring drawers by neutron counting does not appear to be excessive.

For illustration, a sampling plan is developed here for the reference core loading described in Sec. II. There are two classes of one-row drawers and three classes of two-row drawers (Table IV). For any desired sampling fraction of the inventory, sarnple sizes for each class are determined in two steps. Step 1 is to determine the desired number of one- and two-row drawers in the sample. Let $I=$ the total reactor inventory $(1220 \mathrm{~kg} \mathrm{Pu}), \mathrm{f}=$ the fraction of $\mathrm{I}$ to be sampled, $\mu=$ the average content of an 18-in. row of fuel plates $(0.565 \mathrm{~kg} \mathrm{Pu}), \mathrm{N}_{1}=$ the number of one-row drawers in the reactor (1008), $\mathrm{N}_{2}=$ the number of two-row drawers in the reactor (576), and $n_{1}\left(n_{2}\right)=$ the number of one- (two-) row drawers in the sample.

The sample sizes $n_{1}$ and $n_{2}$ must satisfy the equation

$\mathrm{n}_{1} \mu+\mathrm{n}_{2}(2 \mu)=E I$.

In addition, $n_{1}$ and $n_{2}$ must be proportional to the amount of plutonium in one- and two-row drawers; that is,

$n_{1} / n_{2}=N_{1} /\left(2 N_{2}\right)$

Then step 1 is completed by solving Eqs. (1) and (2) for $n_{1}$ and $n_{2}$.

Step 2 consists of finding the desired sample sizes of one- and two-row drawers for each class; these are denoted by $n_{1 k}$ and $n_{2 j}$, where $k$ and $j$ identify classes of one- and two-row drawers, respectively. The class sample sizes must be proportional to the amount of plutonium in the class; that is, 
$n_{1 k}=n_{1} N_{1 k} / N_{1}$

and

$n_{2 j}=n_{2} N_{2 j} / N_{2}$

where $\mathrm{N}_{1 k}\left(\mathrm{~N}_{2 \mathrm{~J}}\right)$ is the total number of one- (two-) row drawers in class $k(j)$.

This two-step procedure exploits the simple 1:2 ratio of plutonium content in one- and two-row fuel drawers. Weighting the sample sizes by the amount of plutonium in each class provides a uniform probability over the entire inventory for detecting a significant-quantity diversion. Similar but somewhat more complicated procedures are available $^{22}$ to compute sample sizes for inventories with greater variation in item content.

Table VI gives the sample sizes determined for 10 , 30 , and $50 \%$ verifications of the reference reactor inventory. The sample sizes correspond to 9,27 , and $40 \%$, respectively, of the total number of reactor fuel drawers (1584).

8. Measurement Quality. Measurement controls and standard operating procedures must be developed and implemented for each type of measurement. Inspector training and familiarity with the instrumentation and procedures are essential. For example, in applying the autoradiography technique (App. C), the optimum size and type of $x$ ray film should be selected, and the exposure time and film processing should be controlled. Standard procedures for reading the autoradiographs, either manually or automatically. should be specified for each fuel geometry.

The NDA instruments must be calibrated for each type of fuel and container geometry. A simple model of NDA measurements that applies to any class of fuel items is given by $^{22}$

$m=\mu(1+\delta+E+\eta)$

and

$M=\mu(1+\delta)$,

where $M=$ the true item content, $m=$ the measured item content, $\mu=$ the true average item content for the class, $\delta=$ the error caused by intrinsic variation in item contents, $\epsilon=$ the error caused by measurement imprecision ("random error"), and $\eta=$ the calibration error ("systematic error").

In this model, $\delta, \epsilon$, and $\eta$ are assumed to be zeromean, Gaussian random variables with RSDs denoted by $\sigma_{M}, \sigma_{\varepsilon}$, and $\sigma_{\eta}$, respectively. The RSDs of a single measurement and of the average of a set of sample measurements are given by (App. D, Sec. IV)

\section{TABLE VI}

\section{SAMPLE SIZES FOR A REFERENCE CONFIGURATION}

\begin{tabular}{|c|c|c|c|c|c|}
\hline Class No. & $\begin{array}{l}\text { Total No. } \\
\text { of Drawers }\end{array}$ & $\begin{array}{c}\text { Total Pu } \\
(\mathbf{k g})\end{array}$ & $\begin{array}{c}10 \% \\
\text { Sample } \\
\text { Size } \\
\text { (Drawers) }\end{array}$ & $\begin{array}{c}30 \% \\
\text { Sample } \\
\text { Size } \\
\text { (Drawers) }\end{array}$ & $\begin{array}{c}\mathbf{5 0} \% \\
\text { Sample } \\
\text { Size } \\
\text { (Drawers) }\end{array}$ \\
\hline \multicolumn{6}{|l|}{ one-row } \\
\hline 1 & 748 & 422.2 & 49 & 146 & 244 \\
\hline 2 & 260 & 147.0 & 17 & 51 & 85 \\
\hline \multicolumn{6}{|l|}{ two-row } \\
\hline 1 & 376 & 424.9 & 49 & 147 & 246 \\
\hline 2 & 104 & 117.4 & 14 & 41 & 68 \\
\hline 3 & 96 & 108.5 & 13 & 38 & 63 \\
\hline
\end{tabular}


$\sigma_{m}=\left(\sigma_{M}^{2}+\sigma_{\varepsilon}^{2}+\sigma_{n}^{2}\right)^{1 / 2}$

and

$\sigma_{\bar{m}}=\left[\frac{1}{n}\left(\sigma_{M}^{2}+\sigma_{\varepsilon}^{2}\right)+\sigma_{r_{1}}^{2}\right]^{1 / 2}$,

where $n$ is the sample size and $\vec{m}$ is the average measured value. The sensitivity of a single measurement $(\mathrm{n}=1)$ is determined primarily by the size of the measurement precision $\operatorname{RSD}\left(\sigma_{e}\right)$. The sensitivity of a set of sample measurements $(n>>1)$ is determined primarily by the size of the calibration error RSD $\left(\sigma_{\eta}\right)$. The size of $\sigma_{q}$ depends on counting statistics, random positioning of the items, fluctuations in background, etc. The size of $\sigma_{\eta}$ depends mainly on the number of calibration measurements and the quality of the calibration standards.

In the model lacility, the intrinsic variations $\left(\sigma_{M}\right)$ in the plutonium content of fuel plates (all lengths), drawers (both one- and two-row), and all full storage canisters are $\sim 1.5,1.0$, and $0.5 \%$, respectively, based on typical data from fuel manufacturers. The uncertainty in the ${ }^{2 \triangleleft 0} \mathrm{Pu}$ content, which is the quantity measured by passive neutron counting. is somewhat larger because of the additional uncer. tainty in the isotopic fraction. This additional uncertainty is estimated to be $\sim 1 \%$, and the total uncertainties in the ${ }^{240} \mathrm{Pu}$ content of plates, drawers, and canisters are $\sim 1.8,1.4$, and $1.0 \%$, respectively. We have adopted these values to evaluate the effectiveness of sampling plans and neutron NDA measurements for verification of the reference reactor inventory (Sec. IV). They will be denoted by the generic symbol $\sigma_{\mathrm{M}}$. We assume that the plutonium isotopic composition is verified by gamma spec. troscopy.

To a large extent, data quality and successful data evaluation depend on adequate measurement controls and accurate knowledge of the instrument parameters $\sigma_{\epsilon}$ and $\sigma_{\eta}$. The measurement precision $\operatorname{RSD}\left(\sigma_{t}\right)$ for neutron counting of fuel plates, drawers, and storage canisters is expected to lie in the $1-5 \%$ range, based on ex perience with similar instrumentation. For counting times of $\sim 1 \mathrm{~min}$, the uncertainty owing to counting stetistics is expected to be $\sim 1 \%$, and the best current estimate of $\sigma_{\varepsilon}$, including counting and other random effects, is $\sim 2 \%$.
The calibration error RSD ( $\left.\sigma_{\eta}\right)$ can be determined by performing a one-point calibration ${ }^{21-22}$ for each class of items. Working standards, consisting of fuel plates or drawer and canister mockups, can be formed by random selection from the critical facility inventory. Fuel assay data are available from the original fuel supplier to characterize these standards. This calibration approach is well justified if the fuel supplier and the critical facility operator reside in different states. In any case, the assay data and the results of calibration measurements should be cross checked with similar data obtained from other fuel suppliers and critical facilities.

The true value of $\sigma_{\eta}$ for a one-point calibration of a particular class of items is the RSD of the average response (counts/s) that would be measured for that class. It is given by

$$
\sigma_{\eta}=\left[\frac{1}{\mathrm{q}}\left(\sigma_{M}^{2}+\frac{1}{\mathrm{p}} \sigma_{E}^{2}\right)\right]^{l / 2},
$$

where $y$ is the number of mockup calibration standards and $p$ is the number of replicate measurements made on each standard. A modest calibration might include $p=3$ replicate measurements on each of $\mathrm{q}=5$ standards, which corresponds to $\sigma_{n}=$ $0.8 \%$ for fuel drawers having $\sigma_{M}=1.4 \%$. If a more intensive calibration is performed, say, 5 replicate measurements on earh of 10 standards, $\sigma_{\eta}$ would be $\sim 0.5 \%$. We adopt the more conservative $0.8 \%$ value. Similar values apply to fuel plates and storage canisters.

To calibrate an NDA instrument for a particular class of items, the calibration data are evaluated as follows. Let $r_{11}$ be the jth response (counts/s) measured for the ith standard. Then the average response for $p$ replicate measurements made on $q$ standards is

$\bar{r}=\frac{1}{q} \sum_{i=1}^{q} r_{i}$

where

$r_{i}=\frac{1}{p} \sum_{j=1}^{p} r_{i j}$. 
The sample variance of the calibration measurements is given by

$s_{r}^{2}=\frac{1}{q-1} \sum_{i=1}^{q}\left(r_{i}-\bar{r}\right)^{2}$.

The quantity

$s_{r} /(\bar{s} \sqrt{q})$

is the desired estimate of $\sigma_{\eta}$. Note that an estimate of $\sigma_{\epsilon}$ is obtained by making many replicate measurements on a single calibration standard, whereas an estimute of the quantity $\left(\sigma_{\mathrm{M}}^{2}+\sigma_{\mathrm{t}}^{2}\right)$ is obtained by measuring many different standards.

The average response $\overline{\mathbf{r}}$ [Eq. (7)] measured for a set of calibration standards representing a particular class of items is an estimate of the response that would be measured for an item containing the nominal amount $(\mu)$ of SNM. This estimate will be acceptable (unbiased) if the standards are truly representative of the class. For an unknown item selected at random from the class, the measured amount of SNM is given by

$m=\mu(r / \bar{r})$,

where $r$ is the response measured for the unknown. Thus, Eq. (9) is the one-point calibration equation for the class. One calibration standard for each class should be saved, preferably under seal at the facility, for periodic checking of the instrument response and calibration.

9. Data Evaluation. Several useful techniques are described in App. D and the references therein for the evaluation of sample data. The sample measurements are examined for evidence of diversion in removals of various sizes. For example, a drawer having $\sim 10 \%$ or more of the fuel removed should be detectable on a go-no-go (attributes) basis, because the 4- $\sigma$ detection limit estimated for neutron NDA drawer measurements is $\sim 10 \%$. The probability of detecting a significant-quantity diversion in such large removals is determined by the sample size.
Statistical testing of the sample data (variables analysis) is required to detect a significant-quantity diversion in removals $<10 \%$ of the drawer contents. We divide this region into two subregions: those removals that are $<10 \%$ of the drawer $\mathrm{c}$ :ntents but not less than the smallest increment of fuel plate 1 in. of plate in the model facility), and those removals that are $<1$ in. of plate (the bias region). Note that $1 \mathrm{in}$. is the smallest increment of fuel plate that can be removed even though there are no $\mathrm{I}$-in. plates in the model facility's inventory. This is because an 8 -in. plate could be replaced by a 7 -in. plate, and so forth. Real facility inventories could contain 1-in. plates as well.

It is very important to extend the effectiveness of the sampling plan over the entire range of possible removals from whole-drawer contents down to the smalles ${ }^{*}$ fisel increment. Diversion strategies that include removing amounts less than the smallest fuel increnunt would be very difficult to implement. even for a facility operator. One might attempt (1) falsify (bias) the fuel manufacturer's assay data or remove the metal jackets and shave fuel from many fuel-plate cores. However, no such strategy for diverting a significant quantity is judged to be credible.

The desired overall balanced effectiveness of the sampling plan and the related verification measurements is illustrated in Fig. 10. The integral reactivity technique, shown for comparison, is uniformly effective against the same total diversion in removals of any size. (It is not, however, uniformly sensitive to every location from which fuel may be removed.) Note that a single 4 -in. plate is $\sim 10 \%$ of the contents of a two-row drawer. The range of particular interest, therefore, is removals of $1-4$ in. of fuel plate.

Autoradiography is effective in this region (at least for plutonium-bearing fuel plates), but it should be combined with other NDA techniques for adequate verification. Neutron NDA is not uniform. ly effective because its sensitivity is instrinsically proportional to the total amount of contained material. Thus, those techniques for measurement and data evaluation that improve the detection sensitivity to 1 - to 4 -in. removals are most important.

One promising measurement technique (App. A, Part II) is to incrementally scan the neutron and 


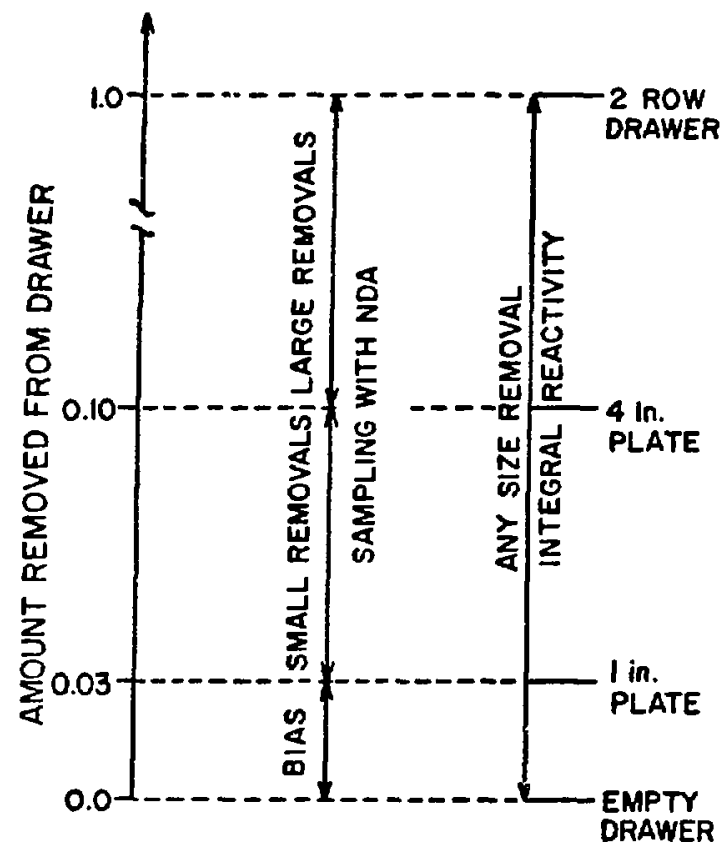

Fig. 10.

Regions of sampling-plan sensitivity that correspond to removing various amounts of plutonium from a fuel drawer are compared with the uniform sensitivity of integral reactivity measurements.

gamma-ray signatures of plutonium fuel plates in reactor drawers. This technique could reduce the attributes limit to $\sim 1$ in. of plate. Two data-testing procedures have been identified (Sec. IV and App. D) that are particularly effective against removals of small fuel increments. They are based on a modified test for detecting measurement outliers and the $\chi^{2}$ test for detecting shifts in variance.

The outliers (OL) test is applied in three steps.

(1) Search for drawer measurements that deviate more than $2 \sigma$ from the nominal value (that is, a difference of $\sim 5 \%$, if $\sigma_{\mathrm{M}}=1.4 \%, \sigma_{\epsilon}=2 \%$, and $\sigma_{\eta}=$ $0.8 \%$ ). This is a low level of significance because $\sim 1$ in every 40 drawer measurements on the average will exceed this $2-\sigma$ limit, even when there is no diversion.

(2) For each 2- $\sigma$ outlier, make replicate measurements on the drawer and test the mean of these measurements at the 3- $\sigma$ level of significance; that is, if the ith drawer measurement $\left(m_{i}\right)$ satisfies $\left(:-m_{i}\right)>2 \mu \sigma_{m}$,

(step 1)

where $\mu$ is the nominal drawer contents for a particular class and $\sigma_{\mathrm{m}}$ is the RSD of a single measurement, make $p$ replicate measurements and test the average of these measurements $\left(\bar{m}_{1}\right)$ to see if

$\left(\mu-\bar{m}_{i}\right)>3 \mu \sigma_{\bar{m}}$.

(step 2)

This 3- $\sigma$ limit corresponds to a false alarm rate of $\sim 1$ in 1000 . The value of $\sigma_{\overline{\mathrm{m}}}$ [not to be confused with the RSD of the mean of a set of sample measurements given in Eq. (5)! is given by

$\sigma_{\overline{\mathrm{m}}}=\left(\frac{1}{\mathrm{p}} \sigma_{\varepsilon}^{2}+\sigma_{M}^{2}+\sigma_{\eta}^{2}\right)^{1 / 2}$.

For example, if five replicate measurements are made, the $3-\sigma_{\overline{\mathrm{m}}}$ limit is $\sim 5.5 \%$ or $\sim 1$ in. of plate from a one-row drawer and $\sim 2$ in. of plate from a two-row drawer.

(3) The likelihood that a drawer with no fuel missing will exceed the limits in steps 1 and 2 is $\sim 1$ in 1000. If a drawer exceeds both limits, the individual fuel plates are measured by NDA to see if a small increment of fuel is missing. The detection limit for NDA plate measurements is estimated to be $\sim 1$ in. of plate.

Use of the $\chi^{2}$ test is based on the observation that random removals of small fuel increments will increase the variability in the drawer contents. This may be signaled by a significant shift (increase) in the value of $\sigma_{\mathrm{M}}$. The $\chi^{2}$ test examines the sample measurements for such shifts. The test statistic is

$c=(n-1) s_{m}^{2} /\left[\left(\sigma_{M}^{2}+\sigma_{\varepsilon}^{2}\right) H^{2}\right]$.

where $\mathrm{n}$ is the sample size, $\mathrm{s}_{\mathrm{m}}^{2}$ is the sample variance, and $\sigma_{M}, \sigma_{\epsilon}$, and $\mu$ denote nominal values. Warning and action limits, say, at the 2.5 and $0.1 \%$ levels of significance (false alarm probabilities), can be determined for any sample size using standard tables of the $\chi^{2}$ distribution function. The test should be sensitive if the variability in drawer contents becomes $\gtrsim 1.5 \sigma_{M}$.

The OL and $\chi^{2}$ tests require accurate estimates for the parameters $\sigma_{\mathrm{M}}, \sigma_{\varepsilon}$, and $\sigma_{\eta}$. (The sample mean is 
an estimator for $\mu$.) If the quality of such estimates is uncertain, nonparametric (distribution-free) tests are available as a back-up; for example, the $T$ test (an essentially nonparametric test) backs up the OL test, and the Kolmogorov-Smirnov test backs up the $\chi^{2}$ test. The applicability of these and other useful tests of the sample data is summarized in App. D, Sec. V.

10. Examples. Consider a routine sampling verification of $10 \%$ of the reactor inventory. We assume that the model facility's reactor is in the reference configuration given in Table IV (that is, 1584 core drawers consisting of 1008 one-row and 576 two-row drawers containing a total of $1220 \mathrm{~kg}$ of plutonium). The sampling plan (Table VI) consists of sampling and measuring 66 one-row and 76 tworow drawers.

We first assume that only neutron and gamma NDA measurements are made on the drawers. The instruments are calibrated and placed in the reactor cell. The use of more than one instrument would facilitate fuel handling and measurement. We also assume that the entire vault inventory has been sealed and verified. If all measuremeints are made by NDA and a matrix loader (Fig. 5) is used to retrieve drawers from the matrix, it is estimated that an average of $\sim 5 \mathrm{~min}$ would be required for each drawer measurement. About $4 \mathrm{~min}$ is required ror automatic retrieval and return of the fuel drawers, and $\sim 1 \mathrm{~min}$ is required for actual counting. Therefore, adding $25 \%$ for contingencies, the total time required in the reference reactor cell is estimated to be $\sim 15 \mathrm{~h}$.

If we next assume that $5 \%$ of the inventory is measured by NDA and, say, 100 additional drawers are verified by autoradiography, the total measurement time in the reactor cell is estimated to be $\sim 10$ h. Note that more than $10 \%$ of the inventory is verified in this case. This assumes that two people working between the matrix halves can insert, expose, and retrieve 100 radiographs in $\sim 2 \mathrm{~h}$ (App. C). Thus, we conclude that $10 \%$ of the reactor inventory in the model facility could be verified in two 8-h shifts or less.

The sampling plan for a special inventory calls for sampling and measuring 329 one-row and 377 tworow drawers $(50 \%$ of the reference reactor inventory). The average time per NDA drawer measure- ment is estimated to be $\sim 2 \mathrm{~min}$, assuming that two or three instruments are used and the fuel drawers are handled manually. Therefore, again adding $25 \%$ for contingencies, the total time required in the reactor cell is estimated to be $\sim 30 \mathrm{~h}$.

The total measurement time would be reduced substantially if the special inspection team used a combination of autoradiography and NDA. For example, if $25 \%$ of the reactor inventory is verified by NDA at $2 \mathrm{~min} /$ drawer and $25 \%$ is verified by autoradiography at 100 drawers $/ h$, the total time in the cell is reduced from $\sim 30$ to $\sim 20 \mathrm{~h}$. However, these time estimates approximately double if the inspection team performs a complete inventory.

During a special inventory, auditing of records, checking of seals on vault storage canisters, and verification of the unsealed portion of the vault inventory proceed in parallel with the verification of the reactor inventcry. Assuming that it takes 1-3 days for the special inspection team to arrive at the facility and prepare for the inventory, 5-7 days to perform a complete inventory, and 1-3 days to analyze the data, a report of the results could be forwarded to IAEA Headquarters within $\sim 1-2$ wk after the special inventory is initiated

\section{EFFECTIVENESS OF SAMPLING VERIFICATION}

\section{A. Modeling and Simulation}

The effectiveness of sampling verifications of the reference reactor inventory using NDA drawer measurements was evaluated by computerized modeling and simulation techniques. Operation of the model facility (Sec. I) was simulated using data from a plutonium critical facility. ${ }^{28}$ These data span a 1-yr period of normal experimental activity including all fuel transfers and loading changes. The following is a description of the modeling and simulation approach.

A complete reactor loading operation is simulated by initially placing the entire reference inventory in the vault, and then loading the reactor into a reference configuration (Table IV). All subsequent loading changes are essentially those described by the operating data. The configurations of the reactor 
and the storage vault are tabulated after each loading change. Separate classes of reactor drawers are maintained for each plutonium-fuel type and fuel-drawer loading. The reference reactor inventory varies between 1200 and $1600 \mathrm{~kg}$ of plutonium during the year of simulated operation.

Figure 11 shows cross sections of the initial reference configuration (upper) and of the reactor configuration 6 months after the initial reference loading (lower). Each blue box containing a "1" denotes a one-row drawer $(0.565 \mathrm{~kg} \mathrm{Pu})$, whereas each red box containing a "2" denotes a two-row drawer (1.13 kg $\mathrm{Pu})$. The inventory in the initial configuration is $\sim 1200 \mathrm{~kg}$ of plutonium contained in $\sim 1600$ fuel drawers. Six months later, plutoniumbearing drawers have been inserted into the blanket

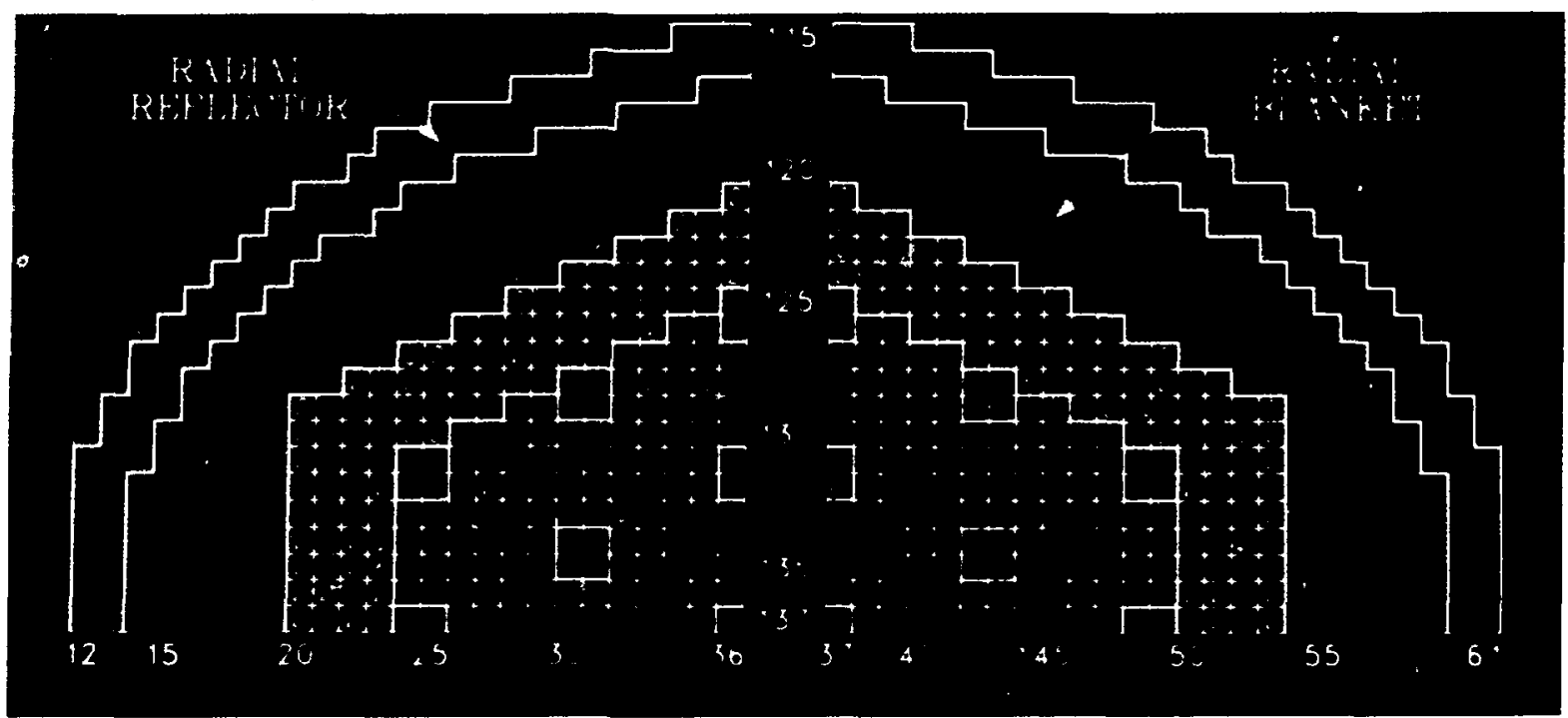

(a)

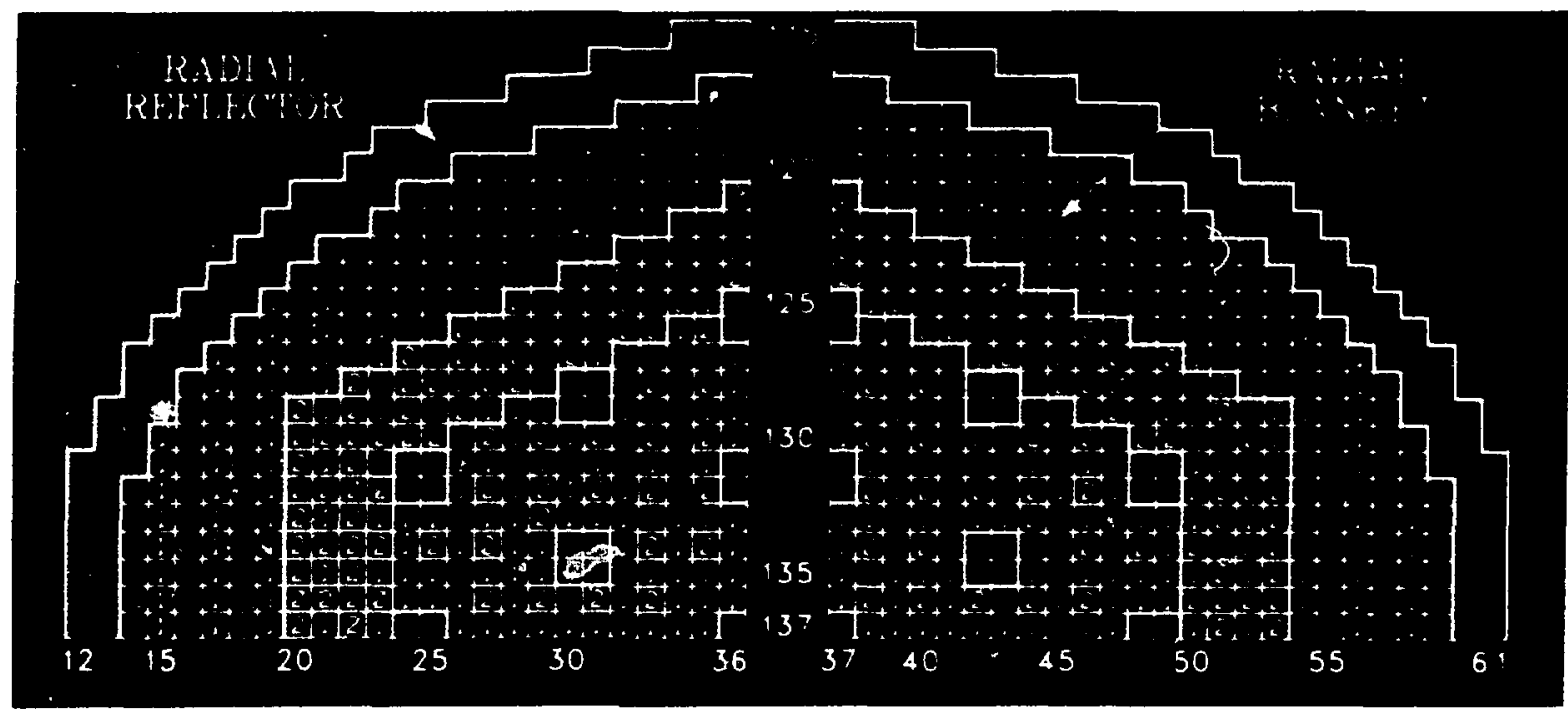

(b)

Fig. 11.

Cross sections of the reference reactor: (a) initial reference configuration; (b) configuration after 6 months of operation. 
region of the matrix during a series of experiments designed to mock up plutonium breeding in the blanket material. At this time the reactor inventory is $\sim 1600 \mathrm{~kg}$ of plutonium contained in $\sim 2200$ fuel drawers. By the end of $1 \mathrm{yr}$ of experiments, the reactor loading is very close to the initial reference configuration.

Computer-generated graphic displays like Fig. 11 were used to track the reactor loading changes and to monitor the progress of the simulation runs. Approximately 8000 fuel drawers were inserted into the reactor during the year.

\section{B. Simulation Cases}

Sampling plans that have been simulated range from routine monthly sampling of $\tilde{5} \%$ of the reactor inventory to special verification sampling of $50 \%$ of the inventory. All drawer measurements are assumed to be made by passive neutron NDA techniques. The NDA measurements are simulated using the measurement model (Sec. III.C.8 and App. D) with the following model parameters:

$$
\begin{aligned}
& \sigma_{M}=1.4 \%\left({ }^{240} \mathrm{Pu}\right. \text { drawer-content RSD), } \\
& \sigma_{\epsilon}=2 \% \text { (measurement-precision RSD), }
\end{aligned}
$$

and

$$
\sigma_{\eta}=0.8 \% \text { (calibration-error RSD) . }
$$

Therefore, the RSD of a single drawer measurement is $2.6 \%$ and the attribute limit is $\sim 10 \%$. These values are all judged to be reasonable estimates; however, operational testing and evaluation of actual NDA instruments, developed and optimized for this specific application, are required to verify the expected performance.

Sample data are evaluated using the statistical tests described in Sec. III.C.9 and App. D. Specifically, the OL test, the $\chi^{2}$ test, and the test of the mean (test for bias) are applied in every case. In applying the OL test, five replicate measurements are made on each 2- $\sigma$ outlier, and the test is constrained to satisfy the detection limit of $1 \mathrm{in}$. of plate estimated for NDA plate measurements; that is, if the OL test flags a drawer as a significant outlier (steps 1 and 2) and the drawer is missing $1 \mathrm{in}$. of fuel plate, the probability of detecting this missing inch of plate by measuring each fuel plate (step 3) is taken to be $50 \%$. The $\chi^{2}$ test is applied to drawerclass samples of size $>20$ to insure uniform application of the test and uniform interpretation of the test results. The test of the mean is applied by summing the partial inventory differences measured for each drawer class, and then testing the significance of the overall measured shift in the inventory. Both the $\chi^{2}$ test and the test of the mean are applied to each routine inventory sample and to sequences of consecutive inventory samples. Sequences of samples are tested because the inspector does not know when a protracted series of diversions may begin.

Each test is applied at two levels of significance (that is, false alarm probability): a warning iimit near the $2 \%$ (one-sided) level and an alarm limit near the $0.1 \%$ level. The OL test has one additional level of significance corresponding to the 1-in. detection limit assumed for plate measurements. The overall rate of false indications of diversion for routine $10 \%$ sampling, verified by numerous simula tion runs, is $<1$ in 100 inventory periods; that is, a false alarm is expected about once in $10 \mathrm{yr}$ for routine monthly verification sampling. A warning limit is exceeded more frequently, averaging about two per year. The false alarm rate encountered in practice depends on strict measurement controls and procedures. In this sense, the quoted false alarm rate may be difficult to maintain in practice. However, the measurement techniques and data evaluation procedures indicate what type of diversion may be occurring, such as the removal of wholedrawer quantities or the replacement of individual plates by dummy plates. Based on this information, the inspector can search for unmistakable evidence of a particular type of diversion, if such diversion is indicated.

\section{Selected Results}

1. Single Samples. 'Table VII shows the probability of detecting that $8 \mathrm{~kg}$ of plutonium is missing from the reference reactor inventory by 10 , 30 , and $50 \%$ samples. Results are given for four strategies of removing the material to achieve the same 8-kg diversion goal: (1) whole-drawer removals totaling $4 \mathrm{~kg}$ from one-row and $4 \mathrm{~kg}$ from two-row drawers; (2) removals of $10 \%$ of drawer contents 


\section{TABLE VII}

\section{PROBABILITY OF DETECTING 8 kg OF PLUTONIUM MISSING FROM THE REFERENCE REACTOR WITH A SINGLE SAMPLE}

\begin{tabular}{|c|c|c|c|}
\hline \multirow[b]{2}{*}{ Diversion Strategy } & \multicolumn{3}{|c|}{$\begin{array}{c}\text { Detection Probability } \\
(\%) \\
\end{array}$} \\
\hline & $10 \%$ Sample & $30 \%$ Sample & 50\% Sample \\
\hline Whole-drawer contents & 63 & 97 & $>99$ \\
\hline $10 \%$ of drawer contents & $>99$ & $>99$ & $>99$ \\
\hline \multicolumn{4}{|l|}{ 1-in.-plate amounts } \\
\hline OL test only & 36 & 69 & 83 \\
\hline OL plus $\chi^{2}$ tests & 66 & 99 & $>99$ \\
\hline \multicolumn{4}{|c|}{ Uniform small removals (bias) } \\
\hline $2-\sigma$ limit $^{\mathrm{a}}$ & 26 & 28 & 30 \\
\hline 3- $\sigma$ limit $^{\mathrm{a}}$ & 5 & 5 & 6 \\
\hline
\end{tabular}

totaling $4 \mathrm{~kg}$ from one-row and $4 \mathrm{~kg}$ from two-row drawers; (3) removals of 1 in. of fuel plate from each of 256 drawers totaling $8 \mathrm{~kg}$ (a 1 -in. removal is assumed to be equally likely for all reactor drawers, for example, by the replacement of an 8-in. plate by a 7-in. plate); and (4) uniform small removals (bias) of $0.66 \%$ of the contents from every reactor drawer ( $3.7 \mathrm{~g}$ from every one-row and $7.4 \mathrm{~g}$ from every tworow drawe $e_{1}$ ) for a total of $8 \mathrm{~kg}$.

One interesting feature of the results in Table VII is that the probability of detecting $8 \mathrm{~kg}$ missing from the reactor inventory for each sample size is essentially the same whether the 8-kg total is removed in whole-drawer or 1-in.-plate amounts. Therefore, the balanced effectiveness desired for the statistical sampling plan (Fig. 10) has been achieved. This balance is provided primarily by the detection capability of the OL and $\chi^{2}$ tests for the diversion of many small fuel-plate increments. In addition, because the sample sizes from each drawer class are weighted by the total amount of plutonium in the class, similar resuits would be obtained no matter how the removals are distributed among the various classes.

With a $10 \%$ sample, the probability of detecting an 3-kg diversion in whole-drawer or 1-in.-plate amounts is $\sim 60 \%$, whereas the probability of detecting a $30-\mathrm{kg}$ diversion is $\sim 95 \%$. The probability of detection decreases rapidly if the SNM is removed in quantities much smaller than 1 in. of plate. The detection probability provided by a $10 \%$ sample decreases from $\sim 60 \%$ for $8 \mathrm{~kg}$ in 1 -in.plate removals to $\sim 5 \%$ (3- $\sigma$ limit) for a uniform bias.

The probability of detecting a shift in the inventory caused by a small bias depends on the size of the inventory, the distribution of the inventory in drawer classes, and the size of the calibration-error RSD $\left(\sigma_{\eta}\right)$. The detection limit of the test for bias is essentially independent of sample size for $n>20$, but it is linearly proportional to the size of $\sigma_{\eta}$ and roughly proportional to the size of the inventory (App. D). With a modest calibration effort, $\sigma_{\eta}$ should be $0.5-1.0 \%$.

For the reference reactor having an inventory of $1220 \mathrm{~kg}$ and with $\sigma_{\eta}=0.8 \%$, the $2-\sigma$ and $3-\sigma$ detection limits for a bias are 11.4 and $17.0 \mathrm{~kg}$, respectively. The 3- $\sigma$ detection limit is $\leqslant 2 \%$ of the reactor inventory, and there is a $50 \%$ probability of detecting a shift in the inventory equal in size to the detection limit. Note that this mode of diversion requires either shaving hundreds of fuel plates or falsifying the fuel manufacturer's assay data and is judged not to be a credible threat. 
2. Sequence of Samples. Figure 12 shows the increase in the probability of detecting the diversion of $8 \mathrm{~kg}$ of plutonium, initially missing from the reference reactor inventory, during a series of monthly $10 \%$ samples. The detection probability is given for two diversion strategies: $8 \mathrm{~kg}$ removed in whole-drawer amounts and $8 \mathrm{~kg}$ removed in 1 -in.plate amounts. The $\chi^{2}$ test and the test for bias have been applied to each sample separately and to consecutive sequences of the samples in combination. For this reason, the detection probability increases more rapidly for 1-in.-plate removals than for whole-drawer removals.

After 6 months, the probability is at least $99 \%$ for detecting either diversion strategy. This exceeds the guideline of detecting $8 \mathrm{~kg}$ missing in 6 months with at least $95 \%$ probability. After 3 months, the probability is $\sim 95 \%$ for both diversion strategies, which is about the performance obtained in 6 months with bimonthly sampling of $10 \%$ of the inventory.

3. Optimal Diversion Strategy. It must be assumed that any group intending to divert SNM from a critical facility is knowledgeable about the safeguards procedures. This knowledge is a deterrent, but it may also be used to advantage by the divertors. It is shown in Ref. 24 that, if the detection probability is the same for diverting equal amounts in large or small removals, the optimum diversion strategy against the combined attributes-

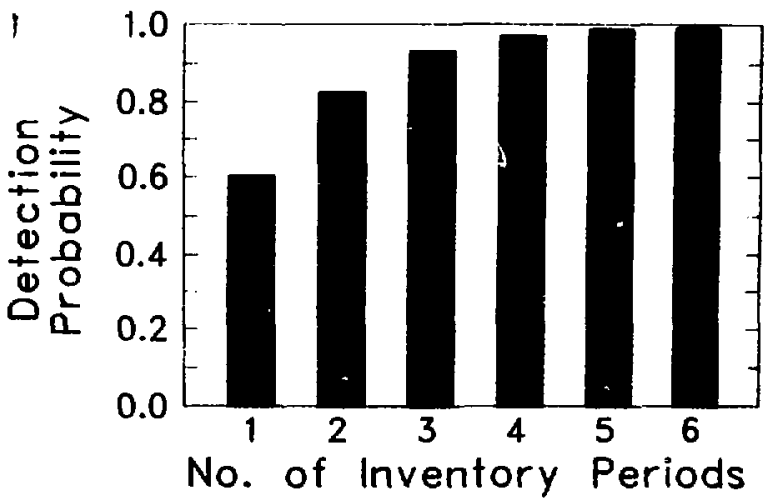

(a) variables sampling plan is to divert half the diversion goal in a few whole-item removals and half in many small removals. This is approximately true for diversion from the reference reactor inventory. Therefore, considering only routine sampling verification, a strategy of diverting $8 \mathrm{~kg}$ by removing $4 \mathrm{~kg}$ in whole-drawer amounts and $4 \mathrm{~kg}$ in 1 -in.-plate amounts is nearly optimal for the divertor, if the very difficult scenario of diverting material in removals much smaller than 1 in. of plate (that is, by a bias) is neglected.

To be successful, the diversion strategy also must be optimized to defeat the containment/surveillance measures and the optimum rate for removing the material covertly must be selected. The IAEA identifies two broad categories of diversion referred to as abrupt and protracted. For protracted diversion, we assume that the divertor will want to avoid detection by using the normal flows of material to mask his repeated diversion attempts and that he must expend considerable time and effort in subverting the containınent/surveillance measures to remove the material from the facility.

Therefore, we have simulated a strategy of protracted diversion of $8 \mathrm{~kg}$ of plutonium over 6 months by taking $4 \mathrm{~kg}$ in random whole-drawer removals and $4 \mathrm{~kg}$ in random 1-in.-plate removals. At the beginning of the simulation, no material is missing from the reactor inventory. Based on the overall diversion goal, probabilities are assigned for diverting either the entire contents or 1 in. of plate

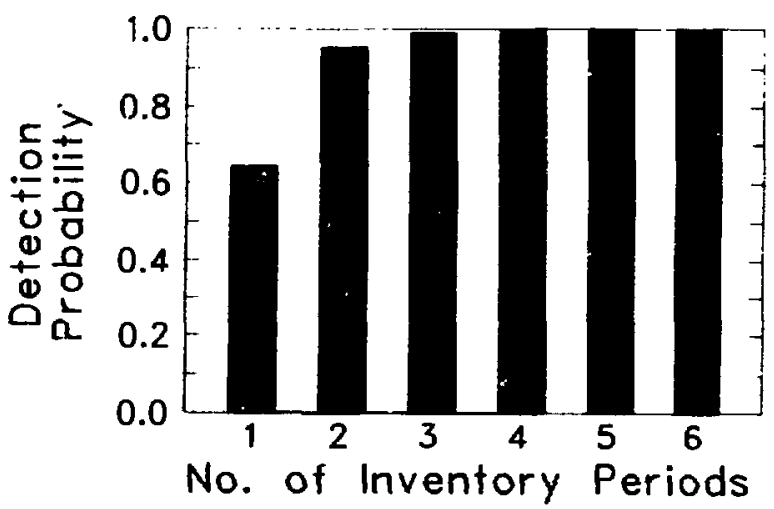

(b)

Fig. 12.

The increase in detection probability provided by a series of monthly $10 \%$ samples of the reference reactor; $8 \mathrm{~kg}$ of plutonium are missing $(a)$ in whole-drawer amounts and $(b)$ in 1 in.-plate amounts. 
from each fuel drawer as it is loaded into the reactor. The average rate of diversion is $\sim 1.3 \mathrm{~kg}$ per month; however, diversion continues in every simulation run until either the $8-\mathrm{kg}$ goal or the end of $1 \mathrm{yr}$ of operation is reached.

The results are shown in Fig. 13 where the average cumulative amount diverted from the inventory is shown on the left and the detection probability provided by a series of monthly $10 \%$ samples with neutron NDA verification is shown on the right. The average diversion only approaches the $8-\mathrm{kg}$ goal because in several simulation runs, this goal was not reached within 1 yr of operation. The probability of detection provided by sampling verifications (alone) is $55 \%$ after three monthly samples, $95 \%$ after six samples, and $>99 \%$ after nine samples. Therefore, the detection probability after 6 months is $\sim 95 \%$ when the average diversion is $\sim 8 \mathrm{~kg}$. Similar results are obtained for bimonthly $10 \%$ sampling and protracted diversion of $8 \mathrm{~kg}$ in $1 \mathrm{yr}$.

\section{Summary of Results}

Modeling and simulation studies of the model critical facility show that random sampling of the reference reactor using NDA drawer measurements is sensitive to significant diversion by any combination of attributes or variables removals (Table VII). However, the detection probability is reduced sub- stantially in the unlikely event of diversion by a small bias.

Because the probabilities of detection for 1-in. plates and whole drawers are similar, the required sample size is determined primarily by the detection goal for whole-drawer removals. However, the same detection goal can be met by taking small samples frequently or larger samples less frequently. Frequent small samples provide enhanced detection of abrupt diversion (Fig. 12) and protracted diversion (Fig. 13).

Figure 14 is a summary of the modeling and simulation results. Probabilities of detecting $8 \mathrm{~kg}$ of plutonium missing from the reference reactor with sequences of 5,10 , and $30 \%$ samples are shown as functions of the cumulative fraction sampled. For 5 and $10 \%$ samples, two values of detection probability are given corresponding to diversion in whole-drawer (lower value) and 1-in.-plate (upper value) amounts.

The results show that detection probability depends primarily on the cumulative fraction sampled; for example, six monthly $5 \%$ samples or three bimonthly $10 \%$ samples or one semiannual $30 \%$ sample all provide $\sim 95 \%$ probability of detecting an 8 -kg diversion within 6 months. This is true despite frequent and sometimes rather large changes in the reactor loading during normal operation. Thus, there is a continuum of sample sizes and inventory frequencies that can satisfy a given detection goal.

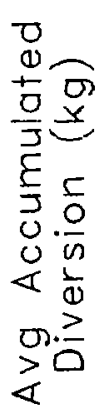

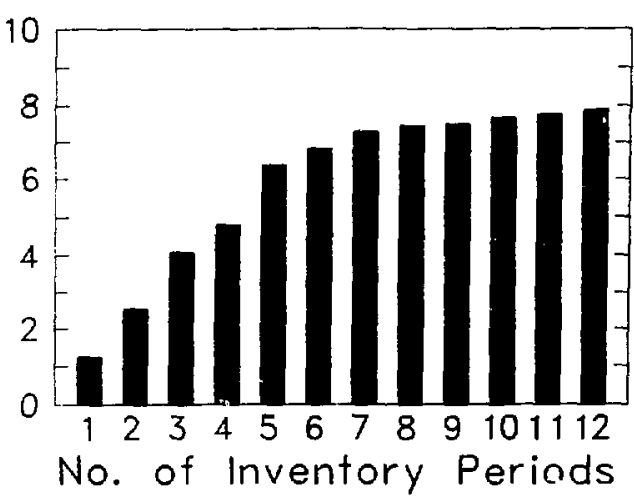

(a)

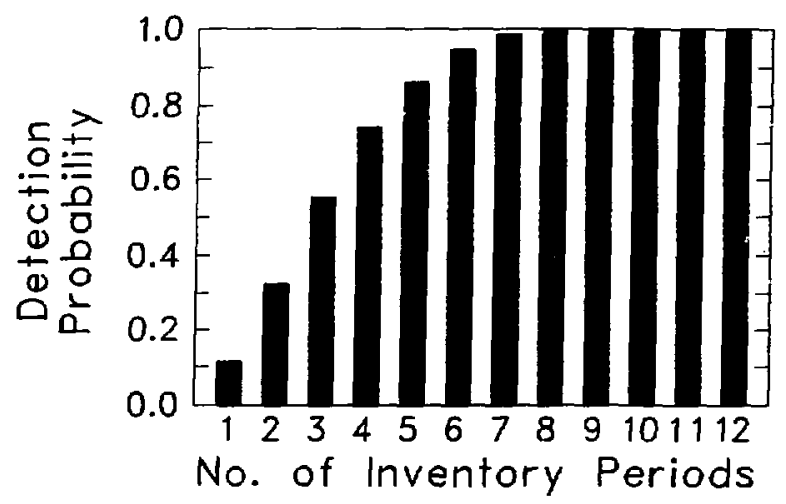

(b)

Fig. 13.

Protracted diversion of $4 \mathrm{~kg}$ of plutonium in whole-drawer amounts plus $4 \mathrm{~kg}$ in 1 -in.-plate amounts by random removals during 6 months of operation of the reference reactor. The average accumulated diversion ( $a$ ) and the detection probability provided by monthly $10 \%$ samples (b) are shown. 


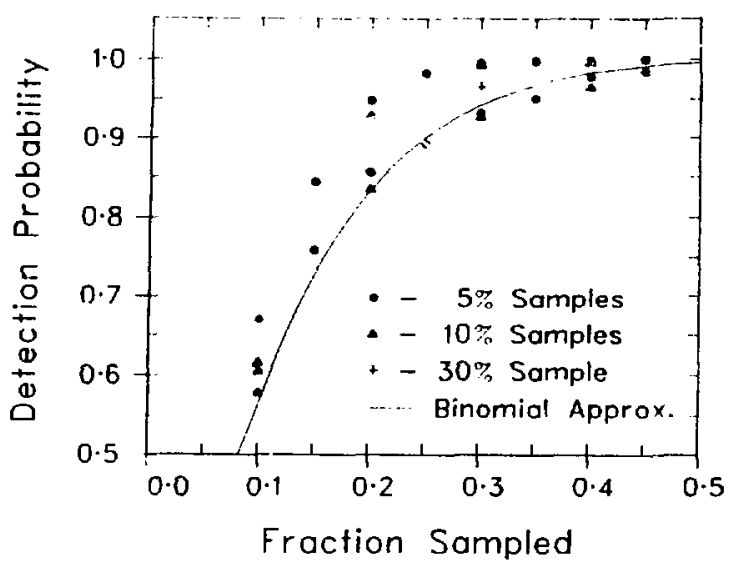

Fig. 14.

Probability of detecting $8 \mathrm{~kg}$ of plutonium missing from the reference reactor with sequences of 5,10 , and $30 \%$ samples.

The solid curve (Fig. 14) is the binomial approximation to the elementary hypergeometric sampling distribution, which applies rigorously to sampling static item inventories without replacement (App. D). Comparing the binomial curve with the simulation results shows that the elementary theory can be used, at least as a first approximation, to design sampling plans that are effective against.most diversion strategies of interest for critical facilities.

Although the effectiveness of combined sampling and reactivity verifications has not been evaluated, effectiveness estimates are given in this report for each technique. These estimates should be updated after operational testing and evaluation of the proposed inventory verification measures. Operational testing of containment, surveillance, and inventory-verification components should be performed to determine the overall effectiveness of the proposed safeguards system.

\section{RESULTS, CONCLUSIONS, AND RECOM- MENDATIONS}

\section{A. Results and Conclusions}

A safeguards-system concept that integrates the functions of containment, surveillance, and inventory verification has been investigated for inter- national safeguarding of fast-critical facilities. Concepts for containment and surveillance developed by SLA are described in Ref. 2, and concepts for inventory verification are reported here. These concepts have been developed for a model plutonium critical facility having a split-table assembly. The actual safeguards system for any real facility must be operationaliy acceptable and must be developed with regard for facility-specific design and operating features.

The foliowing is a summary of inventoryverification concepts developed for the model critical facility.

- Frequent inspection visits are made to the model facility by one inspector to perform routine safeguards procedures, such as checking facility records, monitoring experimental activities, sealing and verifying vaul $t$ storage containers, calibrating instruments, and monitoring the containment/surveillance syst $\epsilon$ ins.

- Seals and NDA verification measurements (gamma ray, neutron, and autoradiography) are applied to the static vault inventory. These activities are performed during normal working hours without disrupting the experimental program. The entire vault inventory is sealed and verified when a routine verification of the reactor inventory is performed.

- The reactor inventory in the model facility is verificd 6 to 10 times annually by sampling or reactivity verifications scheduled randomly at 1- to 3-month intervals. Reactor downtime for each routine verification is limited to two 8 -h shifts that can be scheduled during normal shutdown. During a sampling verification, $\sim 10 \%$ of the reactor inventory is verified using a combination of NDA techniques such as gamma-ray, neutron, and autoradiography measurements to verify the fuel in reactor drawers. Automated fuel handling is used to minimize the radiation exposure incurred by personnel. Two to four times per year when the reactor loading is near a reference configuration, a reactivity verification is performed in place of a sampling verification. Supplementary measurements such as foil activation and material worth verify that reactivitycompensating changes have not been made in the reference configuration. 
- If the IAEA concludes that diversion probably has occurred and a special inventory of the model facility is justified. a team of inspectors is available to complete the special inventory in 1$2 \mathrm{wk}$. The facility records are audited. The sealed portion of the vault inventory is checked for seal integrity and the unsealed portion is verified by NDA. The reactor inventory is verified using a combination of measurement techniques determined by the inspector based on his investigation of the suspected diversion. For example, sampling and measurement of $50 \%$ of the reactor inventory provides $>95 \%$ probability of detecting a significant quantity missing from the reactor.

In this study, the detection goal for inventory verification (alone) was taken to be a $95 \%$ probability of detecting a signiricant-quantity diversion within 6 months. This goal can be met in the model facility using a combination of periodic sampling and reactivity verifications of the reference reactor inventory. Onerous and timeconsuming physical inventories are not normally necessary. Sampling and reactivity verifications are complementary and provide better assurance in combination than either method provides by itself.

The detection probability provided by a series of sampling verifications depends primarily on the cumulative fraction sampled and is essentially independent of normal changes in reactor inventory (Fig. 14). Therefore, a continuum of sample sizes and inventory frequencies can satisfy any given detection goal. However, small samples taken frequently enhance the detection capability by improving the timeliness of detection.

A combination of complementary NDA techniques such as gamma-ray, neutron, and autoradiographic measurements is necessary to adequately verify the contents of reactor fuel drawers and vault canisters. When combined with appropriate measurement-control and data-evaluation procedures, NDA drawer measurements are sensitive to any combination of unauthorized removals including 1-in. plates and whole-drawer amounts. For this reason, if the sample size is selected to satisfy the detection goal for whole-drawer (attributes) removals, the sampling verifications will be sensitive to any combination of attributes and variables removals from the reactor inventory.
Table VIII is the detection capability provided by routine bimonthly sampling of $10 \%$ of the model facility's reactor (1200-1600 kg of plutonium in more than 1500 fuel drawers), using NDA techniques to make verification measurements on the fuel drawers. The table shows the probability of detecting $8 \mathrm{~kg}$ of plutonium missing from the reactor inventory, assuming that the plutonium has been diverted in whole-drawer amounts. The detection probability is near $95 \%$ after 6 months. Each $10 \%$ sample provides $95 \%$ probability of detecting $30 \mathrm{~kg}$ missing. Bimonthly $10 \%$ sampling verifications also provide $95 \%$ probability of detecting the protracted diversion of $8 \mathrm{~kg}$ over $1 \mathrm{yr}$. The rate of false indications of diversion is estimated to be $<1$ in 100 inventory periods with proper measurement controls and procedures.

Measurements of integral reactivity made on a reference configuration are very sensitive to small shifts in the reactor inventory. Supplementary measurements are required to verify that reactivitycompensating changes have not been made in the reference configuration. Table $\mathbf{I X}$ gives calculated detection limits corresponding to a 3 -Ih reactivity change that would be produced in various reference configurations by removing fuel from regions of minimum worth. In all cases a shift of considerably $<1 \mathrm{~kg}$ of plutonium is detected out of a reactor inventory of $>1000 \mathrm{~kg}$.

\section{TABLE VIII}

\section{PROBABILITY OF DETECTING $8 \mathrm{~kg}$ OF PLUTONIUM MISSING FROM THE; REFERENCE REACTOR}

\begin{tabular}{|c|c|c|}
\hline $\begin{array}{c}\text { Detection } \\
\text { Time } \\
\text { (months) }\end{array}$ & $\begin{array}{c}\text { Cumulative } \\
\text { Fraction } \\
\text { Sampled } \\
(\%) \\
\end{array}$ & $\begin{array}{c}\begin{array}{c}\text { Detection } \\
\text { Probability } \\
(\%)\end{array} \\
\end{array}$ \\
\hline 2 & 10 & 61 \\
\hline 4 & 20 & 82 \\
\hline 6 & 30 & 93 \\
\hline 8 & 40 & 97 \\
\hline 10 & 50 & $>99$ \\
\hline 12 & 60 & $>99$ \\
\hline
\end{tabular}


TABLE IX

\section{DETECTION LIMITS ${ }^{a}$ FOR INTEGRAL REACTIVITY CHECKS OF EIGHT REFERENCE CONFIGURATIONS}

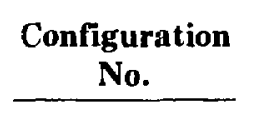

$3-1 \mathrm{~B}$

4-1

4-3

$5 \operatorname{Ref}^{\mathrm{b}}$

$5 \operatorname{Ref}^{\mathrm{c}}$

$5 \mathrm{FS}^{\mathrm{b}}$

$5 \mathrm{FS}^{\mathrm{c}}$

$6 \mathrm{EOC}$

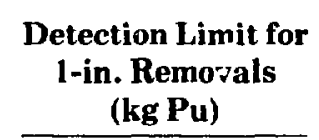

0.37

0.37

0.35

0.53

0.46

0.34

0.28

0.44

\author{
Detection Limit for \\ 4-in. Removals \\ (kg Pu)
}
0.31
0.31
0.29
0.42
0.38
0.27
0.23
0.35

${ }^{\text {a }}$ Corresponding to a 3 -Ih change in reactivity produced by removing fuel from regions of minimum worth.

Axial half 1 .

"Axial half' 2.

\section{B. Recommendations}

The design of safeguards systems for real facilities should rely on field tests and evaluations of the sensitivity, reliability, and operational acceptability of specific system components and procedures. The following identified areas require further development.

- The integral reactivity technique should be developed, including the use of supplementary foil-activation, material-worth, and reactionrate measurements along with specific procedures and instruments for inspector use. The potential operational impact of this technique should be assessed.

- Methods should be investigated to harden the autoradiographic technique for plutonium fuels and to apply it to HEU fuels.

- Gamma-ray and neutron NDA instrumentation should be optimized for the fuel compositions and geometries encountered in fast-critical facilities. Prototype hardware systems for measuring plutonium fuels in reactor drawers and vault canisters should be built and field tested. Appropriate NDA techniques such as active neutron interrogation for measuring $\mathrm{HEU}$ fuels should be evaluated.

- The potential operational impact of sampling verifications using automated fuel handling and NDA drawer measurements should be assessed.

- Based on the results of operational testing and evaluation of specific system components, an advanced safeguards system should be designed and evaluated for an operating critical facility.

\section{ACKNOWLEDGMENTS}

We gratefully acknowledge the cooperation and assistance of the staff of Argonne National Laboratory, East and West, for supplying us with essential information used in this study and for reviewing the results. We also acknowledge the many helpful discussions with staffs of Argonne National Laboratory, Sandia Laboratories, Albuquerque, and the International Atomic Energy Agency. 


\section{REFERENCES}

1. W. G. Davey and W. C. Redman, Techniques in Fast Reactor Experiments (Gordon \& Breach, Science Publishers, New York, 1970).

2 D. O. Gunderson and J. L. Todd, "International Safeguards for Fast Critical Facilities," Sandia Laboratories report SAND78-0168 (to be published).

3. H. Lawroski, "Zero Power Plutonium Reactor Facility," Nucl. News 11 (2), 47 (1968).

4. L. R. Dates, "Design, Construction Details and Preoperational Testing of an Argonne Fast Critical Facility," USAEC report ANL-7195, Argonne National Laboratory (1966).

5. C. E. Cohn, G. S. Rosenberg, L. R. Dates, W. B. Loewenstein, and G. H. Golden, "Safety Analysis for the ZPR 9 Facility, " USAEC report ANL-7166, Argonne National Laboratory (1966).

6. J. Hirota, S. Nomoto, and T. Nakamura, "The JAERI Fast Critical Facility," in Proc. Int. Conf. Fust Critical Experiments and Their Analysis, Argonne National Laboratory report ANL-7320 (1966), pp. 776-784.

7. P. Engelmann, W. Bicket, and U. Daunert, "Construction and Experimental Equipment of the Karlsruhe Fast Critical Facility, SNEAK," in Proc. Int. Conf. Fast Critical Experiments and Their Analysis, Argonne National Laboratory report ANL-7320 (1966), pp. 725-733 (1966).

8. A. P. Schmitt, F. Storrer, and G. Vendryes, "MASURCA, A Fast-Neutron Critical MockUp: Operation and Uses," in Exponential and Critical Experiments (IAEA, Vienna, 1964) Vol. I, pp. 135-155.

9. R. D. Smith, "ZEBRA-A Zero Power Fast Reactor," Nucl. Eng. 7, 364 (1962).

10. J. W. Weale, M. H. McTaggart, H. Goodfellow, and W. J. Paterson, "Operating Experience with the Zero-Energy Fast Reactor VERA," in Exponential and Cr.tical Experiments, (IAEA, Vienna, 1964) Vol. I, pp. 159-195.

11. A. L. Keipunsky, I. I. Bondarenko, and O. D. Kazachkovsky, "Experimental Studies on FastNeutron Reactor Physics," in Proc. UN Int. Conf. Peaceful Uses of At. Energy, (United Nations, Geneva, 1965) Vol. VI, pp. 152-169.

12. "Program Plan for Technical Assistance to IAEA Safeguards," US Department of Energy/Safeguards and Security, International Safeguards Project Office (March 1978); Subtask C.17.

13. D. D. Cobb and J. L. Sapir, "Preliminary Concepts for Materials Measurement and Accounting in Critical Facilities," Los Alamos Scientific Laboratory report LA-7028-MS (January 1978).

14. "The Structure and Content of Agreements Between the Agency and States Required in Connection with the Treaty on the NonProliferation of Nuclear Weapons," IAEA INFCIRC/153 (June 1972).

15. "IAEA Safeguards Technical Manual, Introduction, Part A: Safeguards Objectives, Criteria, and Requirements," IAEA-174 (1976).

16. R. Rometsch, E. Lopez-Menchero, M. N. Ryzhov, C. G. Hough, and Yu. Panitkov, "Safeguards: 1975-1985," in Proc. Symp. Safeguarding Nucl. Mater., (IAEA, October 1975), Vol. I.

17. B. Sanders and R. Rometsch, "Safeguards Against the Use of Nuclear Material for Weapons," Nucl. Engn. Int. 20, 234 (September 1975).

18. "Safeguards Criteria for Significant Quantities and Timely Detection," Standing Advisory Group on Safeguards Implementation report AG-43/10, IAEA (December 1977).

19. J. F. Ney, Sandia Laboratories/Albuquerque, personal communication (March 1978). 
20. "Report Forms and Explanations for Their Use," Code 10, IAEA (September 30, 1976).

21. J. E. Lovett, Nuclear Materials Accountability, Management, Safeguards (American Nuclear Society, 1974).

22. J. L. Jaech, "Statistical Methods in Nuclear Material Control," TID-26298, US Government Printing Office, Washington, DC (1973).

23. F. Brown, P. T. Good, J. B. Parker, A. E. Ross, and D. R. Terrey (UKAEA); A. Lumetti, E. Kerr, ' $\Gamma$. Otoms, and M. Sultan (IAEA), "Progress in the Development of a System for the Safeguards Inspection of the Fuel Store of a Zero-Energy Test Reactor," Cos. 20, UK Atomic Energy Authority (October 1970).
24. C. G. Hough, R. A. Schneider, K. B. Stewart, J. L. Jaech, and C. A. Bennett, "Example of Verification and Acceptance of Operator Data-Low Enriched Uranium Fabrication," Battelle Pacific Northwest Laboratories report BNWL-1852 (August 1974).

25. C. G. Hough and T. M. Beetle, "Statistical Methods for the Planning of Inspections," in Proc. Symp. Safeguarding Nucl. Mater., (IAEA, October 1975), Vol. I.

26. R. J. Forrester and H. A. McFarlane, Argonne National Laboratory-West, personal communication (March 1978). 


\title{
APPENDIX A
}

\section{NONDESTRUCTIVE ASSAY METHODS FOR FAST-CRITICAL FACILITIES}

\author{
PART I
}

\section{SURVEY OF METHODS FOR PLUTONIUM AND URANIUM FUELS}

\author{
H. O. Menlove, N. Ensslin, M. S. Krick, and S. T. Hsue
}

LASL Safeguards Staff, Q-1

\section{INTRODUCTION}

Quantitative, NDA methods are necessary for verification of $\mathrm{SNM}$ inventories in fast-critical facilities. IAEA inspection teams require NDA instruments to measure individual fuel pieces, reactor fuel drawers, and vault storage canisters. These instruments must be adapted to the specific geometries and fuel compositions found in each critical facility under IAEA safeguards and they must satisfy the requirements of both routine inventory verification and rapid, special inventories in response to alarms.

The specific NDA measurement techniques described here quantitatively determine the elemental and isotopic composition of uranium and plutonium fuels by detecting and recording neutrons and gamma rays emanating from the fuel material. NDA methods are grouped into two major categories, passive and active. Passive assays use naturally accurring gamma or neutron radiation as direct signatures of the nuclear materials being assayed. Active assays first interrogate the material with a neutron or gamma-ray source to induce fissions and then measure the resulting prompt or delayed radiation. During the past decade, these techniques have been developed and demonstrated under field conditions so that a variety of instruments exist that are sufficiently reliable and accurate to satisfy safeguards needs. In many cases, the instruments are portable or, at least, transportable.

During the past $2 \mathrm{yr}$, NDA instrumentation has been under development at LASL in support of the IAEA, which could be used to assay fast-critical- assembly fuel. This work has resulted in the development of a portable High-Level Neutron Coincidence Counter (HLNCC), ${ }^{1,2}$ which is currently being used by IAEA inspectors to verify the plutonium fuel in critical-assembly drawers. This passive neutron assay technique measures the effective ${ }^{240} \mathrm{Pu}$ content $^{3}$ in the sample. Additional gamma-ray spectroscopy measurements may be performed simultaneously to verify the isotopic composition. ${ }^{2}$ Figure A-1 shows an experimental setup that combines the IAEA intrinsic germanium detector with the HLNCC for the verification of fast-critical-assembly fuel drawers. Methods to

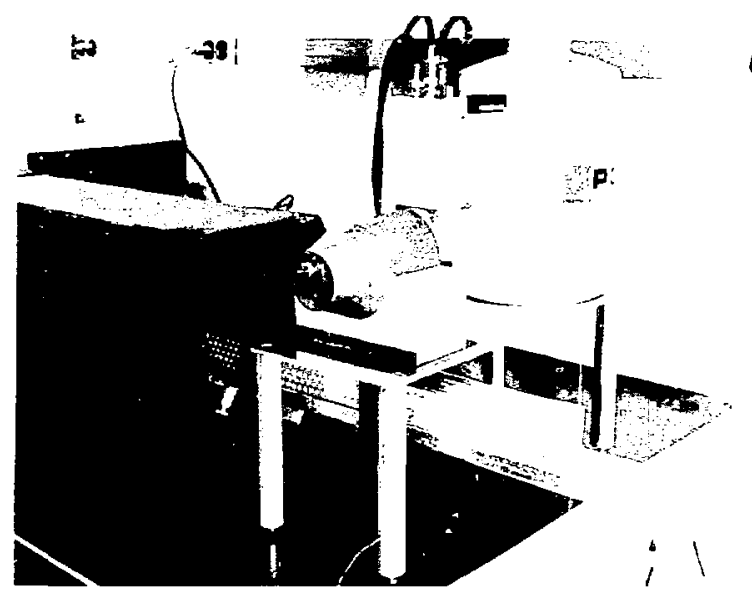

Fig. A-1.

Measurement setup for a fuel drawer showing the $H L N C C$ for neutron counting and the IAEA intrinsic germanium detector with its collimator for measurement of plutonium gamma-ray line ratios. 
correct for self-multiplication effects ${ }^{4}$ in the highmass samples are being developed.

Because passive neutron techniques can not be applied directly to the assay of ${ }^{235} \mathrm{U}$, active neutron interrogation techniques are necessary to verify fastcritical-assembly fuel drawers that contain mixtures of plutonium and enriched uranium. Active techniques such as the ${ }^{252} \mathrm{Cf}$ Shuffler ${ }^{5}$ and the Active Well Coincidence Counter (AWCC) ${ }^{6}$ are being evoluated for this purpose.

This Appendix surveys the NDA instruments and methods being considered for quantitative verification of the plutonium and uranium in fuel pieces, fuel drawers, and vault storage canisters. The plutonium and uranium fuels used in a critical facility generally present a favorable situation for quantitative NDA methods of verification because of their well-characterized shape, isotopic composition, and packaging. In evaluating the measurement approaches, we normally can assume that the composition and configuration of the material is given either by the facility operator or by previous measurements on the same sample. Thus, the role of NDA instruments is to give a quantitative verification that the sample contains the expected amount of plutonium or ${ }^{236} \mathrm{U}$.

\section{PASSIVE GAMMA-RAY ASSAY METHODS}

\section{A. Gamma-Ray Assay of Fuel Drawers}

The plutonium content of fuel drawers can be assayed using an "enrichment" measurement. The ${ }^{239} \mathrm{Pu}$ and ${ }^{241} \mathrm{Pu}$ contents of the entire drawer and their isotopic ratio can be measured simultaneously. The counting rate is proportional to the product of the fraction of plutonium isotope in the heavy metal (the enrichment) and the surface area of the fuel plates viewed by the detector. Moreover, if the plutonium fraction, the alloy type, and the widths of the fuel plates are the same, the counting rate is proportional to the total lerigth of fuel plates in the drawer.

The plutonium can be assayed in an experimental setup depicted in Fig. A-2. The drawer is placed sideways so that the edges of the plates are facing the detector. The detector-to-drawer distance

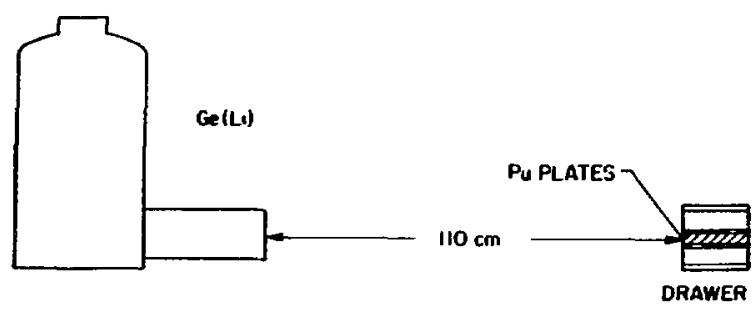

Fig. A-2.

Experimental configuration for gamma-ray measurements on a fast-critical-assembly fuel drawer.

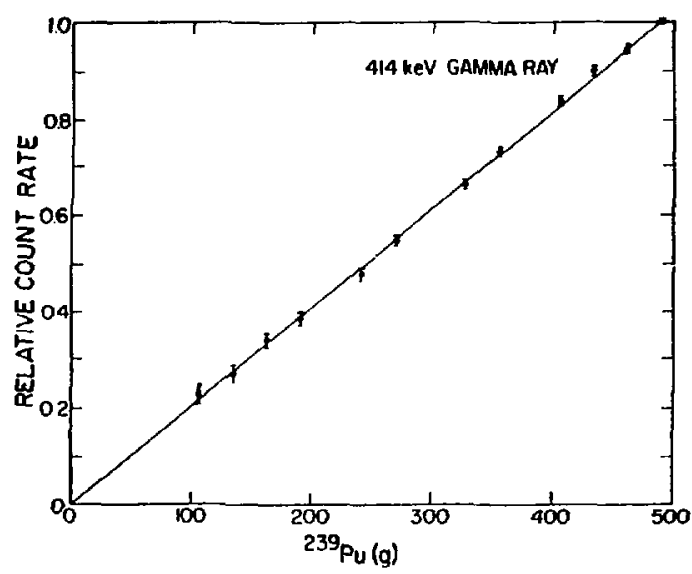

Fig. A-3.

Relative counting rate for the 414-keV gamma line as a function of plutonium loading in the drawer.

should be large enough that the $1 / \mathrm{r}^{2}$ variation across the drawer is negligible.

The following data were taken with a $\mathrm{Ge}(\mathrm{Li})$ detector (efficiency $16 \%$, surface area $18 \mathrm{~cm}^{2}$ ) placed $110 \mathrm{~cm}$ from a drawer containing plutonium fuel plates. Figure A-3 shows the relative counting rate of the ${ }^{230} \mathrm{Pu} 414-\mathrm{keV}$ gamma ray versus the total ${ }^{239} \mathrm{Pu}$ content of the drawer. The ${ }^{239} \mathrm{Pu}$ content in the drawer is proportional to the counting rate. The 41.4$\mathrm{keV}$ gamma peak yields the most precise determination of ${ }^{239} \mathrm{Pu}$ content; the $208-\mathrm{keV}$ gamma peak yields the most precise determination of ${ }^{241} \mathrm{Pu}$ content. For a drawer containing one row of plutonium 
plates, the precision at $1 \sigma$ for a 200 -s assay is $2.1 \%$ for ${ }^{239} \mathrm{Pu}$ and $1.4 \%$ for ${ }^{241} \mathrm{Pu}$; for a drawer containing two rows, the precision is $1.5 \%$ for ${ }^{239} \mathrm{Pu}$ and $1.0 \%$ for ${ }^{24} \mathrm{Pu}$. With some optimization of the detector size and detector-to-drawer distance, it should be possible to reduce the assay time by a factor of 2 while maintaining these precisions.

Several comments should be made concerning this type of measurement. First, the counting rate is proportional to the product of the enrichment and the total exposed area of the plate edges. If the drawer contains fuel plates of different enrichments, the gamma emission rate alone cannot determine the total length of the plutonium fuel plates. However, if the plutonium enrichment is the same for all fuel plates in the drawer, the counting rate is proportional to the total length of the fuel plates. Second, the 208-keV gamma ray arises not only from ${ }^{241} \mathrm{Pu}$ decay but also from ${ }^{241} \mathrm{Am}$ decay. For equal amounts of ${ }^{241} \mathrm{Pu}$ and ${ }^{241} \mathrm{Am}(14.35 \mathrm{yr}$ after the separation of americium), the americium decay contributes $\sim 3.8 \%$ of the $208-\mathrm{keV}$ gamma peak. Third, the plutonium mass fractions of the different fuel plates should be similar. If these assumptions are satisfied and the ${ }^{241} \mathrm{Am}$ build-up is known, the plutonium content of the drawer can be measured by gamma rays.

\section{B. Gamma-Ray Assay of Storage Canisters}

Plutonium fuel plates are stored in canisters or birdcage containers. The plutonium content of the canisters also may be assayed using the enrichment measurement described for the fuel drawers. The aluminum canister wall can be used to advantage in reducing the $60-\mathrm{keV}^{241} \mathrm{Am}$ gamma ray without substantially attenuating the gamma rays from plutonium. The cc-anting time and the canister-todetector distance can be reduced sumewhat, compared with the assay of drawers.

With storage canisters, complications may arise if portions of the side surfaces of the plates are also viewed by the detector. This increases the effective surface area and changes the counting rate. Nevertheless, the plutonium isotopic ratio of the material within the canister can still be measured by gamma-ray assay.

\section{Discussion}

The plutonium fuel drawers and certain types of storage canisters can be assayed rapidly by gammaray measurements. The main advantage of the gamma-ray assay is that it uniquely identifies the fissile isotopes. Therefore, it can be used to determine the isotopic ratios and, with proper calibration, the isotopic content of the fuel containers. The unique gamma signature of various plutonium isotopes makes plate substitution difficult. However, the fuel plates are very dense and the gamma rays verify the enrichment of only the outer surface on the top edge of the plates. Investigations are needed to determine the optimum assay geometry and detector size for gamma-ray measurements of critical-facility fuels.

\section{PASSIVE NEUTRON ASSAY METHODS}

\section{A. Introduction}

Passive neutron verification of plutonium fuel plates can be performed by counting the total number of neutrons emitted by the fuel or by counting the neutrons emitted in coincidence by the spontaneous fission of the even plutonium isotopes and by the induced fissions in plutonium or uranium. The total number of neutrons emitted by the fuel depends on the mass of the even isotopes of plutonium (spontaneous fission neutrons), the chemical composition of the fuel $[(\alpha, n)$ reaction neutrons], and the total fissile mass and geometry of the fuel (neutron multiplication). On the other hand, the neutron coircidence counting rate does not depend on chemical composition (except for small self-multiplication effects) or room neutron background fluctuations.

Measurements have been made with simultaneous totals and coincidence counts of plutonium fuel plates in a fuel drawer and in a rault canister to study the usefulness of passive neutron counting for quantitative inventory verification. 


\section{B. Neutron Counters}

Measurements were made in two thermal-neutron coincidence counters, the Dual Range Counter (DRC) in its high-efficiency mode and the AWCC in its passive mode. These instruments consist of a sample cavity surrounded by a polyethylene annulus to thermalize the neutrons from the sample. Several ${ }^{3} \mathrm{He}$ proportional counters are incorporated in the polyethylene to detect the thermal neutrons. A polyethylene shield outside the detectors reduces the neutron counting rate caused by room background. The detector pulses are sent to a shiftregister coincidence counting module," which simultaneously measures and records the totals and coincidence counting rates.

The DRC was placed on its side for measurement of fuel drawers. The fuel canister does not fit inside the sample cavity of the DRC and, therefore, it was measured in the larger AWCC operated in the passive mode. A coincidence counter designed for permanent installation to assay plutonium fuel drawers would differ from the DRC used for the present measurements in three major ways. The sample cavity would be smaller in diameter and would be longer to provide a more uniform response along the length of the drawer; the detector would be designed for higher efficiency ( $30-40 \%$ compared to the present $\sim 25 \%$ ); and the outer shielding would be increased to reduce room background.

\section{Plutonium Fuel Plate Characteristics}

Measurements were made with 15 plutonium fuel plates, $2.54-17.78 \mathrm{~cm}$ (1-7 in.) in length with $26-200$ g Pl. The isotopic composition was either $11.6 \%$ or $8.7 \%{ }^{260} \mathrm{Pu}$. All fuel plates were Pu-U-Mo alloy, $5 \mathrm{~cm}$ (2 in.) wide and $0.64 \mathrm{~cm}(1 / 4 \mathrm{in}$.) thick.

\section{Counting Sensitivity}

Individual plates with $11.6 \%{ }^{240} \mathrm{Pu}$ were counted in the DR.C. The totals counting rate, with a $64-\mu \mathrm{s}$ coincidence gate, was $\sim 290 \mathrm{cps} / \mathrm{g}{ }^{240} \mathrm{Pu}$; the coincidence counting rate was $\sim 39 \mathrm{cps} / \mathrm{g}{ }^{240} \mathrm{Pu}$. Therefore, a fuel drawer containing $1 \mathrm{~kg}$ of plutonium at $11.6 \%{ }^{240} \mathrm{Pu}$ will have a totals counting rate of $\sim 3.4 \times 10^{4} \mathrm{cps}$ and 8 : incidence counting rate of $\sim 4.5 \times 10^{3} \mathrm{cps}$. For a $100-\mathrm{s}$ measurement, the totals count will be $\sim 3.4 \times 10^{6}$ and the coincidence count will be $\sim 4.5 \times 10^{5}$. The standard deviation, owing to counting statistics oniy, will be $\sim 0.05$ and $\sim 0.9 \%$ for the totals and coincidence counts, respectively.

\section{E. Fuel Drawer Measurements}

For a coincidence counter with $40 \%$ efficiency, the totals counting rate would be $\sim 460 \mathrm{cps} / \mathrm{g}{ }^{200} \mathrm{Pu}$ and the coincidence counting rate would be $\sim 100 \mathrm{cps} / \mathrm{g}$ ${ }^{240} \mathrm{Pu}$. If the plutonium loading is assumed to be 12 $\mathrm{g} / \mathrm{cm}$, a fuel drawer with two $46-\mathrm{cm}$ rows of plates would contain $1104 \mathrm{~g} \mathrm{Pu}$. At $11.6 \%{ }^{240} \mathrm{Pu}$, the ${ }^{25 c} \mathrm{Pu}$ content would be $128 \mathrm{~g}$. The totals and coincidence counts for a 100 -s measurement would be $\sim 5.9 \times 10^{\circ}$ and $\sim 1.3 \times 10^{\mathrm{s}}$, respectively, with standard deviations owing to counting statistics of 0.04 and $0.5 \%$, respectively.

The absence of a $2.54-\mathrm{cm}$ (1-in.) length of fuel plate from the drawer would produce a count-rate shift of $-3 \%$, if multiplication effects are small and the axial detector response is uniform. If $0.1 \%$ is an acceptable rejection probability for good drawers, then a $3 \%$ deviation is detectable with a probability $>99 \%$ in 100 s using coincidence counting, provided that counting statistics are the dominant sources of error. In practice, the nonusiformity of loading for drawers of a given type is likely to provide the limitation for the detection of deviations.

It is possible to rearrange the plutonium plates in a fuel drawer to increase the totals and coincidence counting rates by placing two or more plates sideby-side to increase the neutron multiplication. Consequently, some fuel can be removed from a drawer, and the remaining fuel can be rearranged to produce the original totals counting rate or the original coincidence counting rate. However, it is not feasible to produce both rates simultaneously. Measuring both totals and coincidences, therefore, allows the detection of such an attempted subversion.

\section{F. Fuel Canister Measurements}

The discussion of the totals and coincidence counting of fuel drawers applies about as well to 
storage canisters. The primary differences are that a different size sample chamber is required for the canisters (perhaps requiring a slightly lower efficiency) and multiplication effects are larger in a filled canister than in a normally configured fuel drawer. In general, there is more plutonium in the canisters than in the drawers, resulting in a higher counting rate and better statistical precision. To the first order, multiplication increases the sensitivity to plate removals. That is, a $10 \%$ reduction in plutonium reduces the counting rate by more than $10 \%$ : However, possible geometric variations might overshadow this advantage. As with fuel drawers, a rearrangement of the plates inside a canister to compensate for missing fuel would be detected by the ratio of totals counts to coincidence counts.

To investigate absorption and multiplication effects in a storage canister, a series of measurements was performed in the AWCC operated in the passive mode. The plates were placed in the canister one at a time, and the individual results were summed to correspond to the higher loadings. In addition, the higher loadings were obtained by loading several plates, side by side, in alternating rows. The results of these measurements are shown in Fig. A-4. There is a small multiplication effect in the coincidence results, amounting to a factor of $\sim 1.10$ for the $750-\mathrm{g}$ plutonium loading. This effect will be considerably

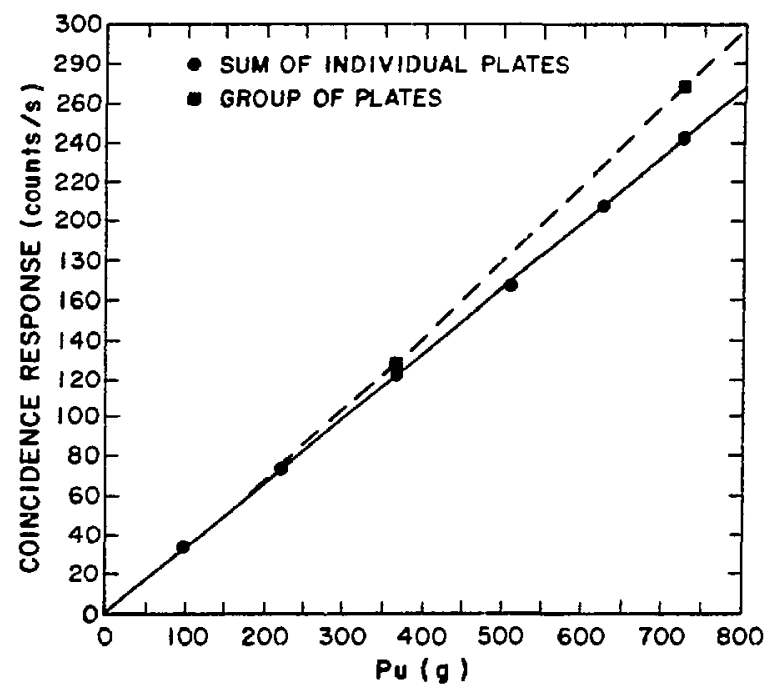

Fig. A-4.

Coincidence response versus plutonium $(8.7 \%$ ${ }^{240} \mathrm{Pu}$ ) loading for plates in a storage canister. larger for the fully loaded canister $(>2 \mathrm{~kg}$ plutonium). The following section describes a technique for correcting for such multiplication.

\section{G. Multiplication}

In passive neutron counting of fuel plates both the totals and coincidence counts are affected by selfmultiplication within the material. Selfmultiplication manifests itself in the following ways.

(1) Spontaneous fission neutrons may induce fissions in the fissile isotopes. The fissions will increase the observed fission muitiplicity from $\bar{\nu}$ to $\mathbf{M} \bar{\nu}$, where $M$ is the leakage multiplication.

(2) If $(\alpha, n)$ reactions are present in the material, the background of random events in the detector will be higher. The totals count rate by itself will not be a direct measuro of the amount of plutonium present. Also, neutrons from $(\alpha, n)$ reactions will induce fissions, thereby further increasing the totals counts and also contributing to the coincidence counts.

For plutonium fuel that does not contain oxides, aluminum alloys, or other materials with high $(\alpha, n)$ cross sections, it is relatively easy to correct for the self-multiplication induced by spontaneous fission [(1) above]. The ratio of coincident events to total events increases as the multiplication $M$ increases. A correction factor can be calculated from this ratio and applied to the data. No free parameters are required, but it is necessary to measure the background and the ratio of coincidence to total events for a small, nonmultipying sample. Figure A5 illustrates the application of this correction to a series of measurements in which plates of 11.6 and $8.7 \%{ }^{240} \mathrm{Pu}$ were added sequentially, side by side, into the counter. The uncorrected coincidence measurements deviated by more than $100 \%$ from the nominal (unmultiplied) count rate per gram. The corrected data were within $5 \%$ of the nominal values. It should be possible to refine this technique to obtain results within $1-2 \%$ of nominal values.

For fuel plates in which significant $(\alpha, n)$ reactions are present, such as with aluminum alloy fuel [(2) above], it should still be possible to correct for selfmultiplication because the ratio of $(\alpha, n)$ neutrons to 


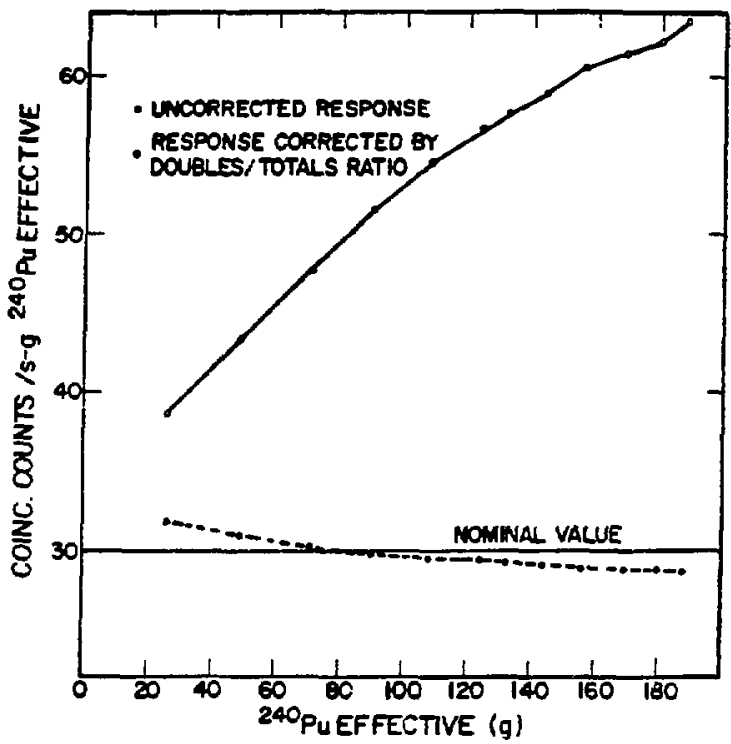

Fig. $A-5$.

Neutron coincidence counts per gram as a function of plutonium loading for stacked plates. The curve would be a horizontal line if there were no multiplication or absorption effects.

spontaneous fission neutrons is usually nearly constant. Under these conditions the coincidences/totals ratio will provide a measure of the multiplication. This correction has not yet been determined experimentally for material with $(\alpha, n)$ reactions, but it will be determined. Another correction that may be developed when $(\alpha, n)$ reactions are present is based on the coincidences/(totals) ${ }^{2}$ ratio. This ratio is independent of efficiency, but it depends on the response per gram of the sample. It would be sensitive to changes in the plutonium isotopics as well as to changes caused by $(\alpha, n)$ reactions. The usefulness of this ratio is still being studied.

The existence of self-multiplication can help or hinder the process of verifying the contents of fuel drawers and canisters. If good calibration standards are available, the effects of multiplication make measurements more sensitive to the removal of a small plate, the rearrangement of large plates, the substitution of plutonium of lower enrichment, or the replacement of plutonium by other neutronemitting sources.

\section{H. Totals Versus Coincidence Counting}

Passive neutron assay of fuel drawers based on totals counting rather than coincidence counting has both advantages and disadvantages. One advantage is that the electronic circuitry required for the assay is much simpler. Another advantage is that the counting rates are higher. Selfmultiplication affects the totals count rate much less than it affects the coincidence count rate. The difference is about a factor of 3 for plutonium. This is illustrated in Fig. A-6, which is based on the same measurements used for Fig. A-5.

The disadvantage of assays based on total neutron counts is that the background must be known very well by separate measurements. Often the room background varies during the measurements, depending on the location of other material or people in the room and on the configuration of the detector itself. For example, during the DRC experiments the room background was $\sim 160 \mathrm{cps}$. With a $17.8-\mathrm{cm}$ fuel plate $\left(\sim 25 \mathrm{~g}{ }^{240} \mathrm{Pu}\right)$ located $1 \mathrm{~m}$ from the detector, the background increased to $164 \mathrm{cps}$. With the same plate inside the detector, the totals rate was $7300 \mathrm{cps}$. However, if there is much more plutonium outside the detector than inside, the background fraction becomes significant.

If $(\alpha, n)$ reactions are present, they will contribute a strong background originating from. the sample. This background affects the totals count rate much more than it affects the coincidence count rate. An

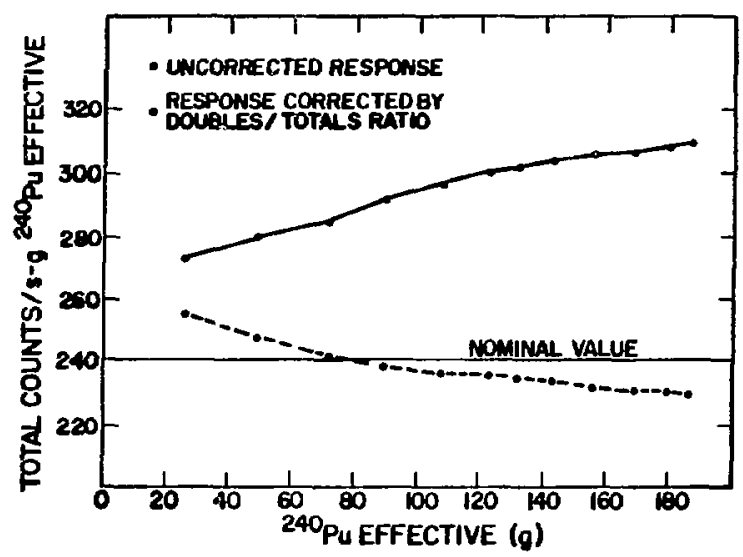

Fig. $A-6$.

Total neutron counts per gram as a function of plutonium loading for stacked plates. 
assay based on totals is not useful unless the ratio of $(\alpha, n)$ reactions to spontaneous fission neutrons is always the same and the room background remains constant during the measurement. Finally, the totals count can be simulated easily with a variety of neutron sources.

We recommend that the passive neutrun assay of fuel drawers be based on coincidence counting to eliminate background problems, but that the total neutron count rate also be recorded. The ratio of coincidences/totals, and possibly the ratio of coincidences/(totals) ${ }^{2}$, can then be used to observe changes associated with self-multiplication. By measuring both the coincidence and totals count rates and by using the information that can be extracted from a comparison of the two rates, we can be virtually assured of detecting any combination of plate removal, rearrangement, or substitution.

\section{FUEL DRAWER MATRIX EFFECTS}

For the NDA of fuel drawers, standards that closely approximate the actual drawers are needed.
By varying the plutonium content in the standard drawers, a calibration curve can be generated. However, one must determine whether the coincidence rate is also a function of the nonfissile matrix materials in the drawers. Typical materials are plates of sodium, aluminum, iron, and depleted uranium positioned parallel to the plutonium plates.

To evaluate this effect, several matrix samples were fabricated in the general shape of the drawer but with the full density of the material in question. Thus, the matrix effect of the sample was larger than the effect of the material in the actual drawer. $\mathrm{A}^{252} \mathrm{Cf}$ neutron source placed in the center of the 5by 5 - by $30-\mathrm{cm}$ matrix sample simulated a plutonium spontaneous fission source. The materials studied for matrix effects, including a typical fuel drawer with the plutonium plates removed are listed in Table A-I. The totals and coincidence count rates are normalized to the rate of the ${ }^{2 ; 2} \mathrm{Cf}$ source in an empty drawer. All matrix materials investigated increase the totals and coincidence rates. In general, this increased counting efficiency is a result of neutrons scattering back into

\section{TABLE A-I}

\section{MATRIX MATERIAL EFFECTS ON THE ASSAY OF FUEL DRAWERS WITH THE HLNCC}

\begin{tabular}{|c|c|c|c|}
\hline Matrix Material & $\begin{array}{l}\text { Normalized } \\
\text { Totals }\end{array}$ & $\begin{array}{c}\text { Normalized } \\
\text { Coincidence } \\
\text { Counts }\end{array}$ & $\begin{array}{l}\text { Coincidences/ } \\
\text { (Totals) }^{2}\end{array}$ \\
\hline None & 1.000 & 1.000 & 1.00 \\
\hline $\begin{array}{l}\text { Sodium } \\
\text { ( } 5 \text { by } 5 \text { by } 30 \mathrm{~cm} \text { ) }\end{array}$ & 1.042 & 1.114 & 1.03 \\
\hline $\begin{array}{l}\text { Aluminum } \\
(5 \text { by } 5 \text { by } 30 \mathrm{~cm})\end{array}$ & 1.068 & 1.142 & 1.00 \\
\hline $\begin{array}{l}\mathrm{CH}_{2} \\
(5 \text { by } 5 \text { by } 30 \mathrm{~cm})\end{array}$ & 1.078 & 1.163 & 1.00 \\
\hline $\begin{array}{l}\text { Iron } \\
(5 \text { by } 5 \text { by } 30 \mathrm{~cm})\end{array}$ & 1.120 & 1.291 & 1.03 \\
\hline Fuel drawer & 1.107 & 1.224 & 1.00 \\
\hline $\begin{array}{l}0.2 \% \text { depleted uranium } \\
(5 \text { by } 5 \text { by } 20 \mathrm{~cm} \text { ) }\end{array}$ & 1.233 & 1.668 & 1.10 \\
\hline
\end{tabular}

The fuel drawer ( 5 by 5 by $60 \mathrm{~cm}$ ) was filled with the normal matrix of sodium. aluminum. iron, and depleted uranium $\left(0.2 \%{ }^{235} \mathrm{U}\right)$ but had no plutonium plates. 
the detector instead of leaking from its ends. This effect is expected to be negligible for a longer detector. If the efficiency depended only on neutron scattering and moderation effects, the normalized coincidences $/\left(\right.$ totals $^{2}$ ratio would remain unity because the coincidence rate depends on the square of the efficiency. This is true of all samples except the depleted uranium, where fast-neutron multiplication occurs. This multiplication effect increases the effective multiplicity, thereby increasing the coincidence rate. The normalized coincidences/(totals) ${ }^{2}$ ratio increases to 1.10 , signaling this effect.

Excluding the depleted uranium case, the matrix effect of the drawer is similar to that of the other matrix materials. A diversion involving loading a drawer with depleted uranium would be noticeable because of the significant weight increase.

We conclude that drawer standards should have the same geometry and composition, including matrix materials, as the drawers to be assayed, whenever possible. However, to reduce the number of standards required, small deviations in matrix materials can be allowed.

\section{ACTIVE NEUTRON ASSAY METHODS}

The preceding sections indicate that adequate verification of plutorium fuels is possible vith passive neutron and gamma-ray techniques. However, for ${ }^{235} \mathrm{U}$ metal fuel, the passive gamma-ray signal is not very intense or penetrating, and there are no significant passive neutron signatures. This section will survey some active neutron NDA techniques that can be applied to the quantitative verification of critical-assembly fuels.

\section{A. The ${ }^{252} \mathrm{Cf}$ Shuffier}

The ${ }^{262} \mathrm{Cf}$ Shuffler ${ }^{5}$ was developed several years ago for applications to a wide variety of SNM, and the experience obtained using this instrument is directly applicable to critical-assembly fuels. The ${ }^{262} \mathrm{Cf}$ Shuffler uses fast- or thermal-neutron interrogation, combined with delayed-neutron counting. The ${ }^{252} \mathrm{Cf}$ Shuffler repetitively transfers the neutron source from the interrogation position to a shielded position while the delayed neutrons are counted. As shown in Fig. A-7, the assay system includes a source shield tank, a decoupling $\mathbf{C H}_{2}$ shield, and an irradiation tank. The assay sample is irradiated inside a high-efficiency neutron well counter used to count the fission-delayed neutrons. For samples containing plutonium, this well counter also can be used in the passive coincidence mode to count the spontaneous fission neutrons. The neutron detector consists of a $\mathrm{CH}_{2}$ matrix filled with $25{ }^{3} \mathrm{He}$ tubes.

The Shuffler system has been evaluated for assay of fuel rods, inventory samples, scrap and waste, uranium ore, irradiated fuel, and plutoniumuranium mixtures. For the plutonium-uranium mixtures, the combination of passive neution coincidence counting and active neutron interrogation can separate the ${ }^{235} U$ and plutonium components in the assay. The system can assay samples with fissile content from a few milligrams up to several kilograms, using thermal-neutron interrogation for the low-mass samples and fast-neutron interrogation for the high-mass samples.

Because fuel drawers contain large amounts of depleted uranium, it is necessary to use neutronspectrum tailoring inaterial, as shown in Fig. A-7, to reduce the energy of the ${ }^{252} \mathrm{Cf}$ neutrons below the threshold for ${ }^{238} \mathrm{U}$ fission.

The performance characteristics of the Shuffler system using a $0.5-\mathrm{mg}{ }^{252} \mathrm{Cf}$ source for ${ }^{236} \mathrm{U}$ assay are given in Table A-II. Plutonium samples will have slightly less response per gram because of the lower delayed-neutron yield compared with ${ }^{236} \mathrm{U}$. Because the uranium and plutonium fuel plates have a high fissile density, only fast-neutron interrogation will be considered, to obtain adequate penetrability for quantitative verification.

For discussion and comparison, we define a typical fuel drawer as one containing $1 \mathrm{~kg}$ of plutonium $\left(11.6 \%{ }^{240} \mathrm{Pu}\right)$ fuel plates or $1 \mathrm{~kg}$ of uranium (93\% enriched) fuel plates. The plates are positioned in two rows, each $45.7 \mathrm{~cm}$ (18 in.) long. Factoring in the geometric differences between the fuel drawer and the small sample used for Table AII, the expected count rate for a drawer of ${ }^{205} U$ plates is 6500 counts/s in the Shuffler system shown in Fig. A-7. Thus, after a 1-min measurement time, the accumulated delayed-neutron counts would be $\sim 195000$ with a background of $<1000$ counts, 

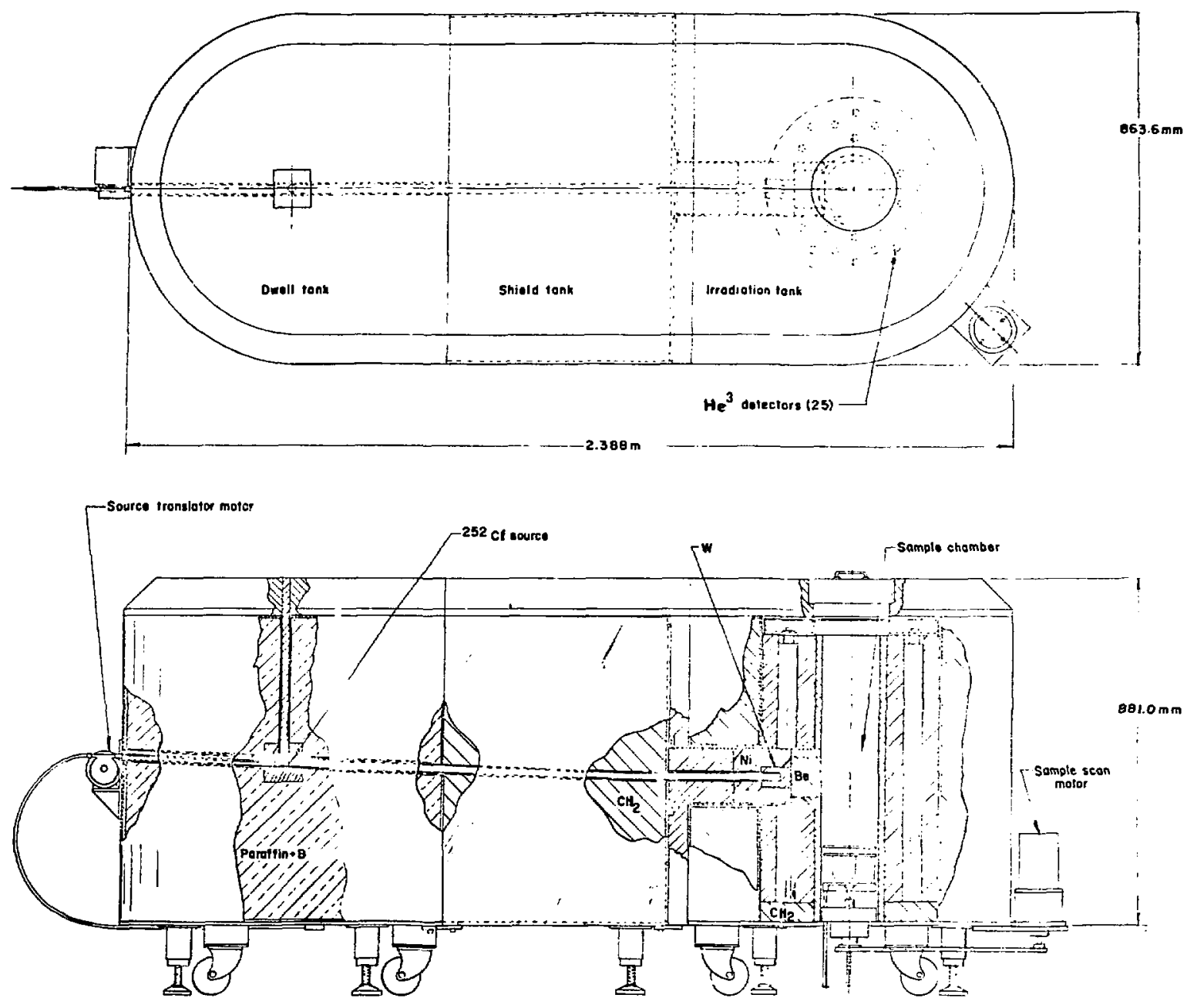

Fig. A-7.

Schematic of the ${ }^{262} \mathrm{Cf}$ Shuffler system showing the neutron well detector, the decoupling shield, and the dwell tank. This size system corresponds to a $500-\mu g{ }^{252} \mathrm{Cf}$ source and a $40-\mathrm{mg}$ ${ }^{233} U$ sensitivity for fast neutrons; a system designed specifically for fast-critical-assembly fuel would be considerably smaller.

resulting in a statistical precision of $\sim 0.23 \%(1 \sigma)$. This precision will be degraded by additional error components from electronic instabilities and background fluctuations. Since a more reasonable goal for the measurements is perhaps $1 \%$ precision for a 1-min assay, the intensity of the ${ }^{252} \mathrm{Cf}$ source used for Table A-II could be reduced by an order of magnitude (that is to say, to $50 \mu \mathrm{g}$ ), resulting in a smaller shield and a less costly system.

The application of the Shuffler system to uranium and plutonium fuel mixtures introduces the problem of more than one fissile component, namely, ${ }^{235} \mathrm{U},{ }^{299} \mathrm{Pu}$, and ${ }^{241} \mathrm{Pu}$. To help unravel this problem, the Shuffler's well counter can be used as a passive neutron coincidence counter to determine the effective ${ }^{240} \mathrm{Pu}$ content, defined as

$$
\begin{aligned}
240 \mathrm{Pu}(\text { effective })= & 240 \mathrm{Pu}+1.69^{242} \mathrm{Pu} \\
& +2.54{ }^{238} \mathrm{Pu} .
\end{aligned}
$$




\section{TABLE A-II}

\section{${ }^{252}$ CF SHUFFLER PERFORMANCE DATA FOR 0.5-mg ${ }^{252}$ CF SOURCE}

\section{Irradiation Geometry for 4-L Sample}

Net signal rate ${ }^{\mathrm{a}}$ Background rate ${ }^{\mathrm{a}}$ Sensitivity limit ${ }^{\mathrm{b}}$

\section{Neutron Interrogation}

\begin{tabular}{cl}
\hline Thermal & \multicolumn{1}{c}{ Fast } \\
& \\
1500 counts $/ \mathrm{s}-\mathrm{g}{ }^{235} \mathrm{U}$ & 13 counts $/ \mathrm{s}-\mathrm{g}^{236} \mathrm{U}$ \\
20 counts $/ \mathrm{s}$ & 14 counts $/ \mathrm{s}$ \\
$1.6 \mathrm{mg}{ }^{236} \mathrm{U}$ & $160 \mathrm{mg}^{235} \mathrm{U}$
\end{tabular}

a ('umulative counts reduced by $50 \%$ irradiate-count duty cycle.

"Sensitivity defined as signal equal to $3 \sigma$ of background for a 1 -min measurement.

The coefficients for the ${ }^{242} \mathrm{Pu}$ and ${ }^{238} \mathrm{Pu}$ terms are weighting factors that account for the difference in spontaneous fission-decay constants and neutron emission multiplicities compared with ${ }^{240} \mathrm{Pu}$. Then, if the plutonium isotopic ratios are known, the spontaneous fission rate from the plutonium can be used to obtain the plutonium fissile content, and the active neutron interrogation can be used to obtain the ${ }^{235} \mathrm{U}$ content. Standards containing both ${ }^{235}$ ! and plutonium are used for calibration.

Figure A-8 shows the passive coincidence response for mixed-oxide fuel pellets measured by the Shuffler system. The response is linear, and both the

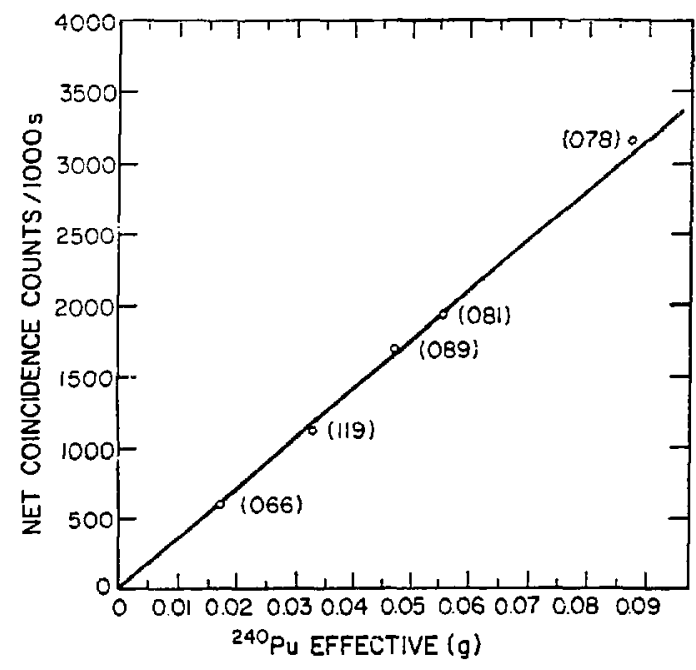

Fig. $A-8$.

Passive neutron coincidence results for the Shuffler system applied to uranium-plutonium mixed-oxide fuel pellets.
Light-Water Reactor $(066,089,081$, and 078$)$ pellets and the Fast-Breeder Reactor (119) pellets fall on the same calibration line because the neutron counting is independent of the pellet's size, density, and uranium content for these small samples.

For the active neutron interrogation of nonmultiplying samples, the response $R$ can be expressed as

$R=A 235 \mathrm{U}+\mathrm{B}^{239} \mathrm{Pu}+\mathrm{C}^{241_{\mathrm{Pu}}}$,

where $\mathrm{A}, \mathrm{B}$, and $\mathrm{C}$ depend on the fission cross sections and the delayed-neutron yields. If the ${ }^{239} \mathrm{Pu}$ and ${ }^{241} \mathrm{Pu}$ contents are known from the passive measurement, and $\mathrm{A}, \mathrm{B}$, and $\mathrm{C}$ are determined from measurements against known standards, then the measured response can be used to determine the ${ }^{236} \mathrm{U}$ content.

In summary, a small Shuffler system could be designed to measure individual ${ }^{235} \mathrm{U}$ plates or fuel drawers with a $1 \%$ precision and $\sim 1$-min measurement times. The same Shuffler's neutron well detector could be used for coincidence counting of the plutonium samples. For drewers containing a mixture of uraniun ${ }_{\perp}$ and plutonium, the combination of active and passive operation modes can be used to obtain both SNM components. However, for this separation, the ${ }^{252} \mathrm{Cf}$ source must be intense enough $(\sim 100 \mu \mathrm{g})$ to override the plutonium passive neutron background with the induced delayed-neutron signal.

Drawers that have received recent irradiations will have a significant gamma-ray background from the induced activity, and any proposed NDA system 
must operate in this background. The ${ }^{3} \mathrm{He}$ detectors used in the passive neutron coincidence detectors and the Shuffler system can operate in a gamma-ray field up to $\sim 1 \mathrm{R} / \mathrm{h}$. If the dose rates are above this level, the sample cavity can be lined with a few centimeters of lead to reduce the gamma dose. The lead will not adversely affect the active or passive neutron methods.

The Shuffler system, compared with other active assay systems employing radioactive sources, is rather large and requires the mechanical complexity of a neutron-source transfer mechanism. However, it covers a wider sample range, is less sensitive to sample matrix materials and gamma-ray backgrounds, and offers better precision and electronic stability. In general, ${ }^{3} \mathrm{He}$ detectors are more stable and less temperature sensitive than scintillator-photomultiplier detectors.

\section{B. Other Active Neutron Assay Techniques}

1. Active Well Coincidence Counter. The AWCC $^{6}$ was designed for the assay of enriched uranium samples ranging in ${ }^{235} \mathrm{U}$ mass from $\sim 100 \mathrm{~g}$ to $5 \mathrm{~kg}$. The system uses a low-intensity $\left(\sim 10^{5} \mathrm{n} / \mathrm{s}\right)$ AmLi neutron source to interrogate the sample, which is located in the interior of a neutron well coincidence counter. The fission reactions induced by the random AmLi neutron source give off coincidence neutrons that are counted in the shiftregister coincidence circuit. ${ }^{7}$ Since the neutron energy of the AmLi source is below the threshold for ${ }^{238} \mathrm{U}$ fission, there is no significant contribution' from the depleted uranium.

The counting rates of the AWCC-type systems are low $(\sim 0.2$ counts $/ \mathrm{s}-\mathrm{g})$, and the accidental pileup is a large fraction of the induced activity, resulting in a relatively poor statistical precision. A 200-s count for a $1-\mathrm{kg}{ }^{235} \mathrm{U}$ canister gives a precision of about $3 \%$ $(1 \sigma)$. Thus, this counter is of primary interest where a larger counting time is available. Also, this type of counter is not applicable to drawers containing plutonium-uranium mixtures because the passive neutron coincidence signal from the plutonium dominates the induced-neutron fission signal from the ${ }^{235} \mathrm{U}$.

2. Random Driver. The Random Driver (RD) system $^{8}$ is similar to the AWCC except that it uses plastic scintillator detectors for coincidence counting of the fast neutrons from induced-fission reactions. The AmLi interrogation source strength is larger $\left(\sim 10^{6} \mathrm{n} / \mathrm{s}\right)$ for the $\mathrm{RD}$ system, and there is less accidental pileup of counts in the accidental channel because of the short ( 40-ns) gate lengths, resulting in a somewhat better statistical precision than with the AWCC for the same counting time. Also, the RD system can measure mixtures of plutonium and uranium fuel plates using a combination of passive and active modes of operation.

A typical neutron coincidéise counting rate for a $1-\mathrm{kg}{ }^{235} \mathrm{U}$ sample is 80 counts/s, giving a statistical precision of $\sim 2 \%(1 \sigma)$ for a 1-min counting time. The measurement times will be significantly longer for mixtures of uranium and plutonium, depending on the uranium fraction.

Drawers that have been irradiated recently in the reactor core will have a significant gamma-ray background level. The plastic scintillator detectors in the $\mathrm{RD}$ are very sensitive to gamma rays, and it may not be possible to shield the instrument adequately from this background.

3. Neutron Generators. Sealed-tube neutron generators could be used as the neutron source for the active verification of critical-assembly fuels. Generators are commercially available that produce either $14-\mathrm{MeV}$ neutrons from the $(\mathrm{D}, \mathrm{T})$ reaction or $2-\mathrm{MeV}$ neutrons from the $(\mathrm{D}, \mathrm{D})$ reaction. The yields from the $(\mathrm{D}, \mathrm{T}) 14-\mathrm{MeV}$ generators are typically $10^{9}$ $\mathrm{n} / \mathrm{s}$, whereas the (D,D) $2-\mathrm{MeV}$ yields are about two orders of magnitude smaller.

Typical assay methods using these tubes induce fission reactions by operating the source in a pulsed mode and counting the induced prompt or delayed neutrons from the sample. For prompt neutron counting, it is normally necessary to use thermalneutron interrogation of the sample to separate the interrogation neutrons from the induced signal neutrons. However, critical-assembly fuel plates have a high fissile density, and thermal-neutron interrogation has the limitation of severe neutron selfshielding in the sample. This method should be used only for a qualitative screening of the fuel.

The fuel drawers often contain large quantities of depleted uranium, making it difficult to use $14-\mathrm{MeV}$ neutron generators because fission reactions are induced in the ${ }^{238} \mathrm{U}$ by the high-energy neutrons. Other neutron sources we have considered have neutron 
energies below the threshold for ${ }^{238} \mathrm{U}$ fission. A large quantity of neutron-spectrum tailoring material surrounding the 14-MeV neutron generator will help reduce this problem. The (D,D) $2-\mathrm{MeV}$ neutron generator has a lower energy, and the reduction of ${ }^{238} \mathrm{U}$ fission is less of a problem; however, the neutron yields are much lower.

A neitron-generator source yield of $\sim 10^{8} \mathrm{n} / \mathrm{s}$ would give about the same counting rates as the 50 . $\mu \mathrm{g}{ }^{252} \mathrm{Cf}$ source. This intensity is probably adequate for pure uranium samples. However, plutonium and uranium mixtures likely will require a higher source strength to override the neutron background from the plutonium. The expected counting precision and measurement times would be roughly the same as given in Sec. V.A for the ${ }^{252} \mathrm{Cf}$ Shuffler of the same source intensity. Neutron generators are difficult to use because they do not have the reliability and stability of operation of radioactive sources.

\section{SUMMARY}

Passive gamma-ray and neutron coincidence methods are adequate for the rapid quantitative verification of plutonium inventories in critical facilities. The passiv, gamma-ray measurement is useful to confirm the ${ }^{239} \mathrm{Pu}$ ard ${ }^{241} \mathrm{Pu}$ isotopic ratios and to determine the length of plates in the contairer when the width and alloy mix are known. For fuels that contain materials with a significant $(\alpha, n)$ yield, such as aluminum, the combination of total and coincidence neutron counting could give a check of the expected plutonium isotopic mixture.
When ${ }^{235} \mathrm{U}$ fuels are present, the ${ }^{252} \mathrm{Cf}$ Shuffler system seems to be the most promising activeneutron method. In the combination active-passive mode, the Shuffler system can be used to verify both uranium and plutonium fuel.

The NDA measurements should be sensitive to the following cases.

(1) Removal of one or more fuel plates from a container or the substitution of plates containing only a portion of the original loading such as the top edge.

(2) Substitution of high- ${ }^{240} \mathrm{Pu}$-content plates for low- ${ }^{240} \mathrm{Pu}$-content plates.

(3) Substitution of radioactive gamma-ray and neutron sources for the plutonium in the container.

(4) Alterations of the geometric configuration within the container to give a higher counting efficiency or multiplication effect, thus masking the removal of part of the plutonium.

The NDA verification should give a quantitative measure of the SNM for the expected configuration of the material. However, if SNM removal has been masked by any of the above cases, the instruments should signal this irregularity. Passive neutron counting takes care of (1), (3), and (4), whereas gamma-ray verification deals with (2), (3), and (4). Therefore, a combination of passive neutron and gamma-ray techniques (possibly in the same instrument) will give a high level of confidence in the verification. For plutonium fuels alloyed with aluminum, the $(\alpha, n)$ passive neutron yield makes the neutron counting sensitive to (2), also. 


\title{
PART II
}

\section{NEW APPROACHES TO RAPID NONDESTRUCTIVE VERIFICATION OF PLUTONIUM FUELS}

\author{
J. T. Caldwell, P. E. Fehlau, S. W. France, A. A. Robba \\ LASL Safeguards Staff, Q-2
}

\section{NDA SCANNING SYSTEM FOR FUEL DRAWERS}

In the event of an international alarm at an IAEAsafeguarded critical facility, the need for a rapid fuel inventory determination is obvious. A promising technique to accomplish this purpose is based on simultaneous rapid gamma and neutron scanning of plutonium-fuel-containing drawers. The system is designed to scan typical fuel drawers at a rate of one or two per minute, with a sensitivity adequate to detect the presence or absence of a typical 1-in.-long plutonium fuel plate in a drawer containing as much as $36 \mathrm{in.} \mathrm{(total)} \mathrm{of} \mathrm{plutonium} \mathrm{fuel} \mathrm{in} \mathrm{one} \mathrm{or} \mathrm{more}$ rows and a variety of coolant, structural, and fertile mockup materials also present in the drawer.

The technique assumes that the plutonium fuel plates in the facility inventory are well characterized, but it does not require that all fuel plates have the same ${ }^{240} \mathrm{Pu},{ }^{241} \mathrm{Am}$, etc., isotopic content. An example of possible fuel inventory variation is shown in Table A-III. Table A-IV shows the measured or calculated neutron and isotope-specific gamma intensities for the plutonium fuel plates listed in Table A-III. The neutron and gamma line

TABLE A-1II

TYPICAL ISOTOPIC VALURS FOR FIVE CLASSFS OF PLUTONIUM FUELS IN A CIRITICAL FACIIITY

\begin{tabular}{|c|c|c|c|c|c|}
\hline Fuel Type & $\begin{array}{c}{ }^{239} \mathrm{Pu} \\
(\%) \\
\end{array}$ & $\begin{array}{c}{ }^{200} \mathrm{Pu} \\
(\%) \\
\end{array}$ & $\begin{array}{c}{ }^{21} \mathrm{Pu} \\
(\%) \\
\end{array}$ & $\begin{array}{l}\text { 24' Am } \\
(\%)\end{array}$ & $\begin{array}{c}\text { Plutonium } \\
\text { Per Inch } \\
\text { (g) }\end{array}$ \\
\hline $\mathrm{Pu} / \mathrm{Al}$ & 95.25 & 4.50 & 0.20 & 0.24 & 34.1 \\
\hline Pu/U/Mo & 90.80 & 8.66 & 0.51 & 0.46 & 20.0 \\
\hline $\mathrm{Pu} / \mathrm{U} / \mathrm{Mo}$ & 87.00 & 11.56 & 1.20 & 0.59 & 31.1 \\
\hline $\mathbf{P u} / \mathbf{A l}$ & 74.20 & 22.33 & 2.86 & 1.80 & 35.3 \\
\hline $\mathrm{Pu} / \mathrm{U} / \mathrm{Mo}$ & 68.70 & 26.40 & 3.39 & 2.19 & 37.7 \\
\hline
\end{tabular}

intensities are tabulated as relative values per inch of fuel plate, with the $\mathrm{Pu} / \mathrm{U} / \mathrm{Mo}$ fuel of $11.56 \%{ }^{240} \mathrm{Pu}$ content arbitrarily designated as the unity response.

Each class of plutonium fuel has a characteristic signature when the three independent quantities (total neutron, ${ }^{239} \mathrm{Pu},{ }^{241} \mathrm{Am}$ ) are considered. Furthermore, based on our experimental measurements with 25 separate fuel plates taken from among the first four classes listed in Table A-IV, the uniformity of signature from plate to plate within a class appears to be quite good. This uniformity is probably due to the excellent quality control required in the manufacture of such plates. The $\mathrm{Pu} / \mathrm{U} / \mathrm{Mo}$ plates have a neutron output consistent with $100 \%$ spontaneous fission, and the $\mathrm{Pu} / \mathrm{Al}$ plates have an additional $\mathrm{Al}(\alpha, \mathrm{n})$ component $(\sim 70 \%$ for the $4.50 \%{ }^{240} \mathrm{Pu}$ plates and $\sim 50 \%$ for the $22.33 \%$ ${ }^{240} \mathrm{Pu}$ plates).

An initial conceptual design of the scanning apparatus required to perform a fuel-drawer inventory measurement is shown in Fig. A-9. Fuel drawers are loaded onto a "conveyor belt" that transports them, first through a collimated fast-neutron detector, and subsequently past a collimated intrinsic Ge or $\mathrm{Ge}(\mathrm{Li})$ gamma detector. For ease and accuracy of drawer identification, we recommend that each drawer be tagged with a "grocery store" laser-scan identification label. This label can also contain information on the drawer's current plutonium contents.

A photocell/laser sensing system reads the label. The drawer ID and the operator's statement of drawer contents are routed to a microprocessor-or minicomputer-based data acquisition system. This system would have the capacity to maintain an upto-the-minute inventory of the contents of all fuel drawers and could maintain the "expected" gamma ray and neutron signatures for every inch of fuel in each drawer as well. 


\section{MEASURED (OR CALCULATFD) NEUTRON AND GAMMA RESPONSES FOR FIVE CLASSES OF PLUTONIUM FUELS}

\begin{tabular}{|c|c|c|c|c|}
\hline Fuel Type & $\begin{array}{l}{ }^{240} \mathbf{P u} \\
(\%)\end{array}$ & $\begin{array}{c}\text { Relative Total } \\
\text { Neutrons per Inch }\end{array}$ & $\begin{array}{l}\text { Relutive Total }{ }^{230} \mathbf{P u} \\
(414 \mathrm{keV} \gamma / \mathrm{in} .)\end{array}$ & $\begin{array}{l}\text { Relative Total }{ }^{241} \text { Am } \\
(662 \mathrm{keV} \gamma / \mathrm{in} .)\end{array}$ \\
\hline $\mathrm{Pu} / \mathrm{Al}$ & 4.50 & $0.73 \pm 0.07$ & $(1.26 \pm 0.13)$ & $(0.42 \pm 0.04)$ \\
\hline $\mathrm{Pu} / \mathrm{U} / \mathrm{Mo}$ & 8.66 & $0.47 \pm 0.05$ & $(0.67 \pm 0.07)$ & $(0.49 \pm 0.05)$ \\
\hline $\mathrm{Pu} / \mathrm{U} / \mathrm{Mo}$ & 11.56 & $1.00 \pm 0.10$ & $1.00 \pm 0.10$ & $1.00 \pm 0.10$ \\
\hline $\mathrm{Pu} / \mathrm{Al}$ & 22.33 & $3.17 \pm 0.32$ & $0.96 \pm 0.10$ & $3.44 \pm 0.30$ \\
\hline $\mathrm{Pu} / \mathrm{U} / \mathrm{Mo}$ & 26.40 & $(2.75 \pm 0.28)$ & $(0.95 \pm 0.10)$ & $(4.47 \pm 0.45)$ \\
\hline
\end{tabular}

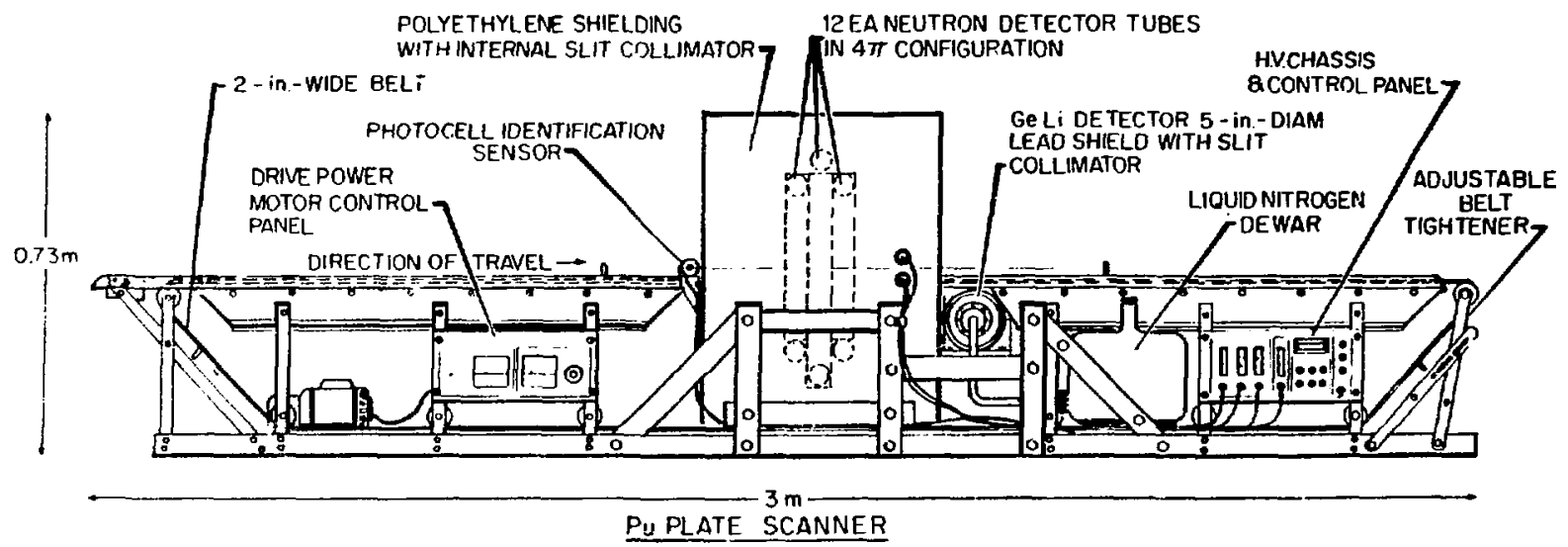

Fig. A-9.

Schematic of proposed neutron/gamma rapid scanning instrument for reactor drawers containing plutonium fuel.

As the scan proceeds, a comparison between the expected and observed signatures is done on line. $(A$ least squares residual analysis would be appropriate.) Pass or fail criteria based on a $\chi$-square analysis can be applied and the drawer's status on the test recorded. Drawers failing the test can be further evaluated by off-line measurements and a running status of the total inventory verification can be maintained.

An initial mockup of the neutron portion of this scan system has recently been built and measurements have been made on representative fuel samples. Total collimated neutron detection efficiencies of $\gtrsim 4 \%$ have been obtained. In this configuration the presence or absence of a 1-in. piece of Pu plate in a douthle row of $\mathrm{Pu}$ plates $24 \mathrm{in}$. long was easily determined using the least squares comparison method and an equivalent scan rate of $1 \mathrm{in} . / \mathrm{s}$.

The conveyor belt scan system lends itself readily to a virtually automated fuel drawer verification system. Hardware could be developed to interface with facility automatic matrix loading/unloading systems. While inspector and operator personnel would certainly be present during the verification process, the automated approach would result in a considerable reduction in personnel radiation dose.

The signatures in Table A-IV show that unique identification of a unit plate does not require high precision in any one characteristic measurement. In fact, there appear to be few instances in which the gamma-ray portion of the overall signature will be required for unique identification. The crucial factor 
in verifying a given fuel drawer will be the shape of its collimated neutron scan. Absolute values of the total neutron count rate are of secondary importance. The absence of an inch of fuel plate somewhere in the drawer matrix appears as a dip in the scan profile.

In summary, a rapid NDA verification system based on simultaneous collimated neutron and gamma scanning of fuel drawers appears feasible. This system is capable (based on prototype system measurements of $\mathrm{Pu}$ fuel plates) of verifying typical $\mathrm{Pu}$ fuel drawers with a sensitivity of better than $1 \mathrm{in}$. of typical fuel plate material at a scan rate of $I$ in./s. The system is microprocessor or minicomputer controlled making possible on-line semiautomatic inventory verification and updated inventory (current status) accounting.

Considerable development of this system is required. Baseline sensitivities have been demonstrated with prototype equipment and typical plutonium fuel plates. Continued development of this equipment is recommended.

\section{VAULT AREA NEUTRON MONITOR}

The international safeguarding of a critical facility will include a vault wherein a large amount of plutonium in the form of plates or other fuel mockup will reside. There might be considerable traffic between the vault and the critical assembly as different reactor configurations are studied.

Possibly, gross diversion of plutonium from such a vault can be detected by placing a grid of neutron detectors on the vault walls and ceilings. A single neutron detector would not be sensitive to a diversion of plutonium far from its location; thus, a grid that monitors the entire vault is necessary to detect diversion from an arbitrary location.

Measurements with a portable ${ }^{3} \mathrm{He}$ neutron detector have been made in a storage vault typical of that expected at a critical facility. The detector was configured so that both fast- (efficiency optimized for fission spectrum) and thermal-neutron fluxes could be measured. Figure A-10 shows a schematic of the vault with measured thermal- and fast-neutron flux values at several locations. All values are given in multiples of the cosmic ray background at $6500 \mathrm{ft}$ elevation (Pajarito Site, LASL). The plutonium storage racks consist of solid concrete "tables" about

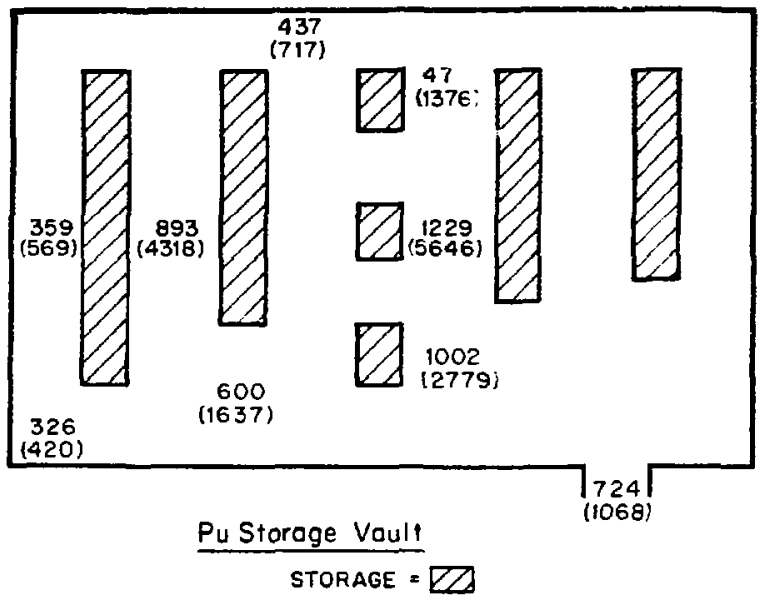

Fig. A-10.

Relative therrial-(fast-) neutron backgrounds measured in a typical plutonium storage vault.

4-5 $\mathrm{ft}$ high and 4-5 ft thick. Holes in the table at 2-ft intervals allow insertion of plutonium-containing canisters.

This highly moderated geometry, the thick concrete tables and the surrounding dirt walls, floor, and roof, result in a reasonably uniform thermalneutron flux around the vault. Measurements were made $\sim 4 \mathrm{ft}$ from the floor. At this height, thermal fluxes varied only a factor of 3.8 at the locations indicated in Fig. A-10. At ceiling height (about 10-12 $\mathrm{ft}$ ), the thermal flux would probably be even more uniform. The corresponding fast fluxes varied a factor of 13.4 in the same locations.

Based on these measurements, we propose that a bare ${ }^{3} \mathrm{He}$ detector grid (sensitive only to thermal flux) be placed near the ceiling, with perhaps a limited number of detectors at lower wall levels. For a vault of the type shown in Fig. A-10, this grid could provide some degree of sensitivity to plutonium diversion. More systematic measurements within such a vault (with experimental movement of plutonium) would be required to both develop and determine the sensitivity of this system.

There are key limitations to such a system. The common practice of storing start-up neutron sources (that is, $\mathrm{PuBe}$ or ${ }^{262} \mathrm{Cf}$ ) in the vaults would have to be eliminated because these sources have neutron outputs equivalent to tens to hundreds of $\mathrm{kg} \mathrm{Pu}$. In any event, the uncontrolled removal or insertion of 
such sources would totally circumvent the system. To be effective, this system would require strict control over all removal and storage of plutonium and a knowledge of the type and neutron output of materials being removed or stored. With strict entry and removal control, the system might have excellent sensitivity. With proper calibration, flux measurements at the $\pm 0.5 \%$ credibility level could be made routinely with ${ }^{3} \mathrm{He}$ tubes. If the vault's nominal storage capacity were $1000 \mathrm{~kg} \mathrm{Pu}$, this credibility level would translate roughly into a $5 \cdot \mathrm{kg}$ $\mathrm{Pu}$ sensitivity.

This system is not likely to be useful within the critical-assembly area. Here, the flux is very sensitive to the multiplication condition and can vary by an order of magnitude during shutdown conditions, depending on shielding configurations, etc.

In summary, vault area plutonium monitoring appears 1 asible using a grid of bare ${ }^{3} \mathrm{He}$ neutron proportional counters attached to ceilings or walls. Correlation of observed neutron count rates with changes in the vault $\mathrm{Pu}$ inventory should be possible at the $\pm 5-\mathrm{kg}$ level in a $1000-\mathrm{kg}$ total inventory. Further development of this system is recommenrind.

\section{REFERENCES}

1. H. O. Menlo' $\epsilon$, N. Ensslin, M.L. Evans, and J. E. Swansen, "A Portable High-Level Neutron Coincidence Counter," in "Nuclear Safeguards Research, Program Status Report, May-August 1976," Los Alamos Scientific Laboratory report LA-6675-PR, p. 10 (January 1977).

2. J. L. Sapir, H. O. Menlove, W. L. Talbert, M. de Carolis, and N. Beyer, "Calibration of the IAEA High-Level Neutron Coincidence Counter for Plutonium Plates in ZPPR Drawers," in "Intense
Neutron Source Facility, January 1-March 31, 1976," Los Alamos Scientific Laboratory report LA-6549.PR, pp. 4-5 (October 1976).

3. R. Sher, "Operating Characteristics of Neutron Well Coincidence Counters," Brookhaven National Laboratory report BNL-50332 (1972).

4. N. Ensslin, M. L. Evans, H. O. Menlove, J. Sapir, and J. E. Swansen, "Thermal-Neutron Coincidence Counting of Large Plutonium Samples," Trans. Am. Nucl. Soc. 27, 182 (1977).

5. H. O. Menlove and T. W. Crane, "A ${ }^{262} \mathrm{Cf}$ Based Nondestructive Assay System for Fissile Material," Nuc. Instru. Methods, to be published (1978).

6. H. O. Menlove, N. Ensslin, C. R. Hatchei, E. Medina, and J. Foley, "Active Well Coincidence Counter," in "Nuclear Safeguards Research and Development Program Status Report, September-December 1977," Los Alamos Scientific Laboratory report LA-7211.PR (August 1978).

7. J. E. Swansen, N. Ensslin, M. S. Krick, and H. O. Menlove, "A New Shift Register for High Count Rate Coincidence Applications," in "Nuclear Safeguards Research Program Status Report, September-December 1976, " Los Alamos Scientific Laboratory repert LA-6788-PR, pp. 4-6 (June 1977).

8. N. Ensslin and D. M. Lee, "Random Driver for DYMAC," in "Nuclear Safeguards Research Program Status Report, May-August 1977," Los Alamos Scientific Laboratory report LA-7030PR, p. 23-27 (March 1978). 


\title{
APPENDIX B \\ INTEGRAL REACTIVITY MEASUREMENTS
}

\author{
J. L. Sapir \\ LASL Safeguards Staff, Q-DO
}

The ability of a reactor or critical assembly to sustain a chain reaction is characterized by the reproduction factor $k$, defined as the ratio of the number of neutrons in any one generation to the number of corresponding neutrons in the immediately preceding generation. The value of $k$ determines the behavior of the neutron population within the assembly. If $k$ is exactly equal to unity, a chain reaction will be exactly maintained, and the neutron population will remain constant with time. Such a system is said to be critical. If $\mathbf{k}<1.0$, the system is said to be subcritical, and any neutron introduced into the system will prcduce chains that eventually die out. If $k>1.0$, the assembly is said to be supercritical, and, after transients die out, the neutron population will rise exponentially. The time for the neutron population to increase by a factor of $e$ in a supercritical assembly is called the stable reactor period. The stable period is related uniquely to the reproduction factor $k$ through the reactivity $\rho$ of the system, which is defined as $(k-1) / k$. A unit of reactivity is the "inhour" (Ih); this is the amount of positive reactivity required to produce a stable period of $1 \mathrm{~h}$. For those more familiar with the $\$$ unit of reactivity, $1 \$ \simeq 350$ Ih in the reference plutonium assemblies.

The reactivity and corresponding period of a system containing fissionable material depends upon the neutron balance or relative extent to which neutrons take part in three main processes: (1) loss or escape from the system (leakage); (2) nonfission absorption in either fuel or nonfissile material such as structure, coolant, or moderator (capture); and (3) fission absorption in fuel (fission). The rates at which these competing processes occur are governed by the size, shape, and composition of the assembly. If no changes have occurred in a given configuration (size, shape, composition, temperature, etc.), it will always have the same reactivity and always produce the same reactor period within the measurement uncertainties. If fuel material is removed from the assembly without additional compensating changes, the reactivity will decrease and such renoval will be observed as an increase in the reactior period or as a change in the critical rod position.

One way to perform an integral reactivity measurement is by establishing a supercritical configuration and measuring the resulting stable reactor period. Periodic measurements of a reference configuration can be used to verify that reactivity and, therefore, material inventory has not changed. Although conceptually simple, the accurate measurement of reactivity by observing the stable reactor period may be difficult to at tain in practice. The waiting time required to reach the stable period may be appreciable, especially at low values of reactivity, making the measurement vulnerable to mechanical, electronic, and thermal drifts during data accumulation. The situation is further complicated in plutonium assemblies where the high neutron source from spontaneous fissions in ${ }^{240} \mathrm{Pu}$ causes high power levels during such measurements and correspondingly high residual radiation levels after the measurements. To avoid these difficulties a method based on "inverse kinetics" has been developed that inters reactivity by analyzing the transient neutron flux without waiting for a stable reactor period. This method requires knowledge of kinetics parameters, that is, effective delayed neutron fractions and neutron lifetimes, and on-line computing capability for data acquisition and analysis. ${ }^{1}$

The effertiveness of integral reactivity measurements as a diversion-detection technique depends upon the sensitivity with which these measurements can detect missing material. Specifically, how much plutonium can be removed before reactivity measurements will detect such removal? The factors influencing the sensitivity to diversion are the reproducibility of the reference reactivity measurements ard the reactivity worth of fue! in the reference a.ssembly.

In fast-critical assemblies, differences in reference reactivity measurements may arise from 
termperature variations, irreproducibility of table clusure and control rod positions, uncertainties in the reactivity measurements, and unavoidable changes in the core composition, particularly the decay of fissionable ${ }^{241} \mathrm{Pu}$. If the temperature of the reactor cell can be held relatively constant and the approach to critical is always the same, uncertainties associat $A$ with temperature variations during reference measurements should be relatively small. Experience at U.S. critical facilities indicates that overall reproducibility of reactivity measurements on the same assembly over a 1- or 2-day period should be better than 1 hh. However, over a longer time period the decay of the fissionable isotope ${ }^{241} \mathrm{Pu}$ (13-yr half-life), present in small quantities in the fuel alloy, produces consistent and observable reactivity lass with time. Figure B-1 shows the results of reactivity measurements made on a large plutonium assembly over the course of several weeks. ${ }^{2}$ The measured reactivity decreased by about $5 \mathrm{Ih}$. Even though the calculated rate of $-0.234 \mathrm{Ih} /$ day agreed well with the measured decrease, the effect of ${ }^{211} \mathrm{Pu}$ decay may produce significant uncertainties in longterm, reference criticality checks. In conjunction with a safeguards program, it will therefore be necessary to accumulate experimental data on reference configurations to determine an accurate experimental value of reactivity loss caused by ${ }^{211} \mathrm{Pu}$ decay.

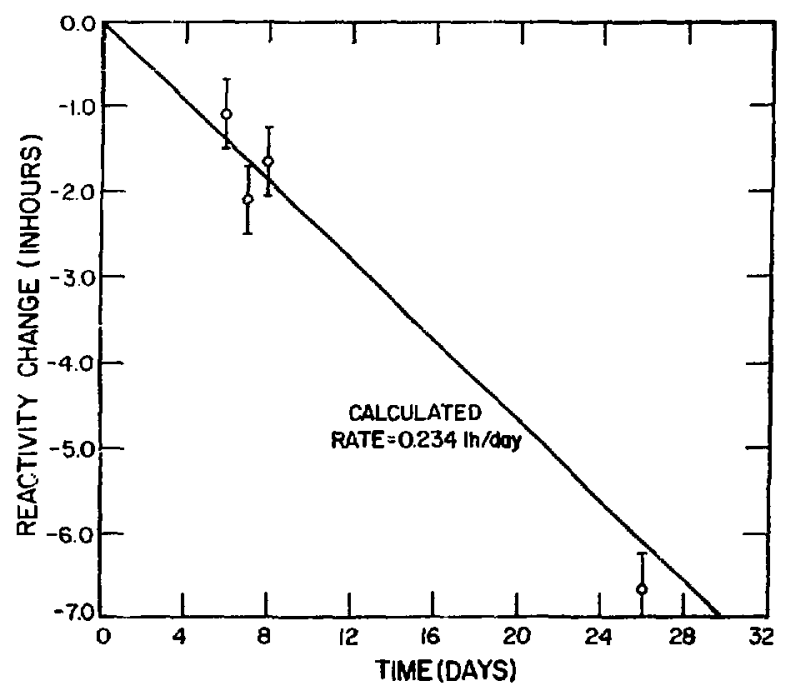

Fig. B-1.

Reference core reactivity loss in a large plutonium assembly.
Based on a review of fast-critical experience and discussions with personnel at ANL, ${ }^{3}$ it appears that in a program designed to use integral reactivity checks for inventory verification, a discrepancy of $\sim 3$ th between the expected and observed reference reactivity can be used to "trigger a safeguards alarm" (that is, require further investigation and explanation) without producing an excessive number of false alarms. However, operational test and evaluation to establish an acceptable alarm limit are necessary.

The amount of fuel that can be removed within the 3-Ih limit depends upon the reactivity worth of fuel plates in the reference core. Although the worth of actual plates has not been measured, extensive mappings of the worths of small ${ }^{299} \mathrm{Pu}\left(1 \%{ }^{240} \mathrm{Pu}\right)$ samples have been performed. We have reviewed such measurements performed from 1971 to 1977 in several plutonium assemblies, as reported in ANL progress reports (ZPR-TM series). These assemblies generally had a core volume of 2400 to $2550 \mathrm{~L}$ and contained $\sim 1050 \mathrm{~kg}$ of plutonium in $\sim 1550$ core drawers. Notable exceptions were Assembly 3-1A, which contained a 3350-L core, and Assembly 7, which incorporated blanket material within the core region and contained $1360 \mathrm{~kg}$ of plutonium.

The reactivity worth of ${ }^{239} \mathrm{Pu}$ strongly depends on its location within the core. Typical radial traverses taken near the core midplane are shown in Fig. B-2 for several of the assemblies. The data plotted in the figure include the extreme values so that additional points not plotted fall within the indicated band. In general, for a homogeneous, uniformly loaded, fast reactor core, the ${ }^{239} \mathrm{Pu}$ worth will peak at the center and monotonically decrease with increasing radius. In some of the configurations, perturbations owing to control rods, sodium experiments, or loading variations caused the worth to dip in the central region. However, in all cases the minimum worth occurred at the outer edge of the core.

Axial worth traverses of ${ }^{298} \mathrm{Pu}$ taken at or near the reactor centerline are shown in Fig. B-3. Except for a configuration in Assembly 5 that simulated fuel slumping during a reactor disassembly accident, the axial worth profiles exhibit the "classical" shape with the minimum core worth occurring at the core edge (axial position $=18 \mathrm{in}$.).

From Figs. B-2 and B-3 it is apparent that the minimum plutonium worth will occur at the outermost corner of the core (in the outer drawers at the 


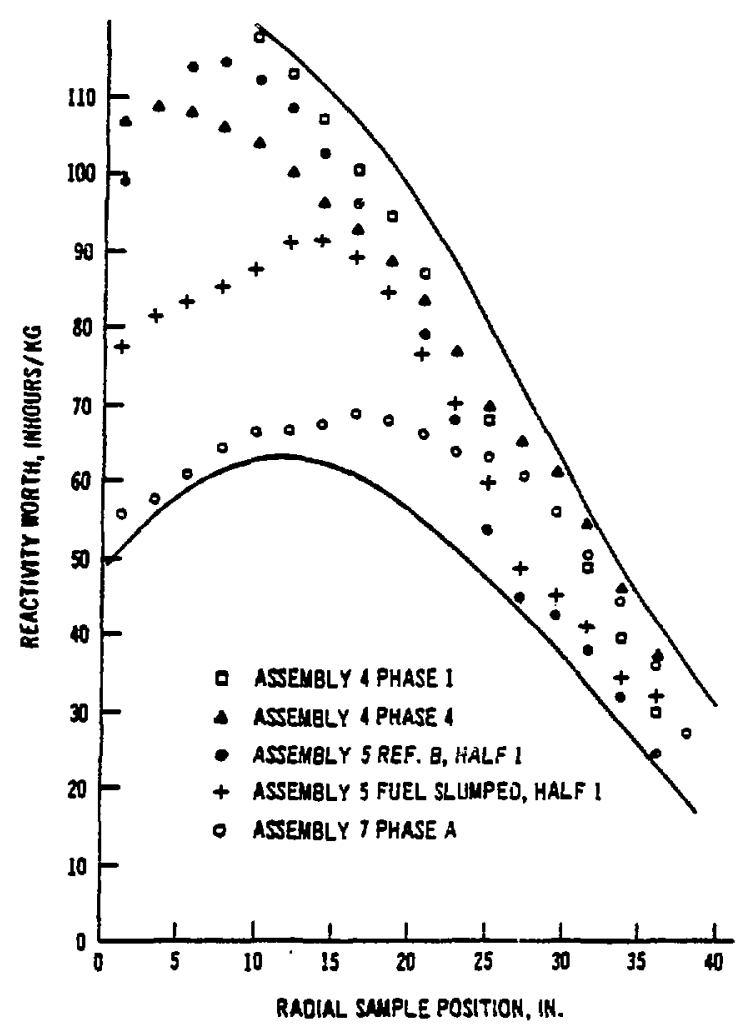

Fig. B-2.

Radial reactivity worth of ${ }^{239} \mathrm{Pu}$ in various plutonium assemblies.

core-axial blanket interface). Although measurements have not been made in this region, the worths there can be estimated by assuming separability of the radial and axial profiles. The data necessary to deduce the minimum plutonium worths are listed in Table B-I, for several assemblies. The approximate outer radial boundary of the core is listed in column 2 of Table B-I, and the corresponding ${ }^{280} \mathrm{Pu}$ midplane worth at the boundary, as obtained from Fig. B-2, is listed in column 3. Column 4 shows the ratio of the minimum-to-central axial worth as obtained from the data in Fig. B-3. The deduced corner worths (that is, the product of columns 3 and 4 , assuming separability) are listed in column 5 . They range from $5.2 \mathrm{Ih} / \mathrm{kg}$ in Assembly 5-Ref. B to $10.0 \mathrm{Ih} / \mathrm{kg}$ in the fuel slumped experiment (Assembly 5 FS).

These worths are essentially point values at the core-axial blanket interface. Because actual plates will extend into regions of higher worth, a more useful number to evaluate safeguards effectiveness

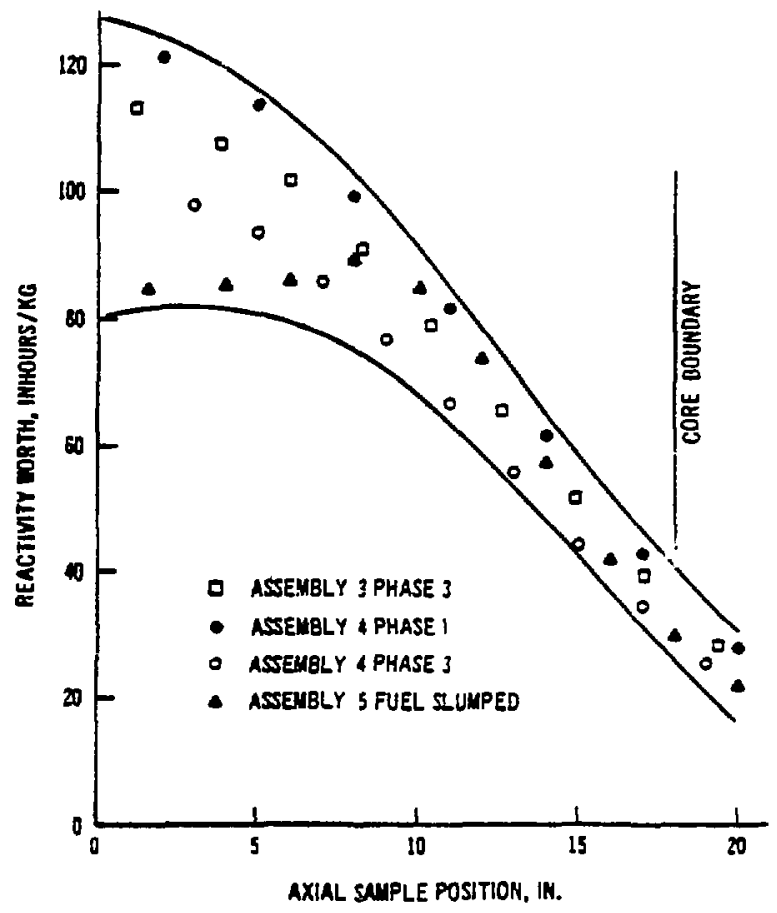

Fig. B-3.

Axial reactivity worth of ${ }^{239} \mathrm{Pu}$ in various plutonium assemblies.

would be the minimum worth averaged over the length of a plate. These values are obtained by averaging the appropriate area of the axial worth profile, and they are given in Table B-I, columns 6 and 7 , for 1 -in. and 4-in. plates, respectiveiy. The corresponding total amount of plutonium equivalent to a 3 -Ih reactivity loss is shown in columns 8 and 9 for 1- and 4-in. plates, respectively. Thus, in previous assemblies for which we have data, ilitegral reactivity checks would have detected removal of $0.28-0.53 \mathrm{~kg}$ of ${ }^{298} \mathrm{Pu}$ in the form of 1 -in. plates $(12-24$ plates) and $0.23-0.42 \mathrm{~kg}$ of ${ }^{239} \mathrm{Pu}$ in 4 -in. plates $(2-4$ plates). These detection sensitivities are for removal of plutonium from minimum worth regions. Smaller amounts removed from other parts of the core would be detectable. The 3 -Ih limit represents a cumulative limit; in other words, it corresponds to the total amount of plutonium that could be removed before positive detection. It does not matter whether this amount of material is removed in 
TABLE B-I

${ }^{239}$ Pu WORTH DATA AND DETECTION SENSITIVITIES FOR 15 PLUTONIUM ASSEMBI IES

\begin{tabular}{|c|c|c|c|c|c|c|c|c|}
\hline $\begin{array}{c}\text { Assembly } \\
\text { No. }\end{array}$ & $\begin{array}{c}\text { Core } \\
\text { Edge } \\
\text { Radius } \\
\text { (in.) }\end{array}$ & $\begin{array}{c}{ }^{239} \mathbf{P u} \\
\text { Edge } \\
\text { Worth } \\
\text { (Ih) } \\
\end{array}$ & $\begin{array}{c}\text { Min/Max } \\
\text { Axial } \\
\text { Worth }\end{array}$ & $\begin{array}{c}{ }^{239} \mathbf{P u} \\
\text { Corner } \\
\text { Worths } \\
\text { (Ih/kg) }\end{array}$ & $\begin{array}{c}\text { Minimum } \\
\text { Worth } \\
\text { 1-in. } \\
\text { Plate } \\
\text { (Ih/kg) } \\
\end{array}$ & $\begin{array}{c}\text { Minimum } \\
\text { Worth } \\
\text { 4-in. } \\
\text { Plate } \\
\text { (Ih/kg) } \\
\end{array}$ & $\begin{array}{c}\text { Detection } \\
\text { Sensitivityc } \\
\text { l-in. } \\
\text { Plate } \\
\text { (kg }{ }^{239} \mathbf{P u )} \\
\end{array}$ & $\begin{array}{c}\text { Detection } \\
\text { Sensitivity } \\
\text { 4-ir. } \\
\text { Plate } \\
\text { (kg }{ }^{239} \mathbf{P u )} \\
\end{array}$ \\
\hline 2 & 36.0 & 25.0 & -. & & & & & \\
\hline $3-1 \mathrm{~A}$ & 40.0 & 22.0 & -. & & & & & \\
\hline $3-1 B$ & 36.0 & 24.6 & 0.31 & 7.6 & 8.1 & 9.8 & 0.37 & 0.31 \\
\hline $3-3$ & -- & -- & 0.31 & & & & & \\
\hline 4-1 & 37.0 & 25.0 & 0.30 & 7.5 & 8.0 & 9.6 & 0.37 & 0.31 \\
\hline $4-2$ & 37.0 & 21.0 & -- & & & & & \\
\hline $4-3$ & 37.0 & 26.7 & 0.30 & 8.0 & 8.5 & 10.2 & 0.35 & 0.29 \\
\hline $4-4$ & 37.0 & 31.9 & -. & & & & & \\
\hline 5 Ref. B ${ }^{a}$ & 37.0 & 20.8 & 0.25 & 5.2 & 5.7 & 7.2 & 0.53 & 0.42 \\
\hline 5 Ref. $B^{b}$ & 37.0 & 20.8 & 0.29 & 6.0 & 6.5 & 8.0 & 0.46 & 0.38 \\
\hline $5 \mathrm{FS}^{\mathrm{a}}$ & 37.0 & 22.8 & 0.35 & 8.0 & 8.8 & 11.1 & 0.34 & 0.27 \\
\hline $5 \mathrm{FS}^{\mathrm{b}}$ & 37.0 & 22.8 & 0.44 & 10.0 & 10.8 & 13.2 & 0.28 & 0.23 \\
\hline $6 \mathrm{EOC}$ & 37.0 & 25.8 & 0.24 & 6.2 & 6.8 & 8.6 & 0.44 & 0.35 \\
\hline $6 \mathrm{BOC}$ & 37.0 & 21.0 & -- & & & & & \\
\hline $7 \mathrm{~A}$ & 39.4 & 21.8 & $-\cdot$ & & & & & \\
\hline
\end{tabular}

${ }^{\text {Axial Half } 1 .}$

'Axial Half 2.

'Based on 3 Ih reactivity loss.

one large removal or in a series of small removals. On the other hand, these detection sensitivities cannot be generalized to other fast-critical assemblies; each case must be evaluated separately.

The above discussion of the use of reactivity measurements to detect diversion assumed only that plutonium fuel was removed from the assembly. There are, however, compensating methods that can increase reactivity and thereby mask fuel removal. These methods include adding moderating materials such as polyethylene, carbon, or beryllium to the core, or moving plutonium from low-worth to high-worth regions. The ease of accomplishing such compensating reactivity changes will depend upon the knowledge and equipment available to the potential divertor. Significant compensating changes would most likely require that the divertor make one or more criticality measurements to assure that the final reactivity is within 3 Ih of the reference value, and hence avoid detection. In domestic facilities, administrative controls prohibit a single insider from performing such experiments. However, from the international viewpoint, it would be relatively simple for the facility operator to make the necessary changes. Thus, the effectiveness and confidence associated with integral reactivity measurements would be higher for domestic inspections than for international ones. Monitoring of the facility's experimental program and reactivity measurements by a permanent IAEA inspector would increase the timeliness and effectiveness of international inspections. In any case, the problems associated with integral reactivity checks do not negate their use, but serve to emphasize the need for complementary and independent verification techniques and sampling plans.

Gross changes in core composition such as the addition of moderator or the rearrangement of fuel affects the neutron flux and other measurable reactor characteristics. Therefore, additional measurements 
could be performed to determine whether such changes have been made. Measurements of reactor parameters such as neutron flux, control-rod worth, reactivity worths of spectrum-sensitive materials (for example, ${ }^{10} \mathrm{~B}$ or ${ }^{238} \mathrm{U}$ ), reaction rates, spectral indices, or leutron lifetime will yield information on gross core changes, even though the overall reactivity is maintained constant. The ease and sensitivity of these measurements will depend on characteristics of the specific facility under consideration.

LASL and Applied Physics Division of ANL have jointly oitlined a study to investigate and quantify the usefulness and sensitivity of reactor measurements as an inventory verification iechnique." The study will determine the following:

- reactivity worth of fuel plates in various parts of the core with special emphasis on the outermost regions where the worth is lowest,

- effectiveness of moderating materials such as polyethylene and graphite in masking fuel removal, and

- sensitivity of complementary reactor measurements to detect compensating reactivity changes.

To minimize the amount of reactor time required, the study will rely initially on calculations. The calculations will determine the distortions caused by fuel removal and compensating reactivity changes as a function of the amount of fuel removed and the distance from the perturbation. The maximum amount of fuel that can be removed before the perturbation is detected can then be estimated. Experiments will subsequently be performed to confirm and normalize the calculations. Special consideration will be given to the need for relatively simple and independent verification techniques required by IAEA inspectors. The results of the study will be reported separately.
The IAEA is currently supporting similar research programs at the Spektr critical facility (small, highly enriched uranium, fast assembly) located at the Lenin Scientific Research Institute in Dimitrovgrad, USSR $^{5,8}$ and at the Japanese FCA facility.

\section{REFERENCES}

1. W. G. Davey and W. C. Redman, Techniques in Fast Reactor Experiments, (Gordon \& Breach, Science Publishers, Inc., New York, 1970) p. 5861, 158-175.

2. R. C. Matlock, R. E. Kaiser, and J. M. Gasidlo, "Reactivity Effects in Critical Facilities Due to Fissile Isotope Decay," 1969 Winter Meeting of the American Nuclear Society, November 1969.

3. R. J. Forrester and G. K. Rusch, Argonne National Laboratory, personal communication, June 1977.

4. P. 1. Amundson, Argonne National Laboratory, personal communication, March 1978.

5. V. M. Gryazev, "Development of Procedures and Techniques for Verifying the Quantity and Composition of Nuciear Materials at the Spektr Fast and Thermal Neutron Critical Facility," translated from Russian, IAEA unpublished data (1974).

6. V. M. Gryazev, "Experiments with a Nuclear Materials Accounting and Control System on the Spektr Fast-Thermal Critical Assembly," translated from Russian, IAEA unpublished data (1976). 


\title{
APPENDIX C
}

\section{AUTORADIOGRAPHY}

\author{
J. L. Sapir \\ LASL Safeguards Staff, Q-DO
}

Autoradiography uses spontaneously emitted radiation (the $60-\mathrm{keV}$ gamma ray from ${ }^{241} \mathrm{Am}$ in the case of plutonium) to form images on $x$-ray film. ANL has developed and used this technique to verify plutonium plates in reactor fuel drawers and vault storage containers. ${ }^{1}$ Exposure time using Kodak AA film (industrial $\mathrm{x}$-ray film) is $\sim 15 \mathrm{~min}$ for reactor drawers and $\sim 45 \mathrm{~min}$ for vault canisters.

In a fast-critical assembly there may be sufficient clearance between the contents of a drawer and the supporting matrix above it to insert a strip of prepackaged film without removing the drawer or the fuel plates. Figure $\mathrm{C}-1$ is a composite photographic print of several autoradiographs performed on fuel drawers inside a fast-critical assembly. ${ }^{*}$ The drawer shown in Fig. C-1A contains a single row of standard 0.25 -in-thick fuel plates. Figure C-1B shows a drawer containing two rows of three plates each. In both cases, the image of the fuel plate edges is clearly defined. Figure C-1C shows an autoradiograph of a drawer with no fuel in it, but with a drawer containing fuel in the matrix position above it. The absence of fuel is apparent. Although a very faint image of the fuel in the drawer above is visible, the steel matrix wall attenuates the gamma radiation so that a significant image is not produced.

For verification of plutonium plates inside storage canisters, the film was placed beneath the aluminum canister without opening the canister or removing it from its vault position. Figure $\mathrm{C}-2$ shows a canister filled with twenty-four 4-in. plates. Each plate image has a contribution from both direct and scattered radiation. The image of the 4 outside plates is lighter than the 20 interior plates because plates with only 1 neighbor have less scattered

"The autoradiographs in this appendix are photographic copies of prints. which were in turn reproduced from the original $x$ rays. Because of reproduction losses in the photographic steps, information in these figures is not as well defined as in the original film. Comments in the text are based on viewing the original film or the initial prints.
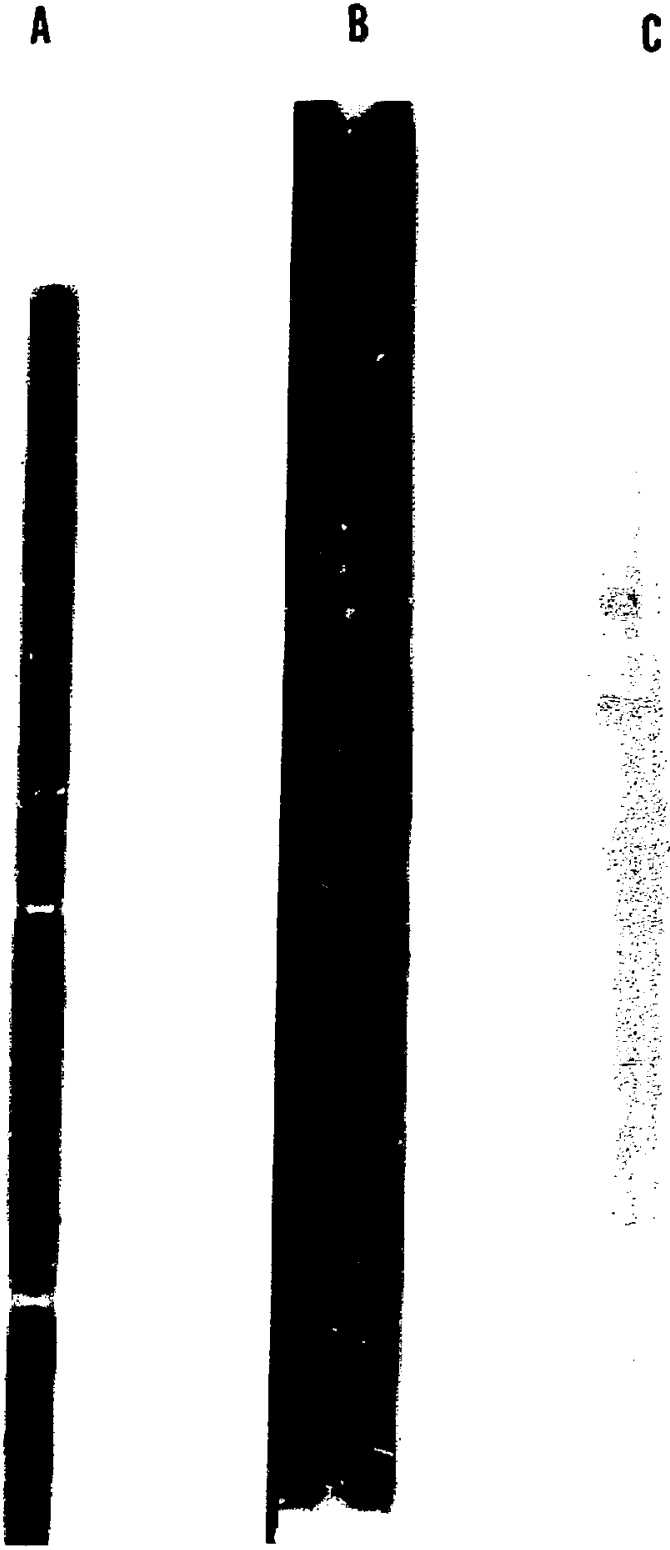

\section{Fig. C-1.}

Composite print of autoradiographs from fuel drawers in the reactor. 


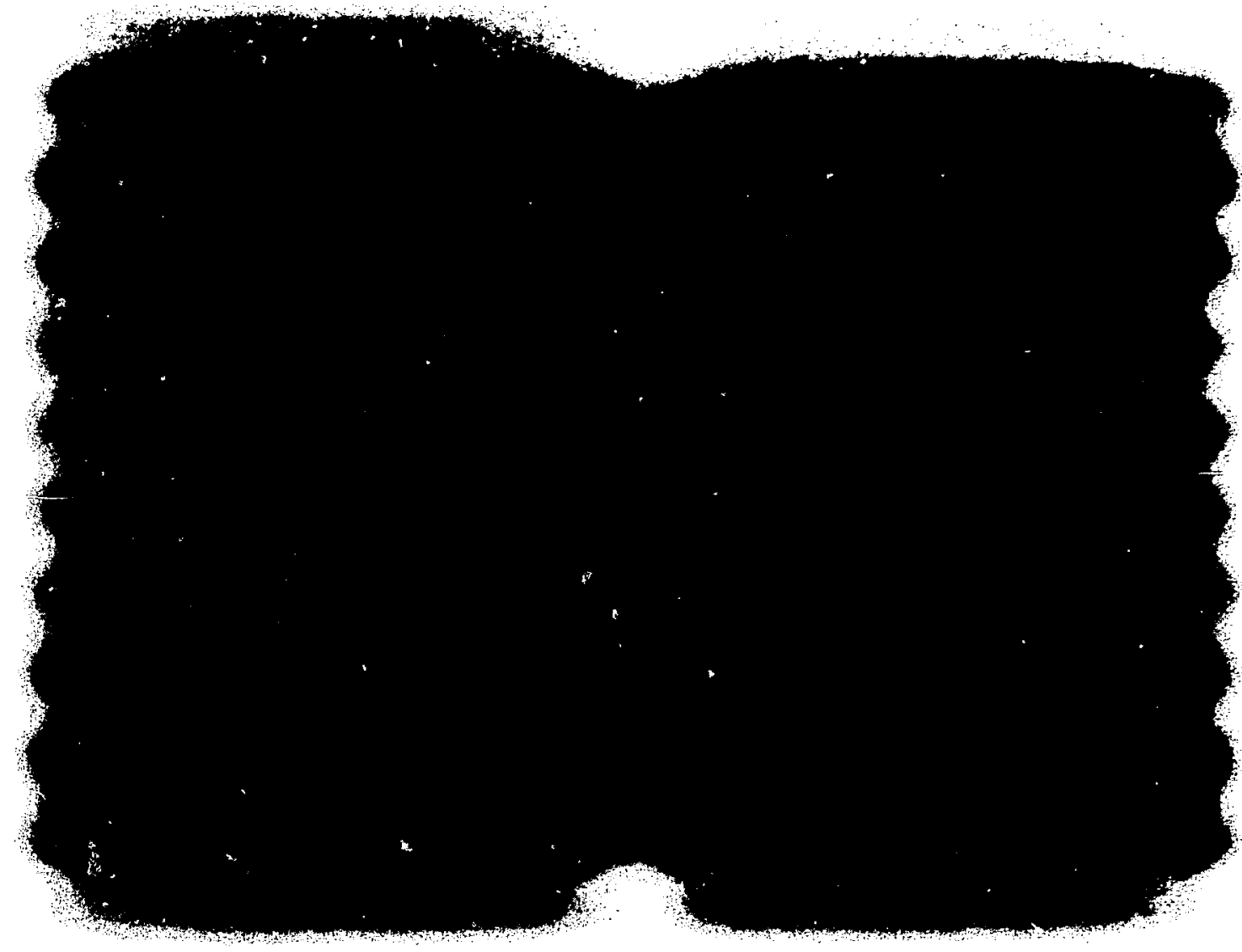

Fig. C-2.

Autoradiograph of a storage canister containing twenty-four 4-in. plutonium fuel plates.

radiation contributing to their image density. Figure C. 3 shows a partially filled canister. The missing plate (third from the bottom, left side) is easily detected. Again the plate images on the outside are less dense. Figure $\mathrm{C}-4$ shows the results of replacing a fuel plate with a stainless steel "dummy" (center, right side). An image of the dummy plate is formed by scattered radiation from its neighbors. However, because the dummy plate emits no radiation, its image is ?ess dense than that of a normal fuel plate. Note that the images of the plates adjacent to the dummy are also less dense than normal because there is no scattered radiation from the dummy. Thus, the neighbors have about the same image density as outside plates. The effect of substituting lead or uranium plates for plutonium fuel plates is the same as that shown for stainless steel. Substitution of low-Z material such as aluminum will give a result more nearly resembling a vacancy. Although radiographs of canisters are not quite as unambiguous or as simple to interpret as radiographs of fuel drawers, a trained inspector should be able to confirm the number of fuel plates in a canister.

Autoradiography was used at a large, U.S. critical facility in May 1977 to verify the entire inventory of 0.25 -in.-thick plutonium fuel plates. At that time the reactor was empty, and all plates were stored in the vault. That exercise required 5 man-days to expose and process the film and 1 day to read and interpret the film.

In November 1977, autoradiography was used to verify the contents of fuel drawers, in situ, at 


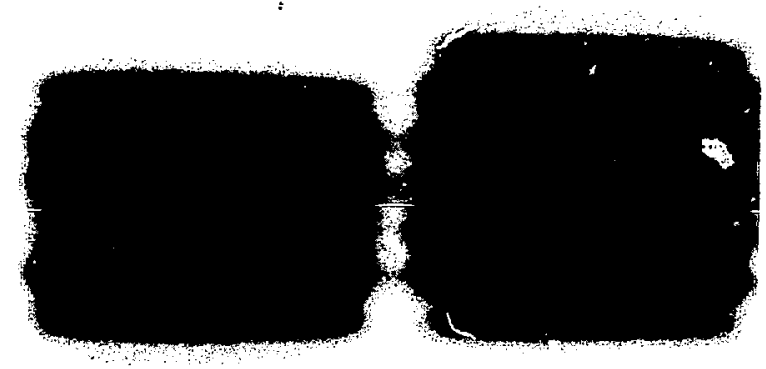

Fig. C.3.

Autoradiograph of a partially' filled storage canister with a missing plate lleft side, third position from bottom). another large U.S. facility. ${ }^{2}$ A total of 386 drawers were examined. The film placement, exposure, and removal were performed by two people working together for $6 \mathrm{~h}$. The processing and subsequent film reading each required approximately $1 \mathrm{man}$ day. One of the people taking the inventory received a radiation dose of $80 \mathrm{mR}$, essentially all betagamma.

The operation was hampered by the presence in some drawers of oversized irori oxide plates, which caused a tight fit and prevented full insertion of the filmstrip. It was estimated that by revising the insertion procedure based on experience gained during the operation, the effurt per drawer could be reduced by $\sim 50 \%$. Thus, an experienced team of two people working between the assembly matrix halves probably can insert, expose, and retrieve film at an average rate of 80-100 fuel drawers per hour.

Autoradiography can confirm the presence of plutonium fuel plates and detect missing plates, substitution of dummy (nonradioactive) plates, or substitutions of plates of a different length. Because it can be performed in place and in parallel, it is a

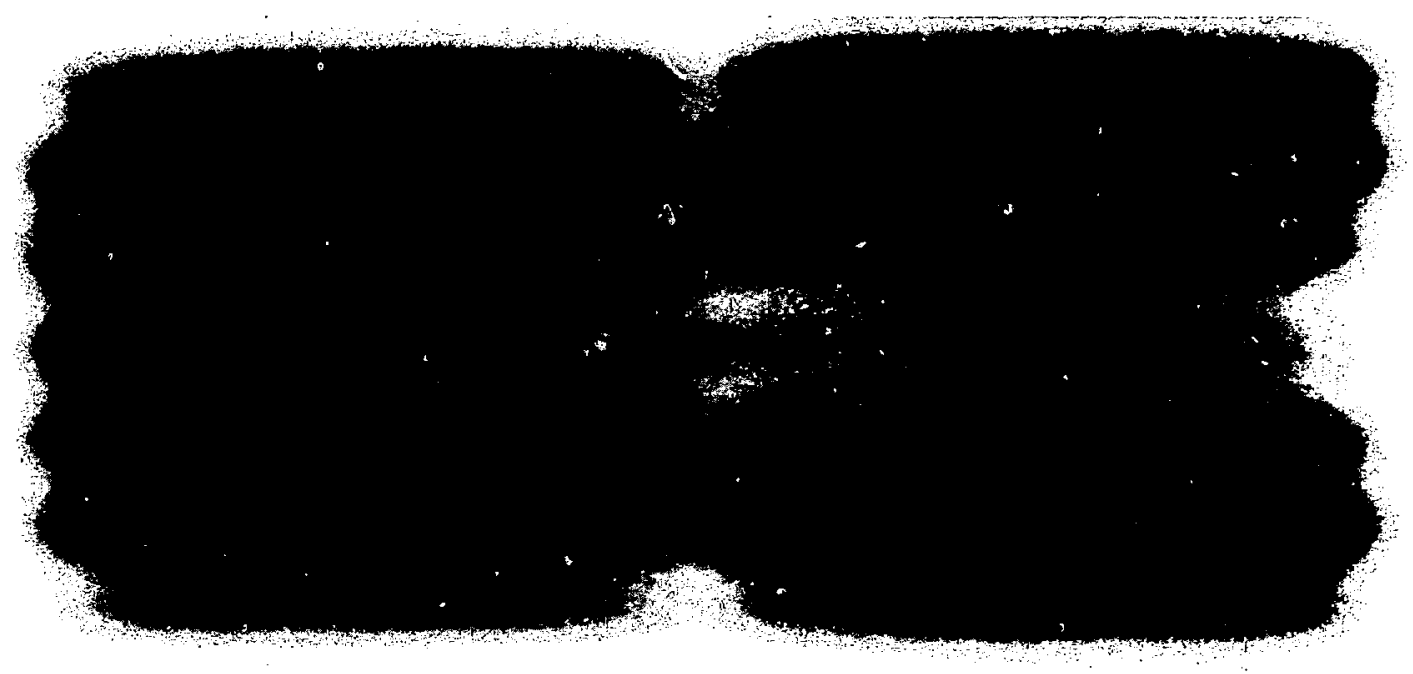

Fig. C-4.

Autoradiograph of a partially filled storage canister with a dummy solid stainless steel plate in the center of the right side. 
relatively rapid inventory method and causes a minimum of interference with normal reactor operations.

The technique, however, has some limitations. The need for processing the film before it can be read may pose a problem to the IAEA. Will the film be processed at the facility or outside the country? Taking the film back to Vienna for processing would seriously reauce the timeliness of this technique.

Because of the low gamma-ray energy and corresponding high self-absorption, autoradiography is essentially a surface measure and does not verify total plutonium content. Furthermore, as presently applied, it does not uniquely identify plutonium, but only identifies the presence of a sufficiently intense radioactive source. These disadvantages should not negate the use of autoradiography, hut they should serve to emphasize that it must be used in conjunction with other, independent verification techniques. Autoradiography of plutonium-bearing fuel material is being studied in the Program for U.S. Assistance to IAEA Safeguards (Subtask A.35). ${ }^{3}$ This subtask will investigate the applicability of autoradiography to international safeguards and will develop procedures for inspectors to implement this technique.

Autoradiography of fuel drawers containing enriched uranium plates is not currently practicable but may be in the future. The technique has been demonstrated for uranium oxide fuel elements. ${ }^{4}$ Ex- posure times to produce an equivalent image from enriched uranium are $\sim 200$ times longer than for plutonium. In addition, the high-energy beta radiation from the ${ }^{236} \mathrm{~Pa}$ daughter of ${ }^{238} \mathrm{U}$ contributes to the image density and results in poor sensitivity to ${ }^{236} \mathrm{U}$ concentration. Use of filters to absorb the beta radiation and image-intensification screens to reduce exposure time are being studied by ANL.

\section{REFERENCES}

1. S. B. Brumbach and R. B. Perry, "Autoradiographic Technique for Rapid Inventory of Plutonium-Containing Fast Critical Assembly Fuel," Argonne National Laboratory report ANL-77-67 (October 1977).

2. S. B. Brumbach, Argonne National Laboratory, personal communication, April 1978.

3. "Program for Technical Assistance to IAEA Safeguards," Second Program Plan, United States Department of Energy/Safeguards \& Security, Subtask A.35 (March 10, 1978).

4. S. B. Brumbach and R. B. Perry (ANL), "Autoradiographic Techniques for Rapid Inventory of Reactor Fuel," Trans. Amer. Nucl. Soc. 27, 190 (1977). 


\title{
APPENDIX D
}

\section{SAMPLING PLANS AND DATA ANALYSIS METHODS FOR INVENTORY VERIFICATION}

\author{
D. D. Cobb \\ LASL Safeguards Staff, Q-4
}

\section{INTRODUCTION}

Statistical sampling plans and statistical techniques for data analysis are key elements of inspection strategies for verification of SNM inventories. Inspection strategies for verifying discrete item inventories have been developed during the past several years and have been reported in the safeguards literature. (See Refs. 1-4 and the references therein.) The purpose of a carefully designed inspection strategy is to detect the misappropriation of a goal quantity of SNM by any strategy of diversion. Diversion strategies include all combinations of the following.

1. Relatively large (whole-item) removals, including the possibility of replacement with lower grade or inert material;

2. Relatively small (fractional) removals with or without replacement; and

3. Records falsification, including deliberate misstatements of the inventory or of the uncertainty in the operator's estimate of the inventory.

To implement a particular inspection plan, the inspection team first must examine the operator's inventory records and stratify the inventory into classes of uniquely identified and similar items. This stratification depends on factors such as the physical forms of SNM present in the inventory, the quantity of SNM in each item, the types of measurements available to the inspectors, and the total planned inspection effort. Once items and classes of items have been defined, the inspection effort should be optimized to counter the various diversion strategies; in general, a more sophisticated diversion strategy requires a more intensive inspection effort for detection. For example, whole-item removals with replacement by inert material might be detected using a go-no-go measurement. Detection of fractional removals might require more sen. sitive measurements and more sophisticated data analysis techniques. On the other hand, it is likely that more of the inventory must be examined to detect the diversion of a goal quantity of SNM in whole-item removals than in fractional removals because a smaller number of whole-item removals is required to reach the diversion goal.

Items are called defects if they contain either more or less SNM than the amount stated by the operator. Relatively large item defects that are detectable on a go-no-go basis are referred to as attributes defects. The go-no-go measurement is called an attributes measurement. Attributes sampling consists of statistical sampling plans and the associated measurements designed to detect attributes defects. Similarly, variables sampling is designed to detect relatively small item defects, referred to as variables defects, using quantitative (assay-type) measurements. In the sequel, we describe a combined attributes and variables sampling scheme ${ }^{1-4}$ applicable to verification of fuel inventories in large critical facilities.

A numerical example of the fuel-inventory verification in a fictitious critical assembly illustrates the application. We assume that the assembly loading consists of similar fuel drawers, each containing the same number and types of fuel plates, and that the arrangement of the fuel plates and diluent materials is the same in each drawer. The inspection team regards each fuel drawer as an item, and, in this idealized example, all the fuel drawers are lumped into a single class.

The operator's inventory record indicates that the population of fuel drawers in the reactor is $\mathrm{N}=$ 1000. The matrix location of each drawer is specified. Based on the fuel manufacturer's original assay data, the operator states that the average amount of SNM in each drawer is $\mu_{0}=1 \mathrm{~kg}$ and that the variation from drawar to drawer in the amount 
of SNM is $\sigma_{0}= \pm 1 \%$. This variation is due to nonuniformities in manufacturing the fuel plates. Thus, the total $S N M$ inventory to be verified is $N_{\mu_{0}}=1000$ $\mathrm{kg}$, and the inspection strategy is designed to verify this total inventory by examining the operator's values $\mathrm{N}, \mu_{0}$, and $\sigma_{0}$.

\section{THE ATTRIBUTES LIMIT}

An overlap region exists between what is to be considered a large (attributes) defect and what is a small (variables) defect. Clearly, this separation depends on the sensitivity of the verification measurements. An attributes defect discovered in a single item may be sufficient cause to reject the inventory. This imposes a severe penalty on the facility, perhaps requiring shutdown and complete physical inventory. Therefore, a sharp boundary, called the attributes limit $(\gamma)$, is established between attributes and variables defects; that is, attributes defects are those $\geq \gamma \mu_{0}$, whereas variables defects are those $\left\langle\gamma \mu_{0}\right.$. The attributes limit is set at a level sufficiently high that the probability of misidentifying an item as an attributes defect is essentially zero (go-no-go measurement). The value of $\gamma$ is usually $\gtrsim 4 \sigma$, where $\sigma$ is the standard deviation of a single measurement.

For example, consider the case in which an NDA instrument is used to verify the quantity of SNM in fuel drawers. A one-point calibration of this instrument is performed using mockup drawers as calibration standards representative of the reactor loading. The actual (but unknown) mass of SNM to be measured in a particular fuel drawer is $M$. The population of SNM in fuel drawers is assumed to be distributed normally with mean $\mu$ and relative standard deviation (RSD) $\sigma_{M}$. Then $M$ can be written as

$M=\mu(1+\delta)$,

where $\delta$ is a zero-mean, Gaussian random variable with RSD $\sigma_{\mathrm{M}}$.

Likewise, the measured value $m$ can be written as

$$
m=M(I+\varepsilon+\eta) \text {, }
$$

where $\mathrm{c}$ is the relative random error of measurement introduced by the measurement imprecision and $\eta$ is a relative systematic error introduced primarily by the inaccuracy of calibration. It is assumed that $\epsilon$ and $\eta$ are both zero-mean, Gaussian random variables with RSDs $\sigma_{\epsilon}$ and $\sigma_{\eta}$, respectively. ${ }^{3} \mathrm{Com}$ bining the population and measurement models [Eqs. (D-1) and (D-2)] gives, to first order in small quantities,

$$
m=\mu(1+\delta+E+n) \text {. }
$$

where the RSD of a single measurement is

$$
\sigma_{m}=\left(\sigma_{M}^{2}+\sigma_{\varepsilon}^{2}+\sigma_{n}^{2}\right)^{1 / 2} .
$$

In our example, the following values are estimated for the RSDs: $\sigma_{M}=1 \%, \sigma_{\mathrm{t}}=2 \%$, and $\sigma_{\eta}=1 \%$. The RSD of a single drawer measurement is $\sigma_{\mathrm{m}}=2.4 \%$, and a reasonable choice for the attributes limit is $\gamma=10 \%$. Therefore, if a measurement indicates that the amount of SNM in a reactor fuel drawer differs by more than $10 \%$ from the nominal 1-kg amount, that drawer is an attributes defect. On the other hand, if all measured differences are found to be $<10 \%$, the drawer measurements are analyzed collectively to decide if these small differences are significant variables defects or are merely the result of expected random fluctuations. Note that we are assuming implicitly that the same NDA instrument is used to look for both attributes and variables defects, but this need not be the case.

\section{ATTRIBUTES SAMPLING}

\section{A. Sampling Distributions}

Consider a population of $\mathrm{N}$ items of which $\mathrm{D}$ are defects. The ratio $F=D / N$ is called the defective fraction. A sample of $n$ items is selected at random from the population. The probability $P(d / n)$ that the sample of size $n$ contains a number $d$ of the $D$ 
defects in the population is given by the hypergeometric distribution ${ }^{3.5}$

$$
P(d / n)=\left(\begin{array}{l}
N-D \\
n-d
\end{array}\right)\left(\begin{array}{l}
D \\
d
\end{array}\right) /\left(\begin{array}{l}
N \\
n
\end{array}\right),
$$

where $\left(\begin{array}{l}\mathrm{X} \\ \mathrm{X}\end{array}\right)=\mathrm{Y} ! /[\mathrm{X} !(\mathrm{Y}-\mathrm{X}) !]$ is the combination of $\mathrm{Y}$ items taken $\mathrm{X}$ at a time. Denoting the fraction of defectives in the sample by $f=d / n$, the mean and variance of $f$ are given by

$$
E(f)=F
$$

and

$\operatorname{Var}(f)=F(1-F)(N-n) /[n(N-1)]$.

The probability that the sample contains none of the defects $(d=0)$ is $P(0 / n)$. This is the probability of nondetection, called the miss probability $\beta_{0}$. From Eq. (D-5), $\beta_{0}$ is given by

$B_{0}=\left(\begin{array}{c}N-D \\ n\end{array}\right) /\left(\begin{array}{l}N \\ n\end{array}\right)$.

The probability of detection $\left(\mathrm{DP}_{0}\right)$ is given by

$D P_{0}=1-B_{0}$.

Note that $\mathrm{DP}_{0}$ is the probability that the sample contains one or more of the defects in the population. Even one defect in the sample is unacceptable. In statistical terminology, the acceptance number is zero.

It is standard practice ${ }^{1-4}$ to approximate the hypergeometric distribution [Eq. (D-5)] by the binomial distribution when $n \ll N$ and $D \ll N$, giving a form for $\beta_{0}$ that is somewhat easier to calculate than Eq. (D-7), namely,

$B_{0}=(1-n / N)^{D}$.

Equation (D-9) is often used to design attributes sampling plans. However, it is instructive to consider a more precise interpretation of the binomial distribution. The hypergeometric distribution and the form of $\beta_{0}$ in Eq. (D-7) apply if one is sampling without replacement from a finite population. This means that, once an item has been selected for the sample, it is removed from the population (that is, checked off the inventory list) and is no longer a candidate for further sampling. On the other hand, if the population is very large, or if the sampling is performed with replacement so that every item in the population is a candidate each time an item is selected for the sample, the probability $P(d / n)$ is described exactly by the binomial distrilution ${ }^{3.5}$

$P(d / n)=\left(\begin{array}{l}n \\ d\end{array}\right) F^{d}(1-F)^{n-d}$.

where again the defective fraction is $F=D / N$. The mean and variance of the sample defective fraction, $f=d / n$, are

$E(f)=F$

and

$\operatorname{Var}(f)=F(1-F) / n$.

The probability of a miss when the acceptance number is zero, that is, the probability of finding zero defects in the sample, is given by

$B_{0}=(1-F)^{n}$.

The detection probability $\mathrm{DP}_{0}$, that is, the probability of finding one or more defects in the sample, is again given by $\left(1-\beta_{0}\right)$.

Values of detection probability calculated fe an inventory of 1000 items using the exact hypergeometric and binomial forms [Eqs. (D-7) and (D.12)] are compared in Table D-I. The probabilities differ by $<10 \%$ (relative) for $n \leqslant 300$ ( $30 \%$ of the SNM inventory). Note that the probabilities in Table D-I apply to any size population as long as the ratio $n / N$ is relatively small. Figure D-1 compares the binomial approximation for sampling without replacement [Eq. (D-9)] with the exact binomial expression for replacement sampling [Eq. (D-12)]. The curves of detection probability are practically the same if the sample size is $<30 \%$ of the inventory. 
TABLE D-I

\section{PROBABILITY THAT A SAMPLE OF SIZE n WILL INCLUDE AT LEAST ONE OUT OF D DEFECTS IN A POPULATION OF 1000}

\begin{tabular}{|c|c|c|c|c|c|c|c|c|}
\hline \multirow{3}{*}{$\begin{array}{c}\text { Sample } \\
\text { Size, } \\
\text { n }\end{array}$} & \multicolumn{8}{|c|}{ Number of Defects, D } \\
\hline & \multicolumn{4}{|c|}{ Hypergeometric Distribution } & \multicolumn{4}{|c|}{ Binomial Distribution } \\
\hline & 1 & 2 & 5 & 10 & 1 & 2 & $\mathbf{5}$ & 10 \\
\hline 50 & 0.05 & 0.10 & 0.23 & 0.40 & 0.05 & 0.095 & 0.22 & 0.39 \\
\hline 100 & 0.10 & 0.19 & 0.42 & 0.68 & 0.095 & 0.18 & 0.39 & 0.63 \\
\hline 150 & 0.15 & 0.28 & 0.56 & 0.80 & 0.14 & 0.26 & 0.53 & 0.78 \\
\hline 200 & 0.20 & 0.36 & 0.68 & 0.91 & 0.18 & 0.33 & 0.63 & 0.87 \\
\hline 300 & 0.30 & 0.51 & 0.84 & 0.98 & 0.26 & 0.45 & 0.78 & 0.95 \\
\hline$\$ 00$ & 0.40 & 0.64 & 0.93 & $1.00^{\mathrm{a}}$ & 0.33 & 0.55 & 0.865 & 0.98 \\
\hline 500 & 0.50 & 0.75 & 0.97 & 1.00 & 0.39 & 0.63 & 0.92 & 0.99 \\
\hline 600 & 0.60 & 0.84 & 0.99 & 1.00 & 0.45 & 0.70 & 0.95 & $1.00^{\mathrm{a}}$ \\
\hline 800 & 0.80 & 0.96 & $1.00^{\mathrm{a}}$ & 1.00 & 0.55 & 0.80 & 0.98 & 1.00 \\
\hline 1000 & 1.00 & 1.00 & 1.00 & 1.00 & 0.63 & 0.86 & 0.99 & 1.00 \\
\hline
\end{tabular}

aProbabilities $>0.995$ have been rounded to 1.00 .

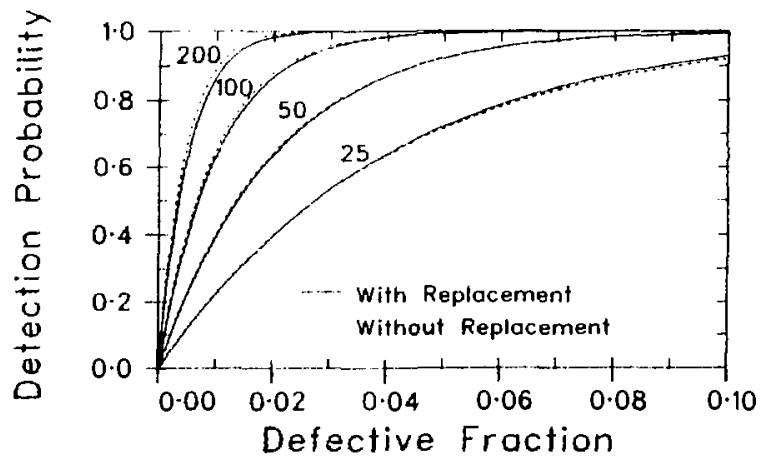

Fig. D-1.

Probability of detecting attributes defects for four sample sizes; $N=1000$, acceptance number $=0$.

\section{B. Attributes Sampling Plan}

Consirier the case in which the reactor inventory is routinely sampled for verification. Each n-size sample is drawn without replacement, but it is returned co the population before the next scheduled sampling verification. We want to analyze each sample for diversion and also to combine successive samples for analysis. This procedure is justified if changes in the reactor inventory during normal operation are relatively small.

These considerations suggest the concept of a mixed sampling plan in which items in each sample are drawn without replacement, but samples from successive periods are combined with replacement. ${ }^{6}$ It is easy to show that the miss probability $\beta_{0}$ for the mixed sampling plan is

$\beta_{0}=\left[\left(\begin{array}{c}N-D \\ n\end{array}\right) /\left(\begin{array}{l}N \\ n\end{array}\right)\right]^{q}$,

where $\mathrm{n}$ is the size of each sample, $\mathrm{q}$ is the number of successive samples to be combined, and $D$ is the number of attributes defects initially in the population. The total number of items sampled in $q$ periods is just qn.

Values of detection probability calculated using the hypergeometric form [Eq. (D-13)] differ by $1 \%$ or less (absolute) from corresponding values obtained using the binomial form [Eq. (D-12)] for replacement sampling, at least over the parameter ranges given in Table D-I. Therefore, using the binomial form in Eq. (D-12) to compute sample sizes for routine attributes sampling guarantees that the samples are the same size as (or slightly larger 
TABLE D-II

\section{ATTRIBUTES SAMPLE SIZES REQUIRED FOR FOUR VALUES OF DETECTION PROBABLITY DP WHEN SAMPLING WITH REPLACEMENT $\mathrm{N}=1060$, ACCEPTANCE NUMBER $=0$}

Detection

Probability

\begin{tabular}{|c|c|c|c|c|c|c|c|}
\hline bability & 1 & 2 & $\overline{5}$ & 8 & $\overline{10}$ & 20 & 50 \\
\hline 0.5 & 693 & 346 & 138 & 86 & 69 & 34 & 14 \\
\hline 0.7 & 1203 & 601 & 240 & 150 & 120 & 60 & 23 \\
\hline 0.9 & 2301 & 1150 & 459 & 287 & 229 & 114 & 45 \\
\hline 0.95 & 2994 & 1496 & 598 & 373 & 298 & 148 & 58 \\
\hline
\end{tabular}

Number of Defects, D

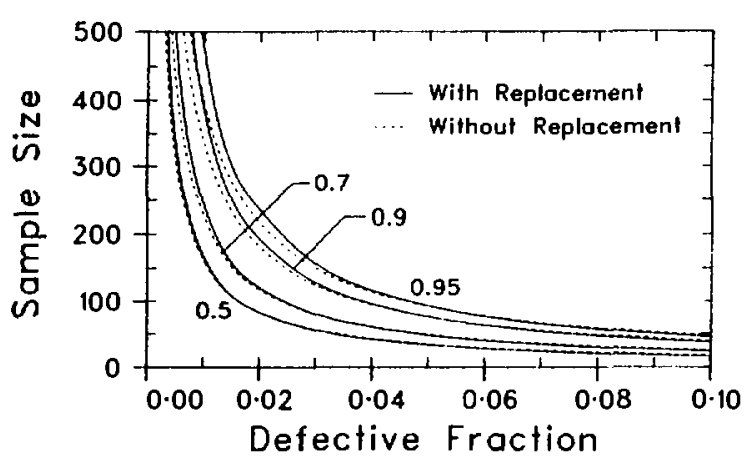

Fig. $D-2$.

Attributes sample sizes for four values of detection probability; $N=1000$, acceptance number $=0$.

than) those that would be calculated using the hypergeometric forms [Eq. (D-7) or (D-13)].

Table D-II and Fig. D-2 give the samples size required for values of detection probability $\mathrm{DP}_{0}$ as a function of the number of attributes defects in the population. For example, assume that the desired detection threshold for each routine sample is set at $8 \mathrm{~kg}$ and $50 \%$ probability of detection. The required sample size is set for the most difficult detection case, namely diversion of the goal quantity in wholeitem removals. From Table D-II, a sample size of 86 out of $1000(8.6 \%$ of the SNM inventory) meets these requirements. Note that $8 \mathrm{~kg}$ or more diverted ir. partial removals of any size larger than the attributes limit $(\gamma=10 \%)$ would correspond to a detection probability of at least $50 \%$ for a sample size of 86 out of 1000 . For example, if $8 \mathrm{~kg}$ are diverted by removing $0.4 \mathrm{~kg}$ from each of 20 fuel drawers, the detection probability is $82 \%$ for a sample size of 86 out of 1000 . If $20 \mathrm{~kg}$ are diverted by removing $1 \mathrm{~kg}$ from each of 20 fuel drawers, the detection probability is also $82 \%$.

\section{Nonroutine Attributes Sampling}

So far, we have considered attributes sampling for routine inventory verification. The detection threshold for each sample was set relatively high. that is, $8 \mathrm{~kg}$ at $50 \%$ detection probability. The response to an alarm condition may include more intensive sampling to determine the amount of unaccounted-for SNM.

If the surveillance system indicates that SNM is being diverted or if defects are discovered diring routine inventory, an alarm condition indicates possible diversion, but the amount of missing material is essentially unknown. It may be desirable to proceed to a level of sampling that is intermedirate between routine sampling and $100 \%$ inventory verification to determine whether the amount of SNM unaccounted for exceeds the significant quantity. Special inventory verification procedures should include sufficient sampling of the reactor inventory to detect the diversion of a significant quantity or more in whole-item removals (worst case) with at least $95 \%$ probability.

Whatever the source of the alarm, it can be concluded that at least one defect has been positively 
identified already, and additional sampling is required to search for more defects. In statistical sampling, we "accept" a single defect and look for additional defects before rejecting the inventory. The sample size required for this intermediate level of sampling depends on the probability that a sample of size $n$ will contain two or more defects; that is, the acceptance number equals one in this case. This probability is given by

$\mathrm{DP}_{1}=1-\beta_{1}$,

where $\beta_{1}=P(0 / n)+P(1 / n)$ is the probability of a miss; that is, the probability that a sample of size $n$ will contain either 0 or 1 defects.

From the binomial distribution for sampling with replacement [Eq. (D-10)], $\beta_{1}$ is readily found to be

$B_{1}=(1-F)^{n}[1+n F /(1-F)]$.

Jaech ${ }^{3}$ gives the following approximate $\beta_{1}$ form for sampling without replacement,

$B_{I}(I-n / N){ }^{D}[I+n D /(N-D-n)]$.

Curves of detection probability $\mathrm{DP}_{1}$ are compared in Figs. D-3 and D-4 for sampling with and without replacement. Tables D-III and D-IV give the sample sizes required for values of $\mathrm{DP}_{1}$ when sampling from a population of 1000 items, respectively, with and without replacement.

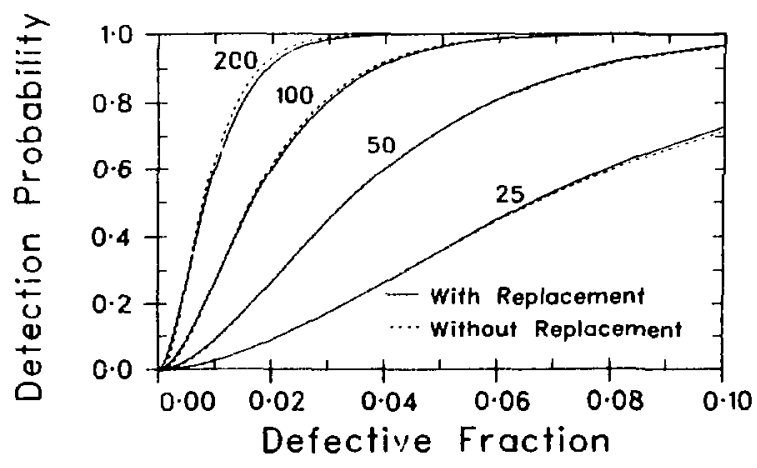

Fig. D-3.

Probability of detecting attributes defects for various sample sizes; $N=1000$, acceptance number $=1$.

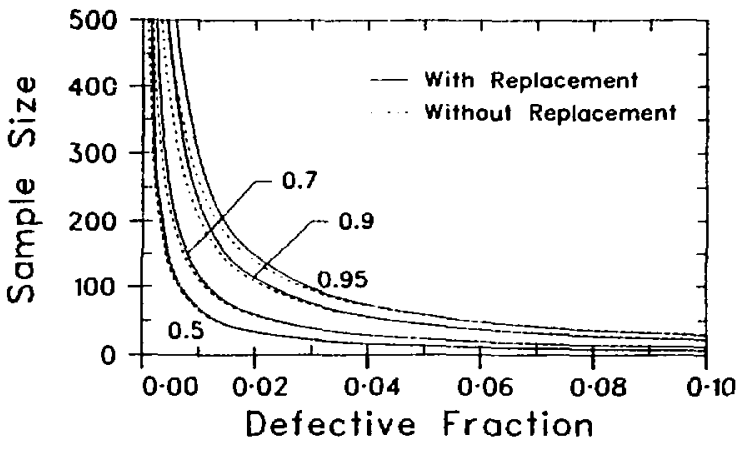

Fig. D-4.

Attributes sample sizes for four values of detection probability; $N=1000$, acceptance number $=1$.

For example, if an attributes defect is discovered during routine sampling and it is desired to determine if $8 \mathrm{~kg}$ or more are missing from the reactor with at least $95 \%$ probability, the required sample size is 592 out of 1000 ( $59.2 \%$ of the SNM inventory) when sampling with replacement and 472 out of $1000\left(47.2 \%\right.$ of the in ${ }^{\prime}$ ntory) when sampling without replacement. If an additional attributes defect is discovered, the inspection team must presume that a relatively large quantity of SNM is missing, and it then will complete the inventory. If another defect is not found, there is strong evidence that less than the significant quantity is missing from the reactor inventory.

\section{VARIABLES SAMPLING}

Data analysis methods are described here for the detection of relatively small, variables defects. The emphasis is on application of standard statistical methods to the verification of inventories in large critical facilities. Details of the statistical methods are given in Refs. 2-5 and 7-11.

Each item defect is assumed to be sufficiently small that it is masked by the intrinsic uncertainty in a single verification measurement. Thus, the basic problem is to analyze collectively the assaytype measurements made on a statistical sample of items to decide whether a significant shift has occurred in the inventory. 
TABLE D-III

\section{ATTRIBUTES SAMPLE SIZES REQUIRED FOR FOUR VALUES OF DETECTION PROBABILITY DP, WHEN SAMPLING WITH REPLACEMENT $\mathbf{N}=1000$, ACCEPTANCE NUMBER $=1$}

\begin{tabular}{|c|c|c|c|c|c|c|c|}
\hline \multirow{2}{*}{$\begin{array}{l}\text { Detection } \\
\text { Probability }\end{array}$} & \multicolumn{7}{|c|}{ Number of Defects, D } \\
\hline & 2 & $\mathbf{5}$ & 8 & 10 & 20 & 50 & 100 \\
\hline 0.5 & 839 & 336 & 210 & 168 & 84 & 34 & 17 \\
\hline 0.7 & 1219 & 488 & 305 & 244 & 122 & 49 & 24 \\
\hline 0.9 & 1944 & 777 & 485 & 388 & 193 & 77 & 38 \\
\hline 0.95 & 2371 & 947 & 592 & 473 & 236 & 93 & 46 \\
\hline
\end{tabular}

TABLE D-IV

\begin{tabular}{|c|c|c|c|c|c|c|c|}
\hline \multirow{2}{*}{$\begin{array}{r}\text { ATTRIBUTES SAI } \\
\text { DETECTION PROBABI } \\
\mathbf{N}= \\
\text { Detection } \\
\text { Probability }\end{array}$} & \multicolumn{7}{|c|}{ Number of Defects, D } \\
\hline & 2 & 5 & 8 & 10 & 20 & 50 & 100 \\
\hline 0.5 & 709 & 315 & 203 & 164 & 84 & 35 & 18 \\
\hline 0.7 & 838 & 424 & 280 & 228 & 119 & 50 & 25 \\
\hline 0.9 & 950 & 585 & 408 & 338 & 182 & 77 & 39 \\
\hline 0.95 & 976 & 659 & 472 & 396 & 218 & 93 & 48 \\
\hline
\end{tabular}

\section{A. Sampling Error}

A fundamental assumption concerning statistical inferences made about population parameters (for example, the mean and variance) from measurements made on a sample is that the sample is representative of the population. Whether this assumption is true depends on the sampling procedure and the homogeneity of the population. If the sample is not truly representative, estimates of population parameters based solely on sample measurements will be in error. This sampling error is separate from the intrinsic errors of measurement, and all variables analysis techniques are degraded by it.

For variables sampling the greatest inhomogeneity in the inventory that need be considered occurs when a significant quantity of SNM is diverted in removals at or just below the at- tributes limit $\gamma$; that is, a diversion strategy that at tempts to attain a significant quantity of SNM in removals of size $\gamma$ will introduce the smallest number of variables defects into the inventory and. hence, will produce the greatest inhomogeneity. Any strategy of removals smaller than $\gamma$ must introduce more defects into the inventory, making it relatively more homogeneous. Note that the smaller $\gamma$ is, the more homogeneous the population will be for a significant diverson in $\gamma$-size removals.

The probability that a sample of size $\mathrm{n}$ will contain one or more defects is given by Eq. (D-12) for replacement sampling. Table D.V shows the dependence of this probability on the parameters $\gamma$ and $n$ for a diversion of $8 \mathrm{~kg}$ in $\gamma$-size removals from an inventory of 1000 items each containing $1 \mathrm{~kg}$ of SNM. For example, the probability is $>0.999$ that a sample of 86 out of 1000 will contain one or more defects if $8 \mathrm{~kg}$ have been diverted in $0.1-\mathrm{kg}(10 \%)$ removals. 
TABLE D-V

\section{PROBABILITY THAT A SAMPLE OF SIZE n WILL CONTAIN ONE OR MORE DEFECTS AFTER DIVER.SION OF $8 \mathrm{~kg}$ IN $\gamma$-SIZE REMOVALS$$
\mathrm{N}=1000, \mu=1 \mathrm{~kg}
$$

\begin{tabular}{|c|c|c|c|c|c|c|c|c|}
\hline \multirow{2}{*}{$\begin{array}{c}\text { Attributes } \\
\text { Limit, } \gamma \\
\end{array}$} & \multirow{2}{*}{$\begin{array}{c}\text { No. of } \gamma \text { - } \\
\text { Size Defects } \\
\text { for } 8 \mathbf{~ k g}\end{array}$} & \multicolumn{7}{|c|}{ Sample Size, n } \\
\hline & & 25 & 50 & 75 & $86^{\mathrm{a}}$ & 100 & 200 & 300 \\
\hline 0.05 & 160 & 0.99 & $1.00^{\mathrm{b}}$ & $1.00^{b}$ & $1.00^{\mathrm{b}}$ & $1.00^{\mathrm{b}}$ & $1.00^{\mathrm{b}}$ & $1.00^{\mathrm{b}}$ \\
\hline 0.10 & 80 & 0.88 & 0.98 & 1.00 & 1.00 & 1.00 & 1.00 & 1.00 \\
\hline 0.20 & 40 & 0.64 & 0.87 & 0.95 & 0.97 & 0.98 & 1.00 & 1.00 \\
\hline 0.30 & 27 & 0.50 & 0.75 & 0.87 & 0.91 & 0.94 & 1.00 & 1.00 \\
\hline 0.50 & 16 & 0.33 & 0.55 & 0.70 & 0.75 & 0.80 & 0.96 & 0.99 \\
\hline
\end{tabular}

${ }^{\text {aC }}$ Corresponds to $50 \%$ probability of detecting $8 \mathrm{~kg}$ diverted in whole-item removals.

'Probabilities $>0.995$ have been rounded to 1.00 .

A sample size of 86 and $\gamma=10 \%$ are the base case values used in the example of routine sampling for attributes defects. It is highly probable that such a sample will contain some number of variables defects if a significant quantity has been diverted in removals smaller than the attributes limit. The question remains whether the sample is truly representative of the population. It is representative if the defective fraction $f$ in the sample is equal to the defective fraction $F$ in the population.

The standard deviation of $f$ for replacement sam. pling [Eq. (D-11)] is

$\sigma_{E}=[F(1-F) / n]^{1 / 2}$.
Values of $\sigma_{\mathrm{r}}$ are given in Table D-VI. When sampling without replacement, $\sigma_{\mathrm{r}}$ is smaller by the factor

$(1-n / N)^{1 / 2}$.

For example, diversion of $8 \mathrm{~kg}$ in $0.1-\mathrm{kg}$ removals from an inventory of $10001-\mathrm{kg}$ items gives $\mathrm{F}=0.08$ and $f=0.08 \pm 0.029$ for a sample of 86 items.

Confidence intervals can be established for $f$ using standard statistical tables. ${ }^{12}$ If $\boldsymbol{n}$ is sufficiently large and $F \gtrsim 0.1$, the binomial distribution can be approximated by the normal distribution, in which case intervals centered at $F$ of size $\pm \sigma_{\mathrm{r}}$ or $\pm 2 \sigma_{\mathrm{f}}$ are $\sim 68$ and $\sim 95 \%$ confidence intervals, respectively.

TABLE D-VI

\section{STANDARD DEVIATION OF THE SAMPLE FRACTION DEFECTIVE $f$ SAMPLING WTIG REPLACEMENT}

\section{True Fraction Defective, $\mathbf{F}$}

0.02

0.04

0.08

0.16

0.32

\begin{tabular}{|c|c|c|c|c|c|}
\hline \multicolumn{6}{|c|}{ Sample Size, $n$} \\
\hline 50 & 86 & 100 & 200 & 300 & 500 \\
\hline & 0.015 & 0.014 & 0.010 & 0.008 & 0.0 \\
\hline 028 & 0.021 & 0.020 & 0.014 & 0.011 & 0.00 \\
\hline 038 & 0.029 & 0.027 & 0.019 & 0.016 & 0.012 \\
\hline 052 & 0.040 & 0.037 & 0.026 & 0.021 & 0.016 \\
\hline 066 & 0.050 & 0.047 & 0.033 & 0.027 & 0.021 \\
\hline
\end{tabular}


Sampling errors can be large. They will not produce false alarms if it is true that defects of any size in the inventory are unacceptable. However, sampling errors can reduce the probability of detecting variables defects.

\section{B. Tests for Outliers}

Measurement outliers should receive special attention because they may be caused by small removals. Even though the sampling error may be large, it is likely that the sample will contain small defects if many small removals have occurred. Therefore, any discrepant drawer measurement should be investigated.

A useful test for outliers is given in Ref. 3 for the case where the population is distributed normally, but the mean and variance are unknown. This socalled T test (not to be confused with Student's $t$ test) is applied by forming the test statistic

$T_{i}=\left(\bar{m}-m_{i}\right) / s_{m}$,

where $m_{1}$ is the measured value of SNM in the ith drawer, and $\overline{\mathrm{m}}$ and $\mathrm{s}_{\mathrm{m}}$ are the sample mean and sample standard deviation given by

$\bar{m}=\sum_{i=1}^{n} m_{i} / n$

and

$s_{m}=\left[\sum_{i=1}^{n}\left(m_{i}-\bar{m}\right)^{2} /(n-1)\right]^{1 / 2}$.

A table of critical values of the $\mathrm{T}$ statistic is given in App. $E$ of Ref. 3. For example, if $n=86$ and $3.33 \leq T_{1}$ or $T_{1} \leq-3.33$ (two-sided test), the probability is $5 \%$ that the ith drawer is not a defect.

The T test will not detect small removals uniformly distributed over the inventory (that is, a bias). If there is a bias, one can check for outliers and bias using the Gaussian statistic

$$
z_{i}=\left(\mu_{0}-m_{i}\right) /\left(\sigma_{m} \mu_{0}\right),
$$

where $\mu_{0}$ is the operator's value for the nominal amount of SNM in each drawer and $\sigma_{m}$ is the RSD of a single drawer measurement [Eq. (D-4)].

The test of the statistic $Z$ is referred to as a normal test. In practice this test could be used at a relatively low level of significance to search for measurement outliers possibly indicating the presence of variables defects. For example, if all measurements falling outside the interval $\mu_{0}\left(1 \pm 2 \sigma_{\mathrm{m}}\right)$ are flagged for further investigation, we expect $\sim 5 \%$ of the drawer measurements to fall outside these 2- $\sigma$ limits even if there is no diversion. However, replicate drawer measurements and measurement of individual fuel pieces in such drawers would be made to verify that, in fact, no small removals have occurred.

Acceptance of the effort required to make additional measurements on drawers that produce discrepant measurements is one alternative to increasing the routine sample size to reduce the sampling error; that is, this procedure is effective in the detection of small defects even though the sampling error may be large. Although the test is applied at a low level of significance, false alarms are minimized because positive verification of missing fuel is required from the replicate drawer fuel-piece measurements to verify the alarm condition.

\section{Standard Tests of the Mean and Variance}

The problem is to verify the operator's estimates $\mu_{0}$ and $\sigma_{0}$ of the true quantities $\mu$ and $\sigma_{\mathrm{M}}$, based on sample data. Figure D-5 illustrates the procedure of hypothesis testing when the measurements are distributed normally (normal test). The null hypothesis $\left(\mathrm{H}_{0}\right)$ is that the true value of the test statistic is zero. The Gaussian curve centered at zero represents the probability of occurrence of measured values of the test statistic when $\mathrm{H}_{0}$ is true. The alternative hypothesis $\left(\mathrm{H}_{1}\right)$ is that the true value is different from zero. The Gaussian curve centered at +3 represents the possible outcomes of measurement when $H_{1}$ is true (true mean $=+3$ in the case shown). A critical value called the alarm limit (AL) is established. If the test statistic is less than $\mathrm{AL}$, we ac(sept hypothesis $\mathrm{H}_{0}$ (one-sided rest); if it exceeds $\mathrm{AL}$, we reject $\mathrm{H}_{0}$ and conclude that diversion is likely. 


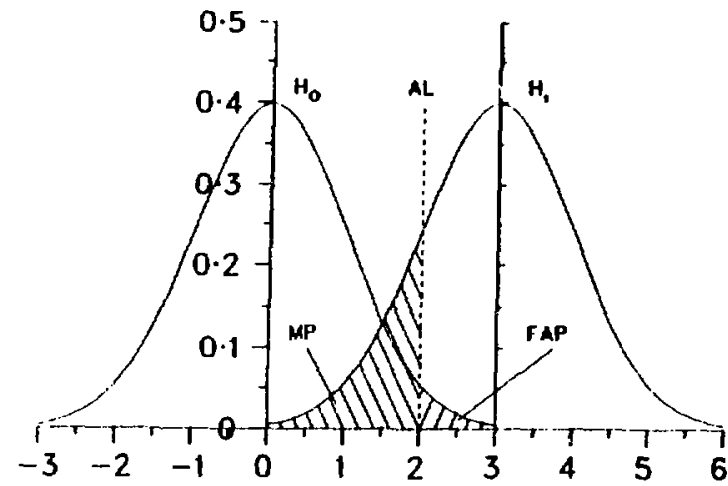

Deviation, Sigma Units

Fig. D-5.

Probability of occurrence of measured values for hypotheses $H_{0}$ and $H_{1}$.

If the measurement distributions for $\mathrm{H}_{0}$ and $\mathrm{H}_{1}$ are widely separated, the probability of a wrong decision is very small. That is the case of go-no-go (attributes) measurement. If the difference is relatively small, the distributions overlap appreciably and two types of incorrect decisions may be made. We may conclude that there is diversion when, in fact, there is none. This is referred to as an error of type I. The probability of a type I error, usually denoted by $\alpha$, corresponds to the shaded area in Fig. D-5 labelled FAP for "false alarm probability." The other incorrect decision is to conclude that there is no diversion when, in fact, there is. This is called an error of type II. The probability of a type II error, usually denoted by $\beta$, corresponds to the shaded area in the figure labelled MP for "miss probability."

The central problem in detection is to minimize the value of $\beta$ for an acceptable value of $\alpha$. Figure D-6 shows the dependence of $\alpha$ on alarm limit for a one-sided normal test. Values of $\alpha$ for a two-sided test are just twice those shown. The value of $\alpha$ is often called the level of significance of the test. The power of the test is the probability of detection (1 B). Figure D-7 shows the power of a normal test as a function of the test statistic for several choices of the alarm limit, that is, at various levels of significance. For example, if the alarm limit is set at $2 \sigma$, the significance of a two-sided test is $\sim 5 \%$. If diversion occurs at the $2-\sigma$ level, the corresponding

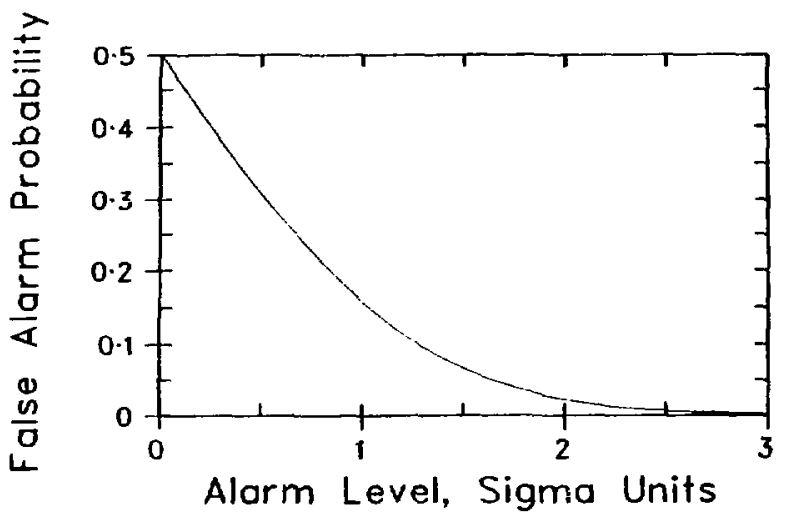

Fig. D-6.

Dependence of the false alarm probability on the choice of alarm limit.

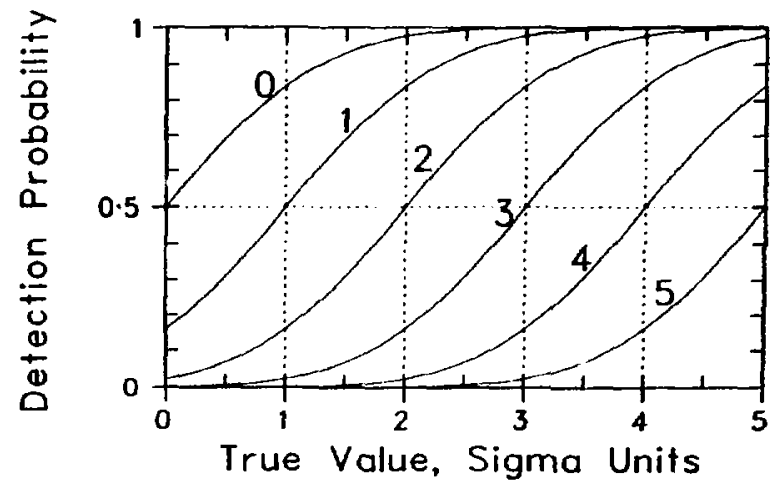

Fig. $D$-7.

The power of a normal test for several choices of alarm limit.

detection probability is $50 \%$. Likewise, the probability of detecting a diversion at the 4- $\sigma$ level is $\sim 98 \%$.

1. Test of the Mean, o Unknown. The standard test in this case is Student's $t$, in which the test statistic is ${ }^{3,9}$

$t=\left(\mu_{0}-\overline{\mathrm{m}}\right) / \mathrm{s}_{\text {而 }}$.

The quantity $s_{\bar{n}}$ is the standard deviation of the sample mean,

$s_{\bar{m}}=s_{m} / \sqrt{n}$. 
The sample mean $\overline{\mathbf{m}}$ and the sample standard deviation $s_{m}$ are given in Eq. (D-18). Values of the $t$ distribution are given in standard tables. ${ }^{12}$ The normal approximation can be used for $n \gtrsim 20$. For example, if $n=86$ and the alarm limits of a two-sided tests are $\pm 2 \mathrm{~s}_{\overline{\mathrm{m}}}$, the significance level of the test is $\sim 5 \%$. Common practice to minimize false alarms is to establish warning limits at $\pm 2 \mathrm{~s}_{\overline{\mathrm{m}}}$ and action limits at $\pm 3 \mathrm{~s}_{\mathrm{m}}(0.25 \%$ level of significance).

Student's $\mathrm{t}$ is a test for bias. It is degraded by biases in the measurements. One source of measurement bias is the inaccuracy of calibration. If calibration error is known to be significant and if it can be treated as a Gaussian random variable with known mean and standard deviation (Sec. II), the following normal test of the mean will perform better than Student's test.

2. Test of the Mean, a Known. The normal test for bias uses the Gaussian statistic

$$
\bar{z}=\left(\mu_{0}-\bar{m}\right) /\left(\sigma_{\bar{m}} \mu_{0}\right) \text {, }
$$

where $\sigma_{\overline{\mathrm{m}}}$ is the RSD of the mean. Using the measurement model of Sec. II, $\sigma_{\bar{m}}$ is given by

$\sigma_{\overline{\mathrm{m}}}=\left[\frac{1}{n}\left(\sigma_{M}^{2}+\sigma_{\varepsilon}^{2}\right)+\sigma_{\eta}^{2}\right]^{1 / 2}$.

where $\sigma_{M}$ is the true RSD of $3 N M$ in the fuel drawers, which the operator estimates to be $\sigma_{0}$, and $\sigma_{t}$ and $\sigma_{n}$ are measurement-error RSDs, which are estimated by the inspection team. For example, if $\mathrm{n}=86, \sigma_{0}=1 \%, \sigma_{t}=2 \%$, and $\sigma_{n}=1 \%$, the estimate of $\sigma_{\bar{m}}$ is $1.03 \%$. A $2-\sigma$ warning limit and a 3- $\sigma$ action limit for deviations from the operator's estimate of the mean $\mu_{0}$ would be $\pm 2.06 \%$ and $\pm 3.09 \%$, respectively.

Examination of Eq. (D-23) indicates that $\sigma_{\overrightarrow{\mathrm{m}}}=$ $\sigma_{m}$ (that is, the RSD of a single drawer measurement) if $\mathrm{n}=1$, and $\sigma_{\overline{\mathrm{m}}} \approx \sigma_{\eta}$ if $\mathrm{n}$ is sufficiently large. Thus, the sensitivity of the normal test to small shifts in the mean is limited by the calibration-error RSD $\sigma_{\eta}$. In turn, $\sigma_{\eta}$ depends on the number $k$ of mockup fuel drawers used as calibration standards. If calibration error is the dominant source of measurement systematic error, $\sigma_{\eta}$ is proportional to $1 / \sqrt{k}$.

Figures D-8 through D-12 illustrate the power of the normal test for values of the parameters $\sigma_{e}, \sigma_{\eta}$,

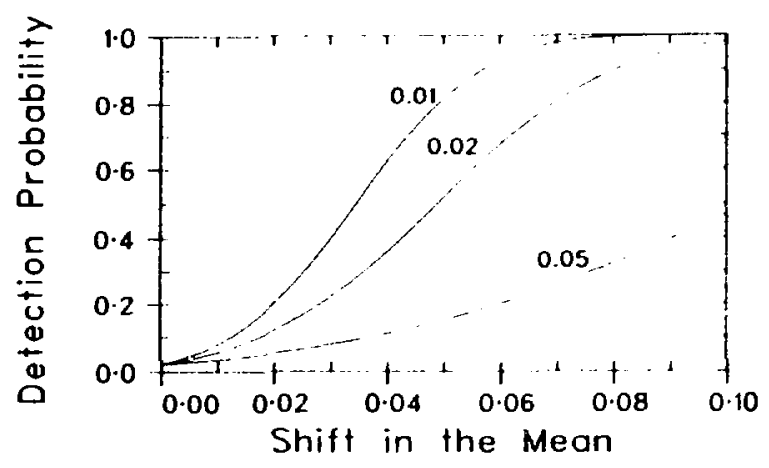

Fig. D-8.

Power of the normal test applied to single measurements $(n=1)$ for several values of $\sigma$. $\left(\sigma_{n}=1 \%\right)$.

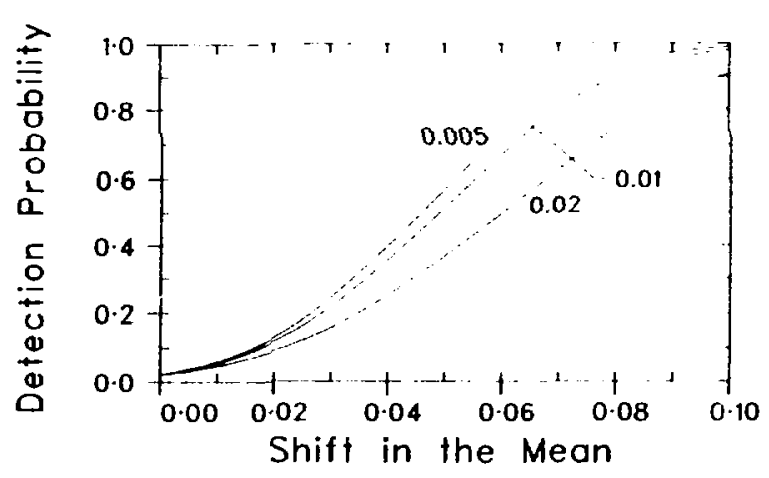

Fig. D-9.

Power of the normal test applied to single measurements $(n=1)$ for several values of $\sigma_{\eta}$ $\left(\sigma_{\mathrm{t}}=2 \%\right)$

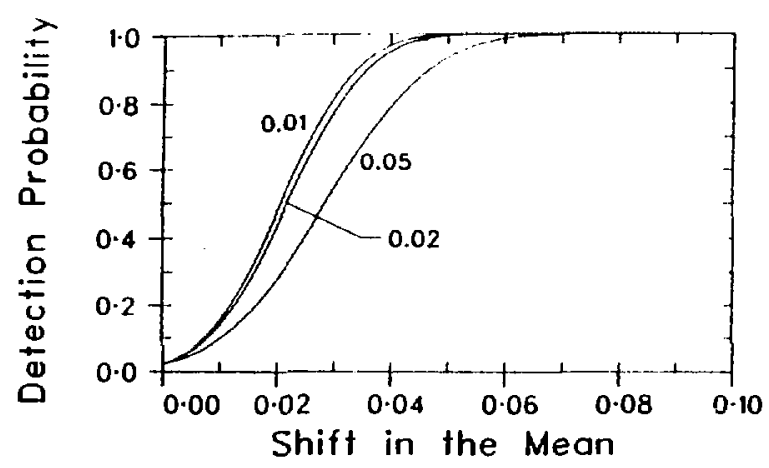

Fig. D-10.

Power of the normal test applied to the sample mean for several values of $\sigma_{\mathrm{t}}\left(n=25, \sigma_{\eta}=1 \%\right)$. 


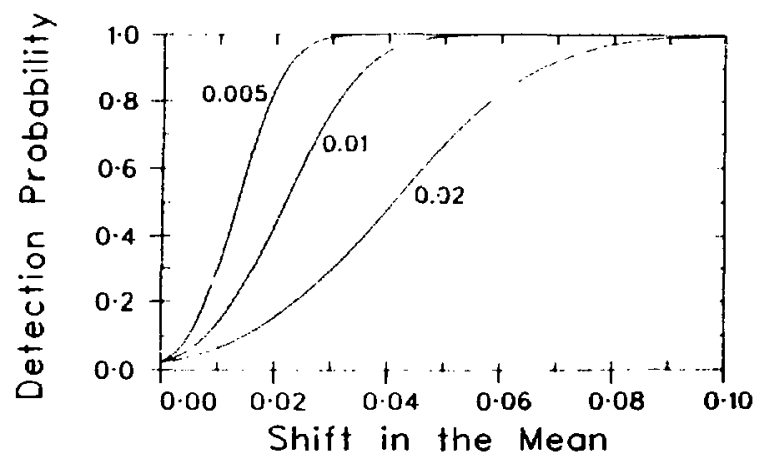

Fig. D-11.

Power of the normal test applied to the sample mean for several values of $\sigma_{\eta}\left(n=25, \sigma_{e}=2 \%\right)$.

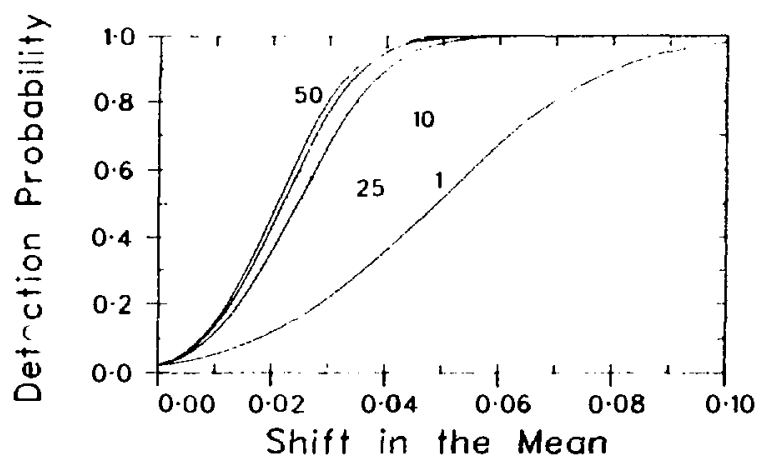

Fig. $D-12$.

Power of the normal test applied to the sample mean for several sample sizes $\left(\sigma_{c}=2 \%, \sigma_{n}=\right.$ (ii).

and $\mathrm{n}$. The dependence on $\sigma_{M}$ is similar to the dependence on $\sigma_{\mathrm{f}}$. The alarm limits are set at $\pm 2 \sigma_{\overline{\mathrm{m}}}$ (significance level of $\sim 5 \%$ ). The probability of detection is plotted as a function of the fractional shift in the population mean $\left(\mu_{0}-\mu\right) / \mu_{0}$. The corresponding shift in the inventory is $N\left(\mu_{0}-\mu\right)$. Note that when the test is applied to single drawer measurements $(n=1)$ its power primarily depends on the size of the measurement-precision RSD, $\sigma_{\mathrm{e}}$ (Figs. D-8 and D-9). When the test is applied to sample measurements ( $\mathrm{n} \gg 1$ ), its power primarily depends on the calibration-error RSD, $\sigma_{\eta}$ (Figs. D10 and D-11). Figure D-12 shows that the power of the test is limited by the size of $\sigma_{\eta}$ so that cont $t^{5}$ ing to increase the sample size $(n \gtrsim 50)$ does crease the power of the test; however, increasing the sample size does reduce the sampling error.

3. Test of the Variance. The problem is to verify the operator's estimate $\sigma_{0}$ of $\sigma_{\mathrm{M}}$, the variation in the SNM content of the fuel drawers. If the measurements are distributed normally, the standard test is the $\chi^{2}$ test. The test statistic is

$c=(n-1) s_{m}^{2} /\left[\left(\sigma_{0}^{2}+\sigma_{e}^{2}\right) \mu_{0}^{2}\right]$.

The statistic $C$ is distributed as $\chi^{2}$ with $(n-1)$ degrees of freedom. It is independent of measurement bias. The mean and variance of $\mathrm{C}$ (under hypothesis $\mathrm{H}_{0}$ ) are given by

$E(C)=n-1$

and

$\operatorname{Var}(c)=2(n-1)$.

A normal approximation applies if $\mathrm{n} \gtrsim 20 .^{7}$ Critical points in the $\chi^{2}$ distribution are given in Ref. 12 .

The sensitivity of the $\chi^{2}$ test to shifts in $\sigma_{\mathrm{M}}$ depends on the relative sizes of the parameters $\sigma_{a}$ and $\sigma_{0}$. The RSD $\left(\sigma_{t}\right)$ of the NDA verification measurement very likely will be larger than $\sigma_{0}$ because the variation in the fuel's SNM content is limited by the fuel manufacturer's ability to meet stringent specifications, as verified by accurate and precise destructive-assay measurements.

The sample variance $s_{m}^{2}$ is an estimate of the quantity $\left(\sigma_{\mathrm{M}}^{2}+\sigma_{\varepsilon}^{2}\right) \mu^{2}$, where $\mu$ and $\sigma_{\mathrm{M}}$ are the true (but unknown) mean and RSD of the fuel drawer contents. The $\chi^{2}$ test is likely to be insensitive when $\sigma_{\mathrm{M}}<\sigma_{\mathrm{a}}$; that is, operator's estimate is too large. For example, if $\mu=1 \mathrm{~kg}, \sigma_{0}=1 \%$, and $\sigma_{\epsilon}=2 \%$, then the true value of the quantity $\left(\sigma_{\mathrm{M}}^{2}+\sigma_{\epsilon}^{2}\right) \mu^{2}$ varies only between $4 \times 10^{-4}$ and $5 \times 10^{-4}$, for $\sigma_{M}$ in the range $0 \leq$ $\sigma_{M} \leq \sigma_{0}$. Therefore, when applying the $\chi^{2}$ test at a reasonable level of significance ( $5 \%$ or less), the inspection team probably cannot reject the operator's value $\sigma_{0}$ as being too large, especially if it is derived from the fuel manufacturer's assay data. This is not a serious limitation if the fuel manufacturer and the critical facility operator reside in different states. If 
the operator attempts to inflate his estimate artificially to the extent that $\sigma_{0} \gtrsim \sigma_{t}$, detection of such action becomes likely.

In practice, the main value of the $\chi^{2}$ test is in detecting the case in which $\sigma_{M}>\sigma_{0}$; that is, the operator's estimate is too small. The operator's initial estimate $\sigma_{0}$ may become too small because random, small removals have increased the variation in the drawer contents. In this regard, a positive indication from the $\chi^{2}$ test that $\sigma_{0}$ is too small, coupled with many outliers or a significant shift in the mean, would be strong evidence of diversion. Alarm limits are given in Table D-VII for a one-sided $\chi^{2}$ test to detect if $\sigma_{M}>\sigma_{0}$. Critical values of the ratio $\sigma_{M} / \sigma_{0}$ are given at these alarm limits.

Note that the usefulness of both the $\chi^{2}$ and the normal tests strongly depends on how well the verification measurements have been characterized by the inspection team. If it is suspected that the measurements are not well characterized, or if supporting evidence is desired for a decision, the nonparametric tests to be described next may be useful.

\section{Nonparametric Tests of the Mean and Variance*}

1. Wilcoxon Test of the Mean. The Wilcoxon test is a nonparametric test for a shift in the median. Rigorous application of the test requires that the measurement data satisfy two assumptions: (1) the measurements are independent and (2) the probability density function of the measurements is symmetric about the median. Assumption (2) is satisfied if the measurement errors are distributed normally, in which case the mean and median coincide. Assumption ( 1 ) is violated if the measurements are biased. Therefore, the test performance will depend on the size of the calibration error and also on the size of the sampling error. These restrictions are analogous to those on Student's t test.

Consider the set of sample measurements $m_{1}, i=$ $1,2, \ldots, n$. Form the quantity $x=\mu_{0}-m$ for each measurement, and arrange the $x$ values in order of increasing magnitude

$$
\left|x_{1}\right|<\left|x_{2}\right|<\cdots<\left|x_{j}\right| \cdots<\left|x_{n}\right| \cdot
$$

The rank of the jth measurement in this ordered sequence is $\mathrm{j}$.

Next, assume that we are looking for a one-way shift in the mean, and let

$$
d_{j}=\left\{\begin{array}{ll}
0 & \text { if } x_{j} \leq 0 \\
j & \text { if } x_{j}>0
\end{array} .\right.
$$

The Wilcoxon test statistic is

$$
w=\sum_{j=1}^{n} d_{j}
$$

*The material in this section is due to J.P. Shipley, LASL Safeguards Staff, Q-4.

\begin{tabular}{|c|c|c|c|c|}
\hline \multirow{2}{*}{$\begin{array}{l}\text { Sample } \\
\text { Size, n } \\
\end{array}$} & \multicolumn{2}{|c|}{ 2.5\% Significance Level } & \multicolumn{2}{|c|}{ 0.5\% Significance Level } \\
\hline & $C /(n-1)$ & $\sigma_{M} / \sigma_{0}{ }^{\mathrm{a}}$ & $C /(n-1)$ & $\sigma_{M} / \sigma_{0}{ }^{a}$ \\
\hline 50 & 1.433 & 1.78 & 1.597 & 2.00 \\
\hline 86 & 1.322 & 1.62 & 1.439 & 1.79 \\
\hline 100 & 1.297 & 1.58 & 1.404 & 1.74 \\
\hline 200 & 1.206 & 1.42 & 1.277 & 1.54 \\
\hline 300 & 1.167 & $1.3 \tilde{5}$ & 1.223 & 1.45 \\
\hline
\end{tabular}

\section{TABLE D-VII}

\section{ALARM LIMITS OF A ONE-SIDED $\chi^{2}$ TEST FOR $\sigma_{M}>\sigma_{0}$}

With $\sigma_{0}=1 \%$ and $\sigma_{\mathrm{e}}=2 \%$. 
The mean and variance of $W$ are given by

$E(W)=n(n+1) / 4$

and

$\operatorname{Var}(w)=n(n+1 / 2)(n+1) / 12$.

A normal approximation applies if $\mathrm{n}$ is sufficiently large ( $\mathrm{n} \gtrsim 10$ ) to be used to set alarm limits for the test at desired levels of significance. For example, a one-sided test for a reduction in the mean when $\mathrm{n}=86$ has $2-$ and $3-\sigma$ limits of $\sim 464$ and $\sim 697$, respectively, and the levels of significance are $\sim 2.3$ and $\sim 0.14 \%$, respectively.

A two-sided test of the mean is obtained by redefining $d_{j}$,

$a_{j}=\left\{\begin{array}{rl}-j & \text { if } x_{j}<0 \\ 0 & \text { if } x_{j}=0 \\ +j & \text { if } x_{j}>0\end{array}\right.$.

The corresponding levels of significance are approximately twice those for the one-sided test.

The simplicity of the Wilcoxon test argues for its use, at least as a back-up to the parametric tests of the mean. However, note that alarm limits sat by using the variance of $W$ [Eq. (D-28)] will be incorrect if the measurements are correlated by significant errors in calibration.

2. The Kolmogorov-Smirnov Test of the Vari nce. This is a nonparametric test of the distribution function (not necessarily Gaussian) postuiated for the measurements. Consider the sample metisurements $m_{1}, i=1,2, \ldots, n$. Form the quantities $x_{1}=\bar{m}-m_{1}$. The null hypothesis $H_{0}$ is that the $x_{1}$ are independent random variables described by the cumulative normal distribution function $\Phi$ with zero mean and variance $\sigma^{2}=\sigma_{0}^{2}+\sigma_{\epsilon}^{2}$. The alternative hypothesis $H_{1}$ is either that the measurements are not distributed normally or that the variance is not $\sigma^{2}$.

The first step in applying the test is to form the empirical cumulative distribution function $\Phi_{n}$. For any value of $x$ in the range $-\infty<x<\infty, \Phi_{n}(x)$ is the fraction of the $n$ observations $\left\{x_{1}\right\}$ satisfying $x_{1} \leq x$; that is

$$
\Phi_{n}(x)=\frac{1}{n} \sum_{i=1}^{n} u\left(x-x_{i}\right),
$$

where

$$
u\left(x-x_{i}\right)= \begin{cases}1 & \text { if }\left(x-x_{i}\right) \geq 0 \\ 0 & \text { if }\left(x-x_{i}\right)<0\end{cases}
$$

Note that $\Phi_{n}(x)$ is constant between observations. Thus, it need be calculated only at the n observation points,

$\Phi_{n}\left(x_{j}\right)=\frac{1}{n} \sum_{i=1}^{n} U\left(x_{j}-x_{i}\right)$

where $\mathrm{j}=1,2, \ldots, \mathrm{n}$.

The test statistic is the maximum distance between $\Phi_{n}(x)$ and $\Phi(x)$ at the observation points, as defined by

$D=\operatorname{ma}_{j}\left|\Phi_{n}\left(x_{j}\right)-\Phi\left(x_{j}\right)\right|$.

Thus, to compute $D$, we must first calculate the values of $\Phi_{n}$ and $\Phi$ at all $n$ observation points and then find the maximum difference in absolute magnitude. An approximate alarm limit at the $\alpha$ level of significance is given by

$D_{\alpha}=\left[\frac{1}{2 n} \ln \left(\frac{2}{\alpha}\right)\right]^{1 / 2}$.

For example, if $\mathrm{n}=86$, the alarm limit is $\sim 0.16$ at the $2.5 \%$ level of significance and $\sim 0.19$ at the $0.5 \%$ level of significance.

In practice, the central limit theorem virtually guarantees that the sample measurements are distributed normally if $n \gtrsim 20$. Therefore, in the form given here, the test reduces to a test for shifts in the variance analogous to the $\chi^{2}$ test. As for the $\chi^{2}$ test, if a good estimate of the measurement precision $\operatorname{RSD}\left(\sigma_{t}\right)$ is available, the value of the test is in searching for an increase in the variation of SNM content $\left(\sigma_{M}>\sigma_{0}\right)$. 


\section{SUMMARY}

A combined attributes and variables sampling plan provides a detection capability for both large and small removals from items in a critical-facility inventory. Sample sizes for routine inventory verification are set for the desired probability of detecting the diversion of a goal quantity of SNM in whole-item removals. The binomial form for replacement sampling [Eq. (D-12)] can be used to calculate the sample size required for routine inventories and to combine any sequence of routine samples taken during periods of normal reactor operation. The sample size for a special inventory in response to an alarm can be calculated using the form given in Eq. (D-16) for sampling without replacement when the acceptance number is equal to 1 . In case of a special inventory, the sample size should be large enough to determine with a prohability $>95 \%$ whether a significant quantity of SNM has been diverted. This requires sampling about $50 \%$ of the SNM inventory.

The detection of small removals from the inventory is complicated by the following effects: (1) sampling errors, especially in the relatively small samples $(\sim 10 \%)$ proposed for routine inventory verification; (2) measurement errors, both in the precision and accuracy of the measurement method; and (3) the intrinsic variability in the SNM content of the items. The effect of sampling error can be circumvented to some extent by applying the outliers and $\chi^{2}$ tests. A battery of tests can be used to examine the operator's estimates of the mean and RSD, $\mu_{0}$ and $\sigma_{0}$. These tests and comments concerning their use are summarized below. Additional tests that are sometimes useful, such as tests for the normality of the measurement data, are given in the references. A battery of such tests should be used to establish the internal consistency of the sample data and of the decisions based on these data. Above all, the inspection team must have a good working knowledge of the instrumentation and of the proper calibration and measurement procedures.

- Tests for Outlying Measurements. The sensitivity of the T test [Eq. (D-17)] is not degraded by measurement bias, but the test is not sensitive to uniform small removals. The sensitivity of the normal test of single measurements [Eq.
(D-19)] is degraded by measurement bias, but some sensitivity to uniform small removals is retained. Measurement imprecision is likely to be the dominant source of error in both tests.

-Tests of the Operator's Mean, $\mu_{0}$. Significant measurement bias may cause false alarms in the Student's t test [Eg. (D-20)] and in the Wilcoxon test [Eq. (D-27)]. The sensitivity of the normal test of the mean [Eq. (D-22)] to small removals is limited by the presence of measurement bias.

- Tests of the Operator's RSD, $\sigma_{0}$. The $\chi^{2}$ test [Eq. (D-24)] and the Kolmogorov-Smimov test [Eq. (D-32)] are primarily useful for detecting an increase in variability of the SNM item content. The sensitivity of both tests is limited by the measurement imprecision.

\section{REFERENCES}

1. F. Brown, P. T. Good, J. B. Parker, A. E. Ross, and D. R. Terrey (UKAEA) and A. Lumetti, E. Kerr, T. Otoms, and M. Sultan (IAEA), "Progress in the Development of a System for the Safeguards Inspection of the Fuel Store of a Zero-Energy Test Reactor," United Kingdom Atomic Energy Authority COS.20 (October 1970).

2. C. G. Hough, R. A. Schneider, K. B. Stewart, J. L. Jaech, and C. A. Bennett, "Example of Verification and Acceptance of Operator Data - Low Enriched Uranium Fabrication," Battelle Pacific Northwest Laboratories report BNWL-1852 (August 1974).

3. J. L. Jaech, "Statistical Methods in Nuclear Material Control," United States DOE Technical Information Center TID-26298 (1973).

4. C. G. Hough and T. M. Beetle, "Statistical Methods for the Planning of Inspections," IAEA-SM-201/99 in Proc. Symp. Safeguarding Nuclear Materials, Vienna, October 1975 (International Atomic Energy Agency, 1976) Vol. I. pp. 561-580. 
5. A. J. Duncan, Quality Control and Industrial Statistics, 3rd ed. (Richard D. Erwin, Homewood, Illinois, 1965).

6. D. D. Cobb and J. L. Sapir, "Preliminary Concepts for Materials Measurement and Accounting in Critical Facilities," Los Alamos Scientific Laboratory report LA-7028-MS (.January 1978).

7. K. A. Brownlee, Statistical Theory and Methodology in Science and Engineering, 2nd ed. (John Wiley \& Sons, New York, 1965).

8. B. E. Cooper, Statistics for Experimentalists (Pergamon Press, Oxford, 1969).
9. J. E. Lovett, Nuclear Materials Accountability, Management, Safeguards (American Nuclear Society, 1974).

10. M. L. Puri and P. K. Sen, Nonparametric Methods in Multivariate Analysis (John Wiley \& Sons, New York, 1971).

11. J. D. Gibson and J. L. Melsa, Introduction to Nonparametric Detection with Applications (Academic Press, New York, 1975).

12. A Hald, Statistical Tables and Formulas (John Wiley \& Sons, New York, 1952). 


\title{
APPENDIX E
}

\section{CHARACTERISTICS OF SEALS}

\author{
J. F. Ney \\ Sandia Laboratories, Albuquerque
}

\section{INTRODUCTION}

Three uses of seals are required in the conceptual safeguards system for fast-critical facilities: (1) to secure SNM storage containers; (2) to secure unattended instrument enclosures; and (3) as tiedowns for unattended instrumentation.

The use of seals is an essential element of inventory verification, for both routine and special inventories. Seals will be used to secure containers of SNM that are expected to remain in storage between successive routine inventories, thereby reducing the inventory effort. For special inventories, these seals will be verified, as a first step, thereby eliminating or reducing the need for performing time-consuming measurements to ascertain that material has not been diverted from sealed containers. A second use of seals is to secure unattended instrument enclosures. Unattended instruments must be secured against unauthorized access, yet be easily accessible by authorized persons. Although seals are typically used to detect any unauthorized opening, a third use for seals is to assure that unattended instruments are not moved or removed in the absence of the inspector. That is, a need exists for a tamper-indicating tiedown, and this function can be satisfied through the use of a seal.

Seals consist of three main elements:

-A loop and locking mechanism;

-A tamper-indicating enclosure to protect the locking mechanism; and

- A unique identifier to protect against seal substitution.

Currently, the IAEA has one seal in widespread use, the IAEA metallic seal (Fig. E-1), which requires destructive verification. To eliminate the need for destructively inspecting the metal seal to verify the unique identifier, programs are under way to develop a secure, tamper-resistant and tamperindicating seal whose integrity and unique identity

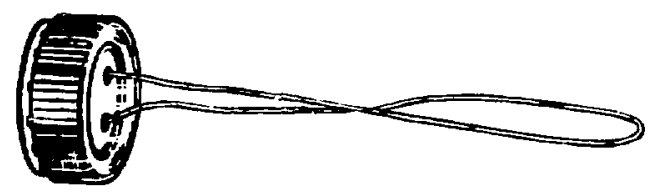

Fig. E-1.

IAEA metallic seal.

can be established in the field without removal or disassembly. Two seals meeting this objective have been designed and prototypes have been fahricated. The first design is a completely passive fiber optic seal; the second design is an active seal that continuously monitors the integrity of a fiber optic loop and provides the option of remote verification.

Detailed descriptions of these seals follows. Each type of seal could satisfy all of the safeguards requirements for seals in a critical facility. The choice of a particular type of seal for a specific application depends on three major considerations: (1) the consequences of losing seal integrity (Would the inspector have to verify the contents of a single fuel container or would the entire facility inventory be compromised?); (2) the maximum interval of time anticipated between inspection checks for seal integrity; and (3) the level of tamper-indicating security desired for the seal between integrity checks.

\section{IAEA METALLIC SEAL}

The IAEA seal (Fig. E-1) consists of a multistrand wire inside a protective plastic sheath and a twopiece metal closure numbered on the outside and uniquely identified on the inner surfaces. After the two ends of the wire are passed through the holes in the closure and fastened securely (Fig. E-2), the 

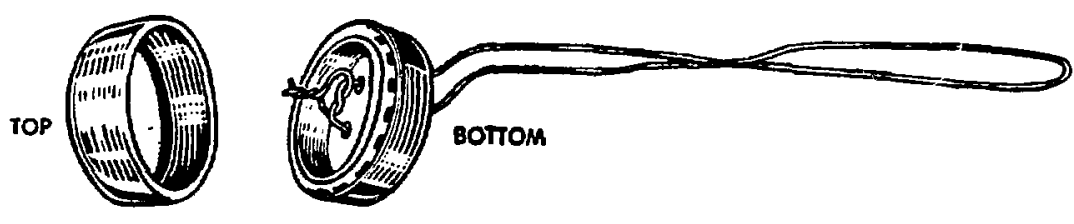

Fig. E-2.

IAEA seal before closure.

closure halves are snapped together in an interlocking way. To verify the seal, it must be removed and opened at IAEA Headquarters. The connection of the wire is verified and the identification marks are compared with the original records.

The top part of the closure is made of copper sheet, formed in the shape of a cylindrical cup (20.5 $\mathrm{mm}$ in diameter and $7.4 \mathrm{~mm}$ high). The rim of the cup is folded inward and the teeth of the crown on the bottom part catch on this folded rim when the seal is closed. The top is imprinted with the initials IAEA and a serial number is imprinted on the outside of the flat part.

The bottom part of the closure is formed by crimping an outer "shell" tu an inner "crown." The crown material varies; it is brass in IAEA seals and steel in US IRS seals. The shell is made of brass, formed in the shape of a cylindrical cup $7.5 \mathrm{~mm}$ high and 21.8 $\mathrm{mm}$ in diameter. The dished shell bottom has two $1.5-\mathrm{mm}$ holes near the center. These holes have sharp edges pointing inward. The securing wire passes through these holes.

Once the seal is applied, it is extremely difficult to open without breaking it. However, it is very simple to remove an IAEA seal and replace it with another seal that looks similar to the original one. To rule out this possibility, each IAEA seal bears unique identification marks on the inside. These marks are recorded by macrophotography at LAEA Headquarters before the seals are issued and they are checked, also at Headquarters, when the seals are brought back from the facility by an inspector.

Installation consists of looping the wire through whatever is to be secured, passing it through the two holes in the seal, and tying a secure knot. Then the two halves of the closure are snapped together to enclose the knot. Care is taken to see that the length of the loop is not too long or too short and that the knot does not open easily or slip through the holes.
On a return visit to the facility, the inspector examines the outside of the seal to see if it has been maintained. He also checks the integrity of the serial number and for any possible contamination of the seal. If the seal shows no signs of tampering, the inspector cuts the wire, removes the seal, and installs a new seal.

The seal is opened at Headquarters. The knot is examined to see if it has remained intact, and the component parts of the seal, especially the unique marks engraved on the inside of the seal, are reexamined with a microscope and are compared with the photographic record.

\section{PASSIVE FIBER OPTIC SEAL}

The passive fiber optic seal (Fig. E-3) depends on the optical continuity of a glass fiber optic bundle, consisting of $\sim 200$ individual fibers, to insure the integrity of the seal loop. The loop is closed in a plastic housing that captures the ends of the fibers when the seal is assembled and insures that the relative position of each glass fiber erd does not change.

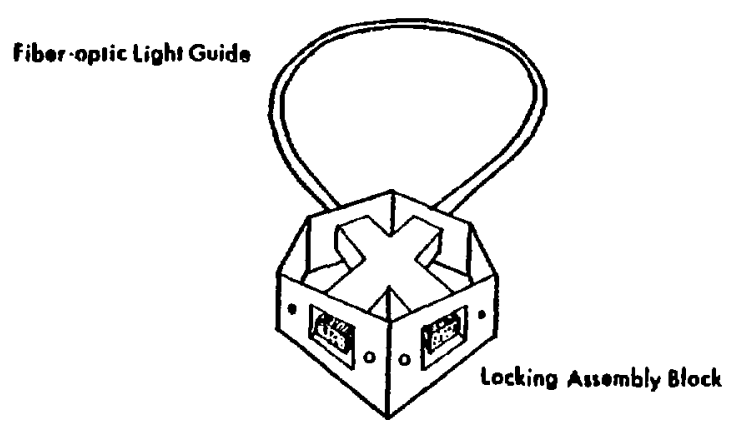

Fig. E-3.

Passive fiber optic seal. 
The optical integrity and continuity of the fibers in the bundle of the seal loop are checked after assembly by noting the transmission of light through the fibers. The unique identity or "fingerprint" of the seal is established, when the seal is assembled in the field, by illuminating part of the fiber bundle to produce a random pattern of dark and illuminated fibers at the bundle's opposite end. The pattern is photographed with a portable, handheld photomicrographic instrument. A direct comparison of a negative made when the seal is assem. bled with a positive print made when the seal's integrity is being checked can provide a high level of confidence that a seal left unattended and unexamined for a significant interval of time has not been compromised. For less demanding situations, the coordinates or relative positions of a small number of fibers can be recorded for future reference.

The seal employs either commercially available or specially prepared glass or plastic optical fiber and a metal or plastic fiber-locking assembly block (Fig. E-3). This hexagorially shaped block holds the fiber bundle securely in place to prevent accidental disassembly. It includes internal components that insure the complete, mutual interpenetration of the fibers at the bundle end.

The internal components (Fig. E-4) of the fiberlocking assembly block are designed to flatten the stripped fiber bundle ends into fan-shaped arrays of fibers, so that the fibers from one end of the bundle may easily intersect and pass randomly between the fanned fibers of the other end. The ends of the fibers beyond the intersection will now appear in the two openings in the exit surface of the assembly block.

In routine use, the seals would be partially assembled during manufacture with one end of a fiber bundle permanently installed in the assembly block. The plastic jacket of the free end is precut, but not stripped. To complete the seal, the free end is passed through the item to be sealed and the precut plastic jacket is stripped. The assembly block then is placed in the carriage of an assembly tool, and the stripped fiber bundle is inserted into the block. The two collets in the block are pressed into place with the tool, completing the sealing operation.

The identity of the seal is established in the field by using a small hand-held microscope and illuminator. All of the fiber ends are illuminated ex-

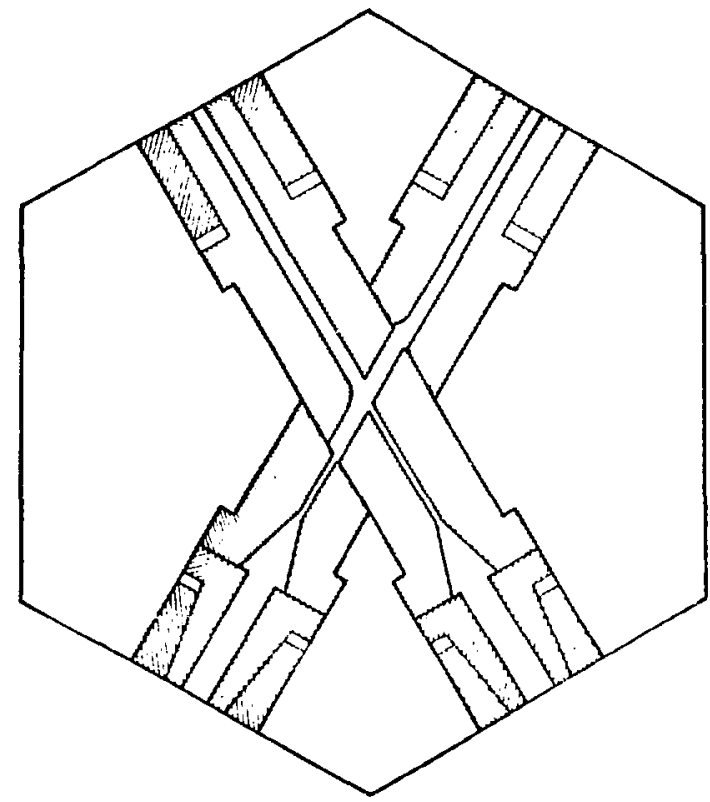

Fig. E-4.

Internal components of fiber-locking assembly black.

cept those lying directly under a reticle containing at least one opaque line whose width is approximately equal to, or slightly larger than, twice the diameter of the optic fibers used in the fiber bundle. This reticle can be scanned across the illuminated end of the fiber bundle or can be positioned precisely over a small number of fiber ends using the micrometer movement incorporated in the indexing stage of the microscope. In this manner, the lighttransmitting properties of every fiber in the bundle can be checked. In addition, the reticle in the eyepiece of the microscope can be used to measure the coordinates of a small set of individual fibers. Combining such data obtained from a small, welldispersed number of fibers $(\sim 5)$ with the seal's serial number is one method to identify a seal uniquely, and thus to provide reasonable assurance that substitution or counterfeiting of a seal would be detected. Alternatively, a photomicrograph may be taken of the random pattern formed by all the fiber ends in the field of view of the microscope using a Polaroid or other type of camera. The photographic procedure is recommended where the highest level 


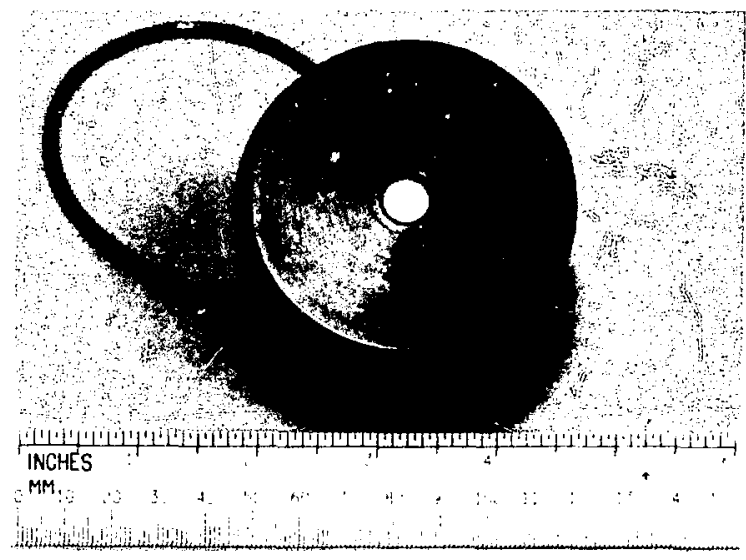

Fig. E-5.

Electronic self-monitoring seal.

of confidence is required and when it must be determined that a seal left unattended and unexamined for a significant period of time has not been compromised.

\section{ELECTRONIC SELF-MONITORING SEAL}

The self-monitoring seal (Fig. E-5) continuously monitors the integrity of the sealing device (fiber optic bundle) and displays the status, inviolate or broken, in a simple manner. The status can be identified by observing the seal's optical display. The observation can be made by an IAEA inspector, by a representative of the facility operator (with the observation reported to the inspector), or by remote electronic monitoring equipment that provides the status information to the authority.

The self-monitoring seal displays an alphanumeric character that changes with time. The correct display sequences are known only to the IAEA. The time interval between changes in the seal display is the time within which the IAEA can determine if a seal has been violated. This time interval can be from 1-32 h.

The seal is completely self-powered and selfcontained. No action is required of the facility operator, except possibly reading the display. The batteries within the seal are adequate for 500 display changes or 6 months, whichever occurs first.
The seal may be installed to secure an area to which the facility operator might need access in a verifiable emergency situation. The $\mathrm{s}$ al is adaptable to these applications. A capability is being designed into the seal to allow one, and only one, opening and reclosing of the seal. During the time that the seal is removed, the sequence of seal displays is different from the sequenre that would have existed if the seal had not been removed. This new sequence is based in part on the time interval during which the seal was removed. When the seal is reinstalled, a new sequence is generated and this sequence is different from the sequence that would have occurred had the seal not been removed and reinstalled. Recording and reporting of these sequences allow determination of how long the seal was open. Removal of the seal a second time immediately terminates the display-sequence generation. Only the IAEA can restart the generation. The IAEA can also reprogram the seal to generate other unique display sequences and, thus, the seal becomes reusabie.

The seal consists of two major parts: a fiber optics loop and an electronic monitor module that verifies the loop's integrity. Figure E-5 shows a completely assembled seal; Fig. E-6 shows the seal partially disassembled.

The monitor module is composed of four subsystems (Fig. E-7): the loop-integrity sensor, the random-display generator, the tamper-responding containers, and the batteries.

The loop-integrity sensor uses an optical source and detector to determine the continuity of the fiber optic bundle while the module and loop are attached. Detection of loss of this continuity either by detaching the module or by violating the loop results in a change of operation of the randomdisplay generator that identifies the seal. The first loss of continuity after the module is attached causes the random-display generator to produce a different identification sequence of displays, unique to the particular seal that was "opened." By requiring the facility operator to record and report the seal display, before and after opening, the IAEA can identify the time interval during which the seal was open. When the loop-integrity sensos: determines that the module has been reattached to the closed loop, the function of the random-display generator 


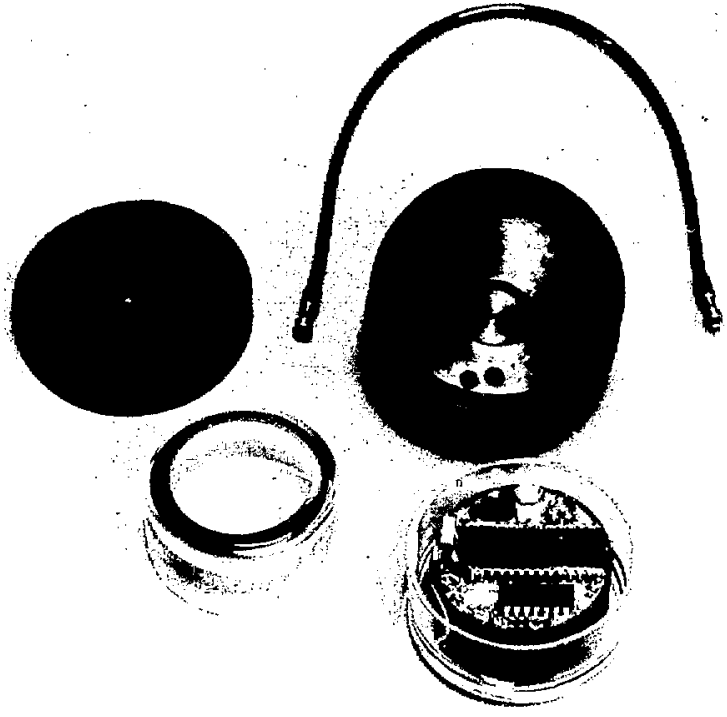

Fig. E-6.

Disassembled self-monitoring seal.

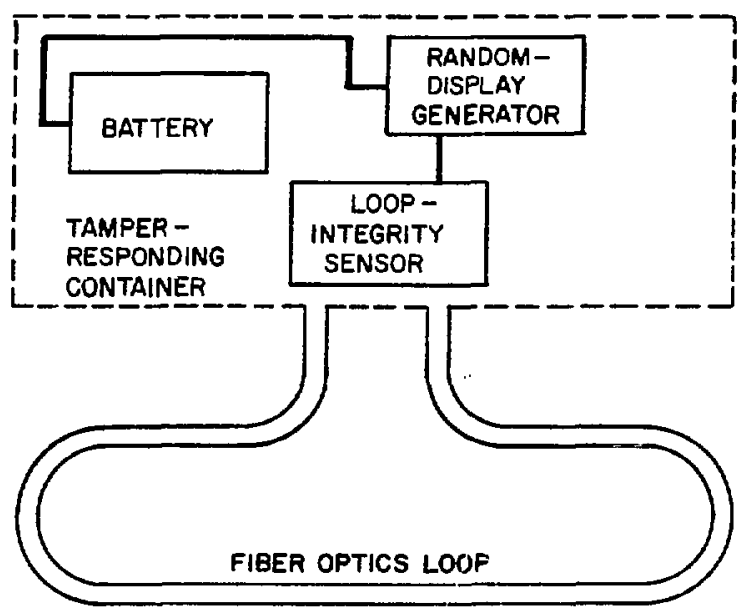

Fig. E-7.

Block diagram of a self-monitoring seal.

is changed again to produce a display sequence $u$ nique to the seal that has been opened and reclosed. If the loop integrity sensor detects a second opening of the loop, the generation of display sequences is stopped, and the display remains fixed at its current output.

The output of the random-display generator is one of four symbols. The single-character display was selected to minimize the amount of information to be stored and retrieved at the verification authority. With four possible display outputs (C, E, 8,0 ), the reporting of a correct single display enables the IAEA to state with $75 \%$ probability that the seal has not been violated. For the reporting of two correct displays in sequence, the probability is $33.7 \%$. The following table shows the corresponding probability at the number of consecutive correct readings. The use of a single alphanumeric character also prevents reporting errors causct by transposition of characters.

\section{Number of Consecutive Correct Reports}

1

2

3

4

5
Probability That Seal Is Not Violated (\%)

75.0

93.7

98.4

99.6

99.9
The random-sequence display generator, the loop-integrity sensor, and the batteries that power them are enclosed within a tamper-responding container. The response of the container to any attempt to gain physical access to these subsystems is interruption of the electrical circuit supplying energy from the batteries to the other two electronic subsystems. Loss of the programming information in the random-display generator results when the supply of energy is interrupted. From that moment on, the generator cannot produce the correct sequence of displays. Without the tamper-responding enclosure, an adversary could gain electrical access to the random-display generator, determine the programming information, and predict the future sequence of displays. With this information, an adversary could delay the verification authority's knowledge that the seal had been violated.

The normal operational cycle for the selfmonitoring seal would be as follows. The randomdisplay generator is programmed by a special circuit or a digital computer and started at IAEA Headquarters just before deployment to the facility. IAEA inspectors attach the module to the fiber optic seal and record the installed seal location and the displays before and after installation. The facility 
operator can read and record the display at the intervals requested by the IAEA and report the information at times selected by the IAEA. During each visit by the IAEA inspector to the facility, the seal's point of application and integrity (correct display value) are determined. During these visits, elec- tronic modules approaching the end of their operational phase because of battery life or the number of display changes, are replaced with reprogrammed modules containing fresh batteries. After the modules are removed, they are returned to Headquarters to be reprogrammed and reused. 